\title{
Adolescent Girls' Livelihoods. Essential Questions, Essential Tools: A Report on a Workshop [Arabic]
}

Carey Meyers

Population Council

Follow this and additional works at: https://knowledgecommons.popcouncil.org/departments_sbsr-pgy

Part of the Family, Life Course, and Society Commons, Health Policy Commons, and the International Public Health Commons

How does access to this work benefit you? Let us know!

\section{Recommended Citation}

Meyers, Carey 2000. Adolescent Girls' Livelihoods. Essential Questions, Essential Tools: A Report on a Workshop [Arabic]. New York and Washington, DC: Population Council and International Center for Research on Women. 


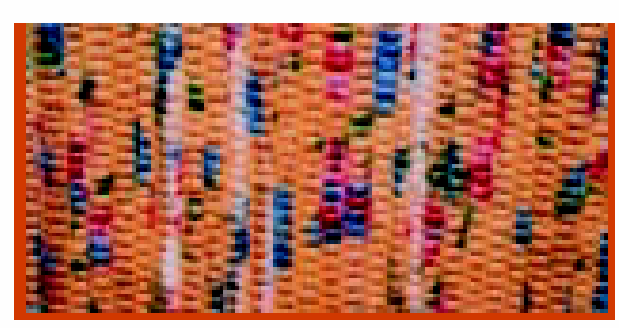

$$
\text { وسائل كسب العيش المر اهقات: }
$$

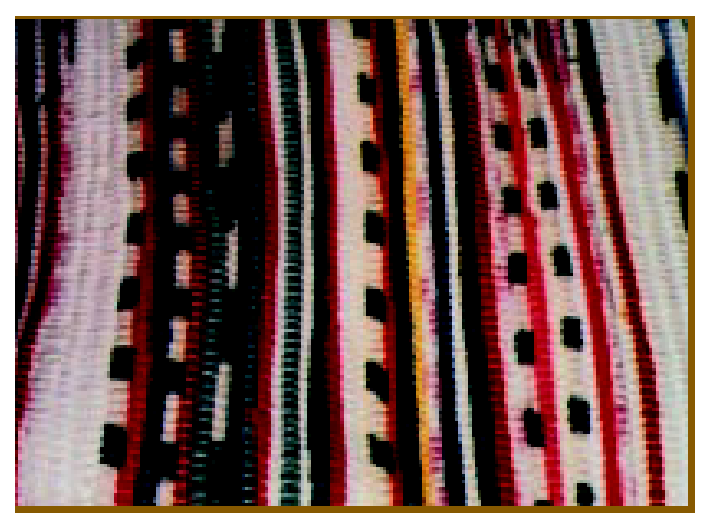

$$
\text { أسئلة أساسية، أدوات أساسية : }
$$

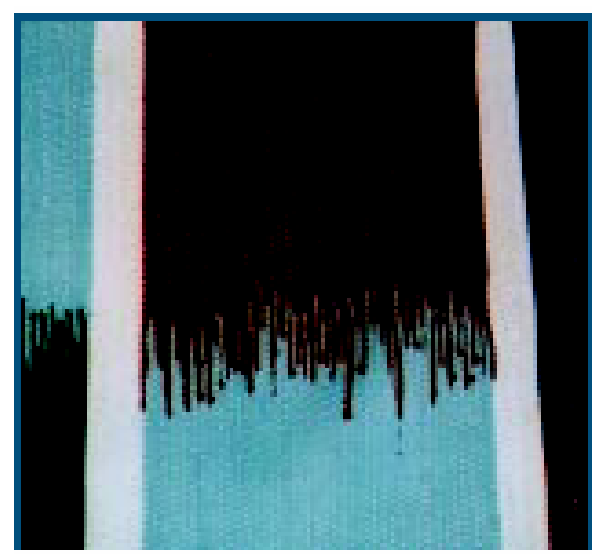




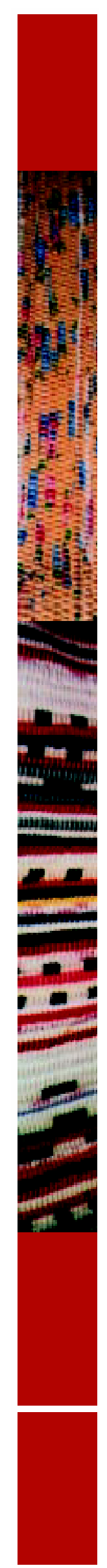

شكر وعرفان

"أسئلة أساسية أدوات أساسية" هى ورشة عمل عقدت بالقاهرة - مصر من 13-14 أكتوبر

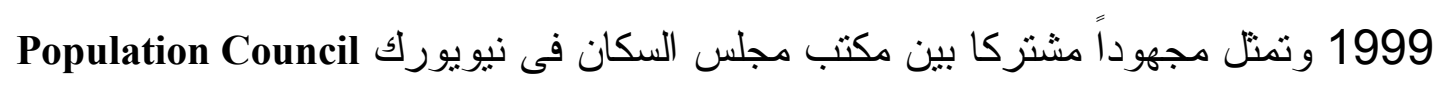

New York

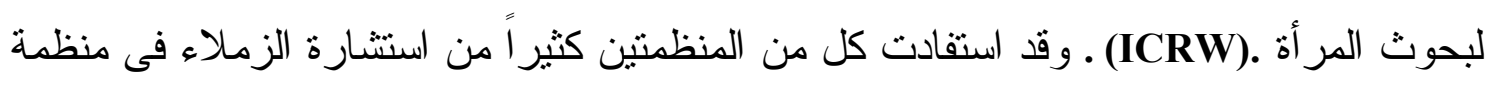

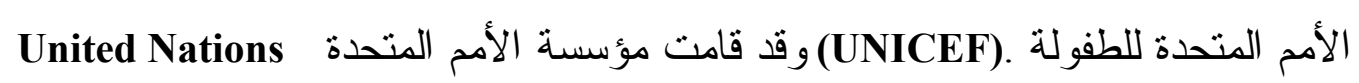
Foundation بتمويل الاجتماع وكان لها دور إيجابى فى نوجيه الانتباه نحو كسب المر اهنئ الهنين اللعيش من خلال إعطاء المنح.

ويو اصل المركز الدولى لبحوث التتمية الكندى (IDRC) خاصة جايمى شنورر Jamie Schnurr

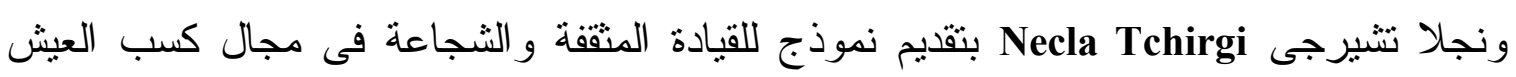

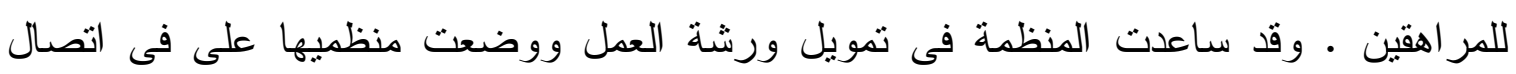

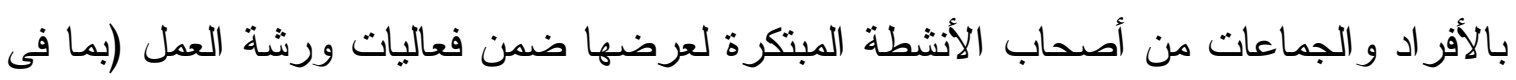

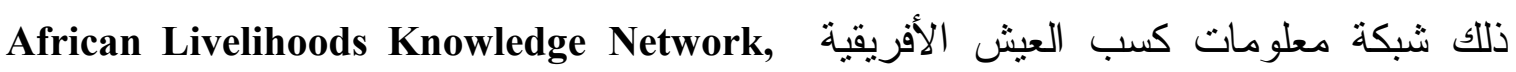
The University of Venda, South ومقرها جامعة فندا بجنوب أفريقيا IDRC التابعة لمركز Africa

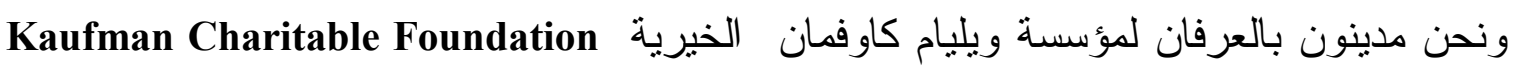
The William H.

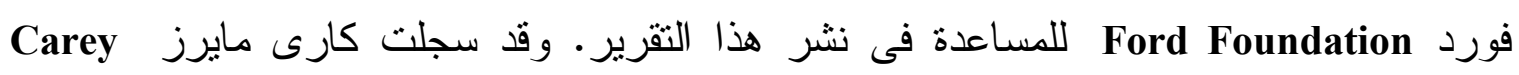
مقررة الاجتماع كافة الملخصات وأثنرفت على إصدار النقرير.

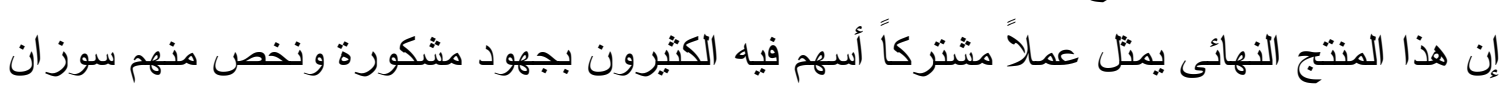

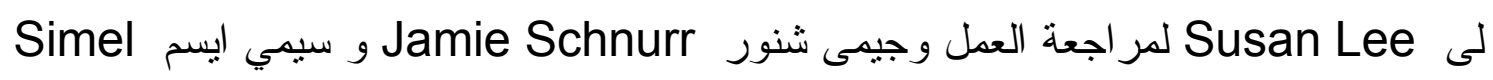

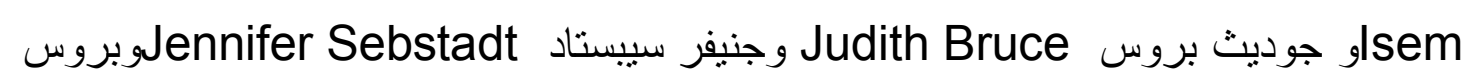
ديك Bruce Dick و جيتا راو جوبتا Gita Rao Gupta لتعليقاتهم الثاقبة

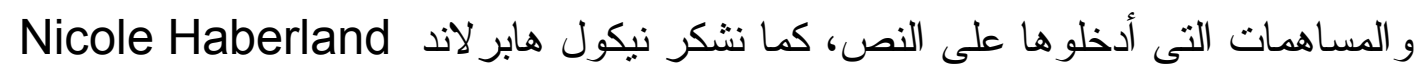

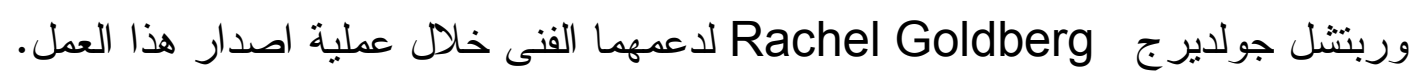




\section{لماذا الاهتمام بكسب المر اهقين للعيش؟}

فى العادة تمتن سياسة دعم المر اهقين - و الثنائع تعريفهم بالفئة العمرية ما بين 10سن و 19

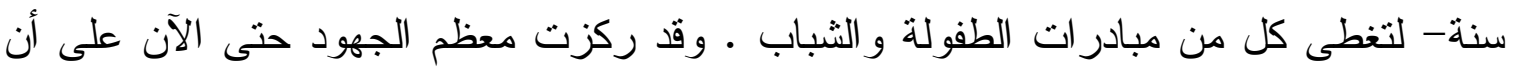

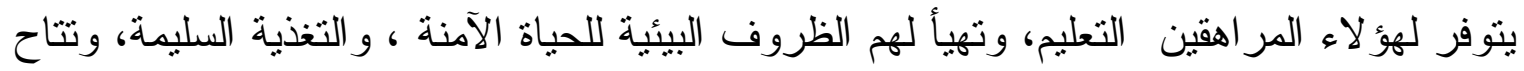

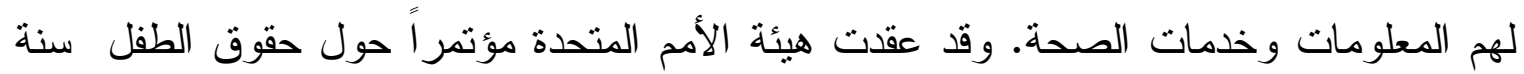

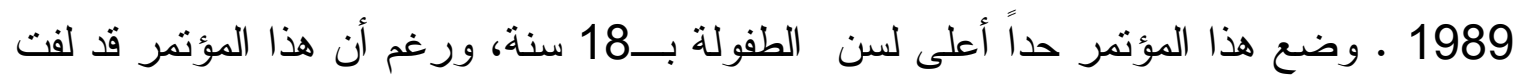

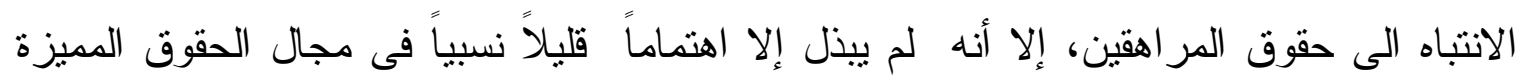

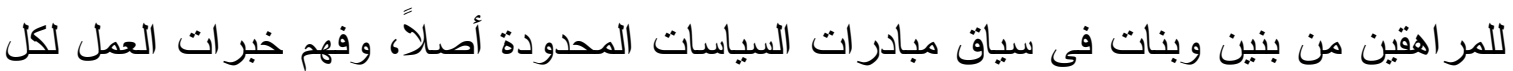
من المر اهقين الأكبر سناً والأصغر سناً، وتقوية قدر اتهم على كسب العيش.

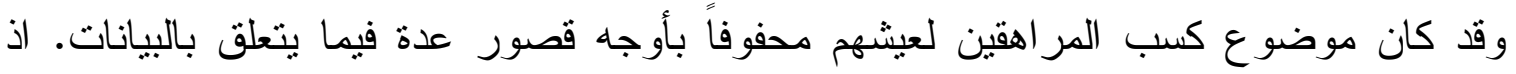

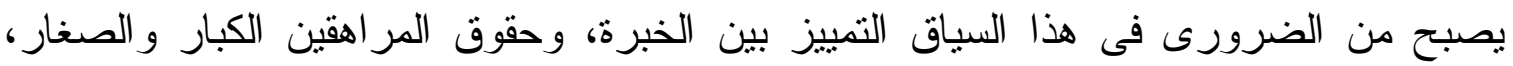

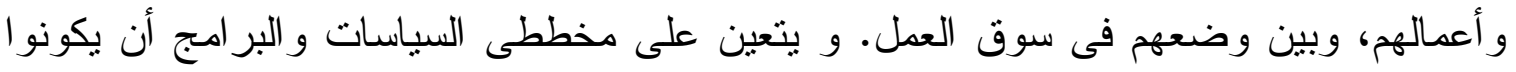

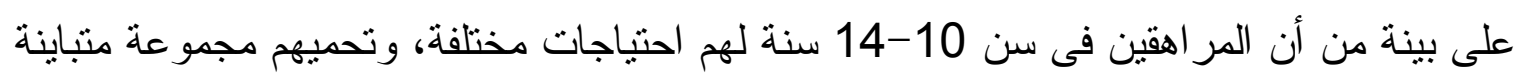
من الحقوق عن أولئك المر اهقين من سن 15 سنة فأكثر ، وهم الذين يشاركون في معظم الأحو ال فى قوة العمل بشكل قانونى.

يلتحق المر اهقون عموماً بقوة العمل تحت ضغط الحاجة الاقتصادية للمساعدة على تخفيف العبء عن عائلاتهم: ترسل العائلات أبناءها وبناتها ممن هم فى سن المر اهقة للعمل كجزء من استر اتيجية عائلية أكبر

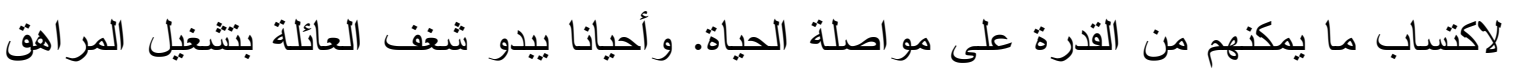

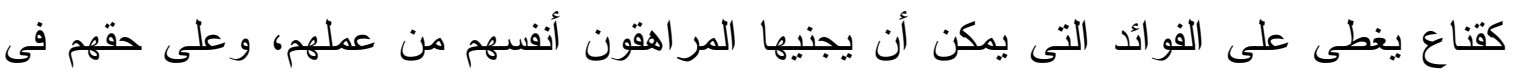

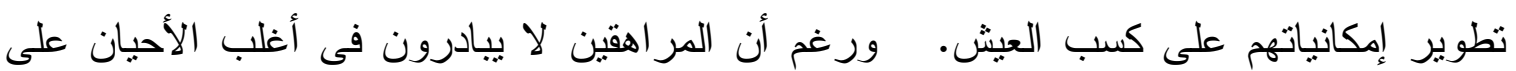

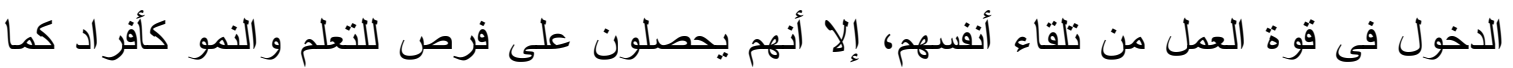
يكتسبون الثعور بما قد يكون عليه مستقبلهم. باختصار، إن الكيفية والتوقيت اللذان يدخل

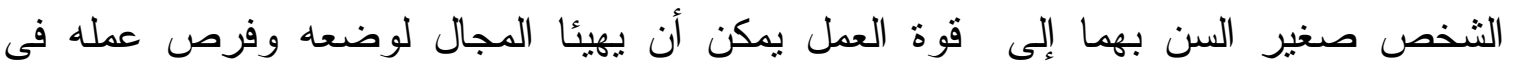

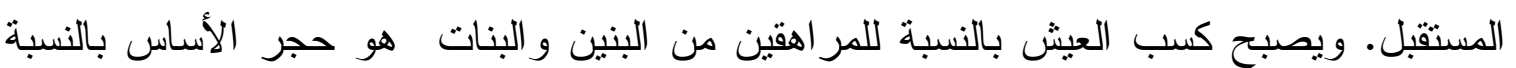

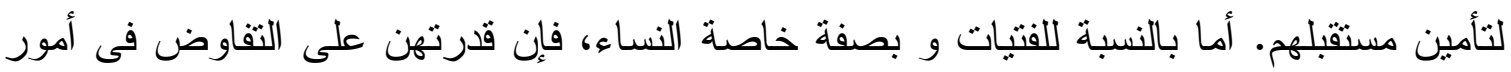

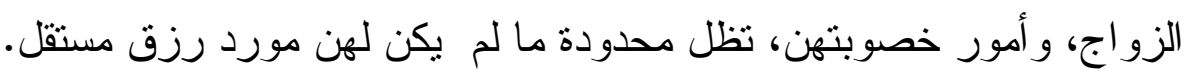


و على مستوى المجتمع، يكون استغلال طاقات الصغار أمر اً مفروغاً منه، خاصة فى المجتمعات الفقبرة حيث يصبح الفتيان و الفتيات مسئولين بعد زمن قصير لا عن إعالة أنفسهم فحسب، بل أيضاً عن إعالة عائلاتهم.

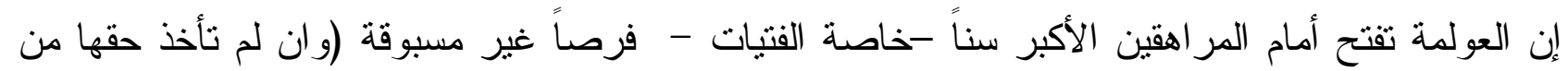

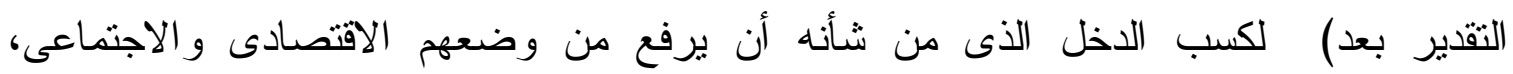

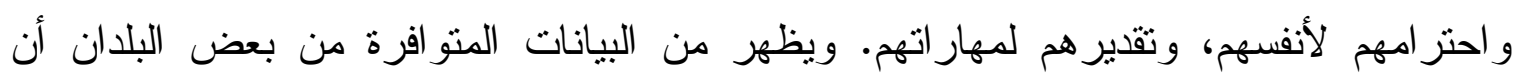

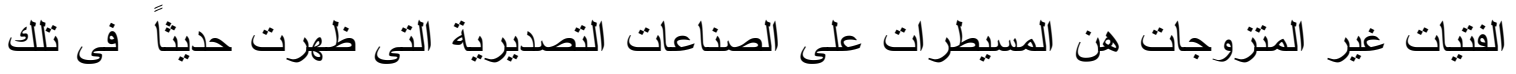

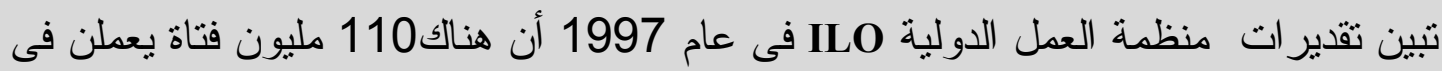
أرجاء العالم مقارنة ب 140 مليون من الفتبان العاملين • ورغم أنه من الممكن أن تعمل الفنتيات

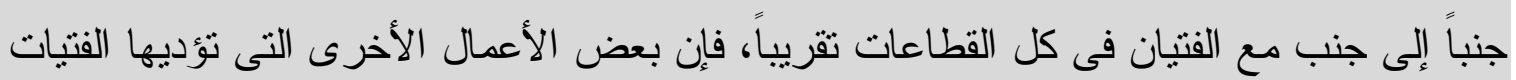

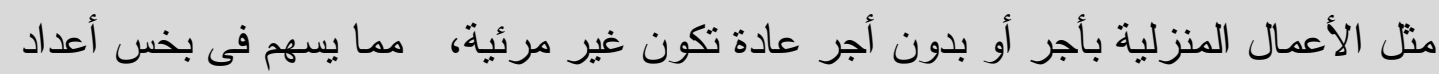

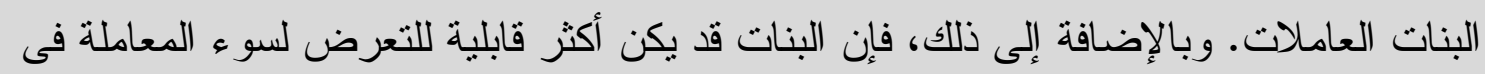

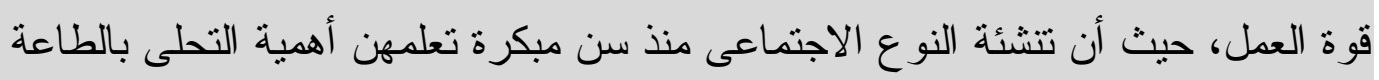

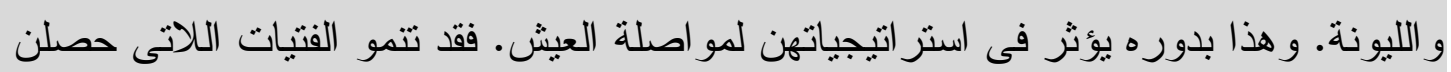

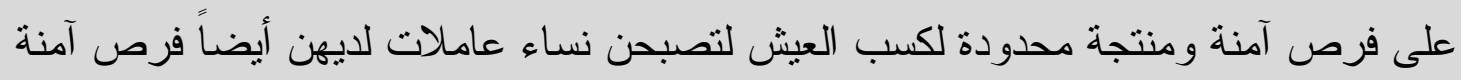

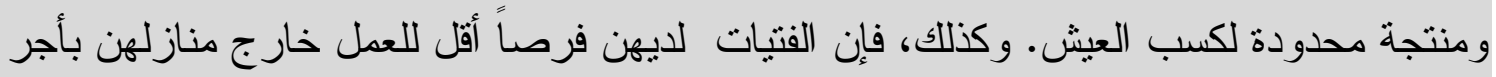

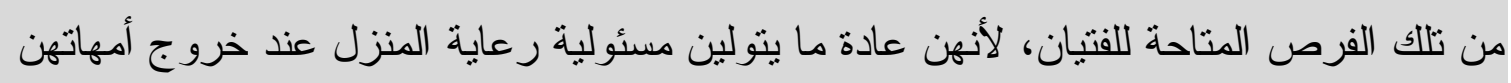

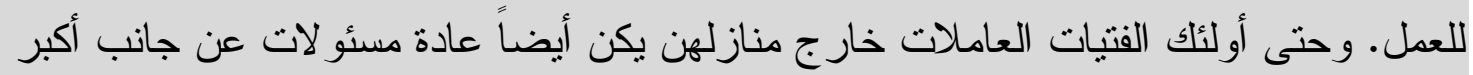

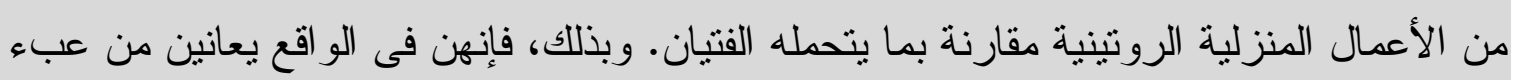
الجمع بين وظيفتين.

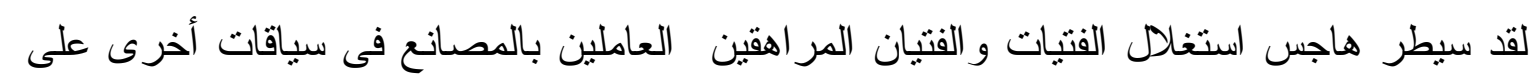

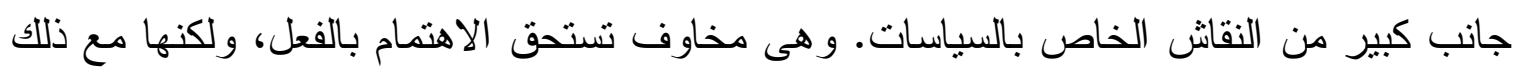
لا ينبغى لها أن تحجب المزايا المحتملة لتلك الفرص المتنامية فى عمل يدر أجراً ويعود بالفائدة

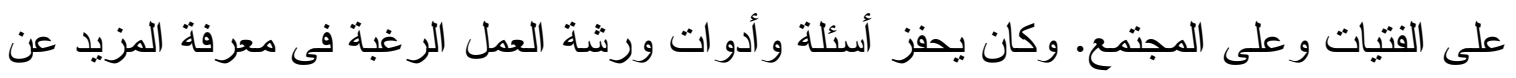

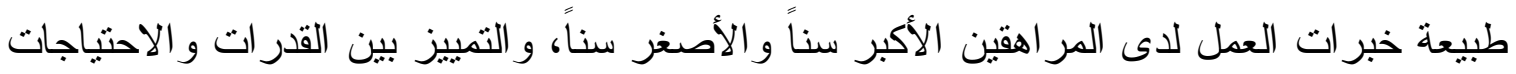


المختلفة للفتيات و الفتبان المر اهقين، وتحديد البرامج و السياسات النى تحمل وعداً بمساندتهم بصرف النظر عن حجمها ودرجة نظاميتها formality للالك فقد ركزت ورشة العمل على خمسة أسئلة أساسية: أين يعمل المر اهقون؟

ماهى السياسات و البيئة المعيارية التى تحيط بعمل الفنبات؟

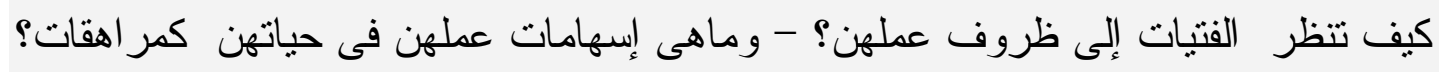

$$
\text { ماهى أساليب كسب العيش؟ }
$$

ماهى الخبرة المتر اكمة حتى الآن فى دعم و /أو خلق فرص كسب المر اهقات للعيش؟

عن هذا التقرير

بذل مجهود كبير لمحاولة استخر اج خلاصة من ثروة المعلومات التى قدت خلال مؤتمر القاهرة

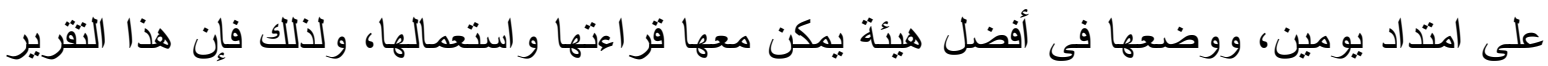

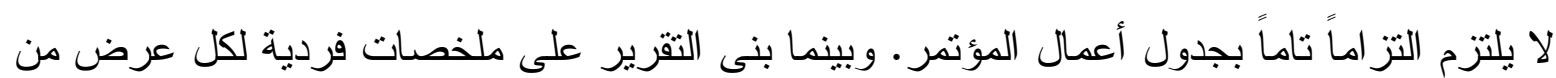

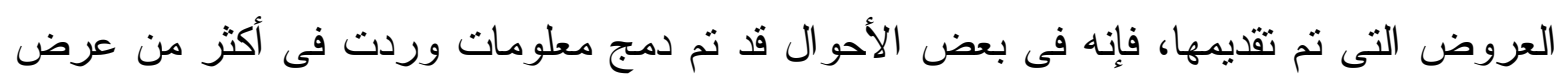

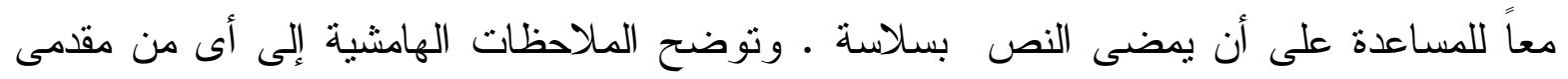

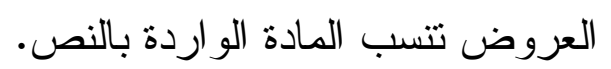

وقد أوردنا جدول أعمال المؤتمر (الأجندة) كملحق (أ) للتقرير . وتتجيعاً للقراء على الاتصال

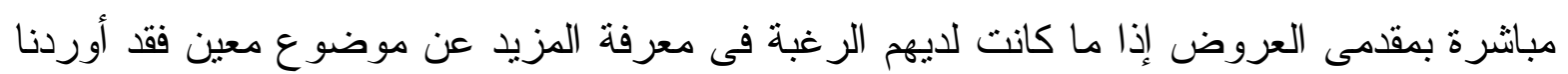
معلومات الاتصال فى ملحق (ب).

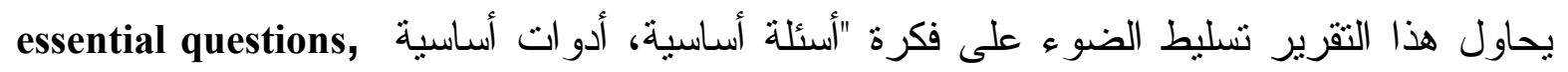
essential tools" إطار ات توضيحية لموضو عات البحث للاستتارة بها.

\section{الأسئلة الأساسية}

نحن نعلم الآن أن ما يربو من 250 مليون من المر اهقين الأصغر سناً والأطفال من سن 5-14 الأسلة

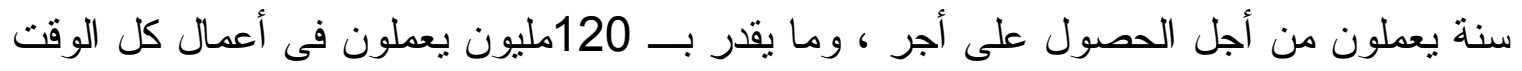
full-time

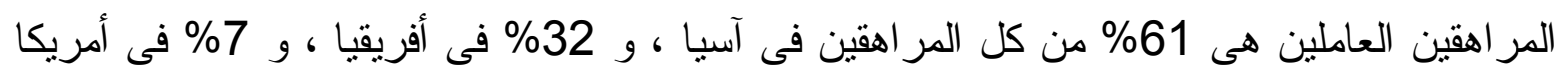

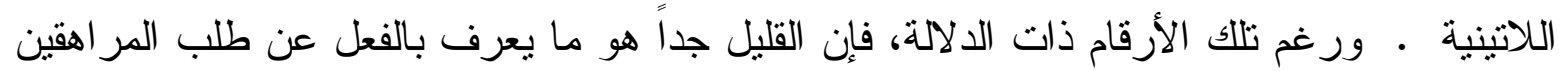

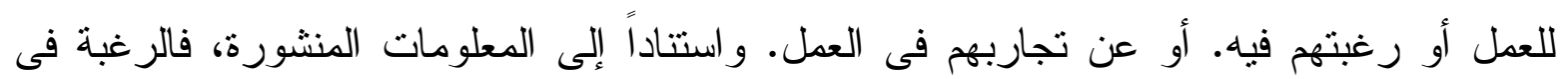


العمل موجودة، ولكن مبعث هذه الرغبة قد يكون واحداً من عدة اعتبار ات من خبرات المر اهقين بالعمل التى التى الأل

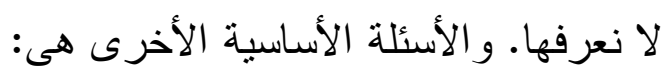

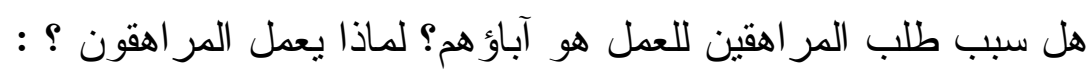

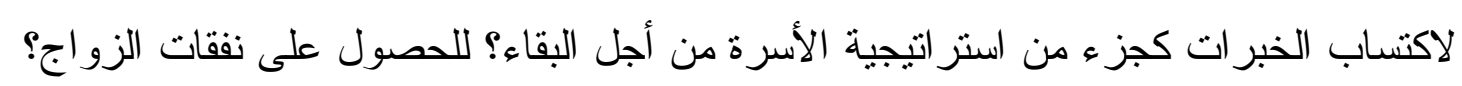

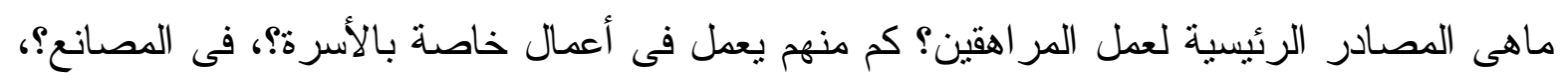
تشغيل ذاتى؟

ما الدور الذى تلعبه قو انين عمالة الأطفال فى تتكيل فرص عمل المر اهقين؟

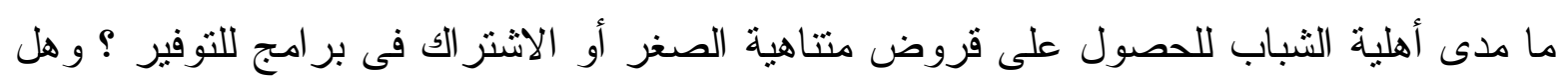
يتغير هذا الوضع حسب الحالة الزو اجية؟ هلئ

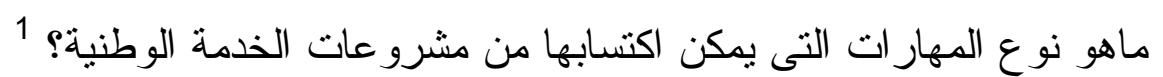

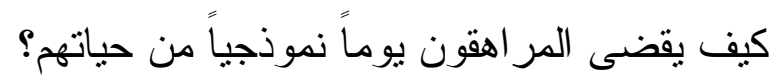
كيف تتغير الأنشطة فى أيام الدر اسية مقارنة بالأيام الأخرى؟ ماهو مدى انتشار عمالة المر اهقين؟ ماهى أنو اع الأعمال التى يقوم بها المر اهقون؟ وتحت أى ظروف؟ وأين؟ ، وكيف تتح مكافئتهج؟، هل

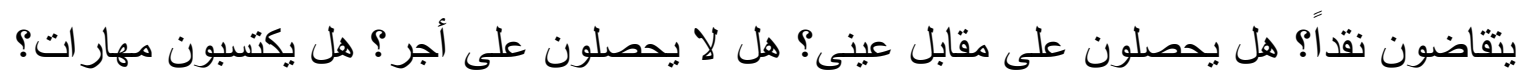

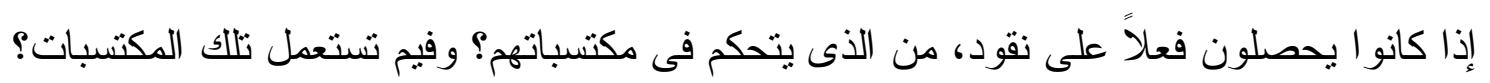

إن الحصول على بيانات عن كيفية قضاء المر اهقين لأوقاتهم يمثل تحدياً صعباً خاصة بالنسبة للمر اهقات.

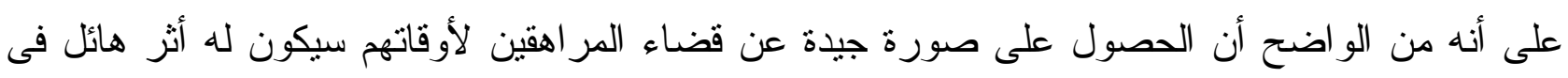

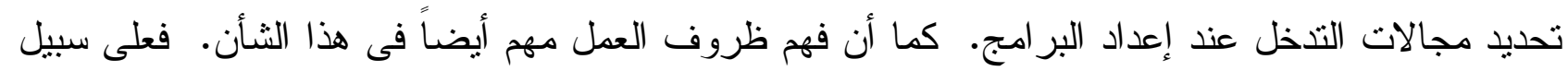

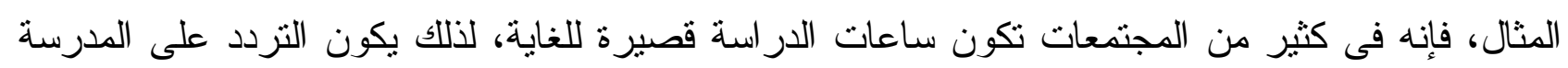

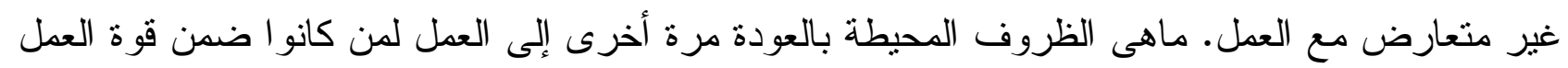

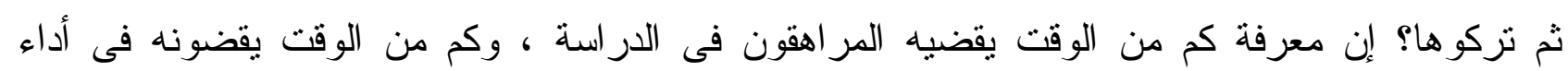

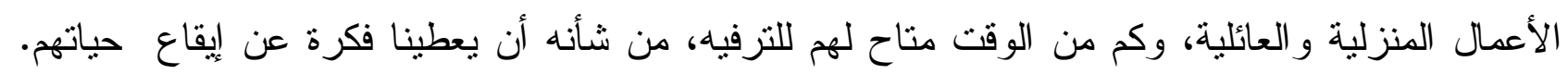

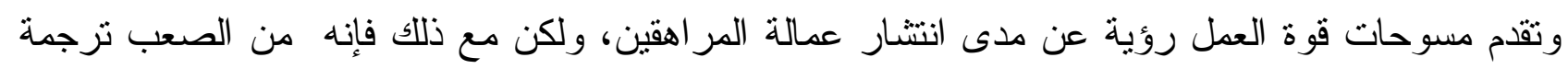
تلك الرؤية بحيث نتعرف على الددى الحقيقى الذى وصلت إليه عمالة المر اهقين. 


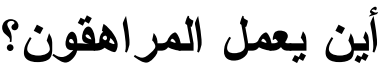

تنشر منظمة العمل الدولية ILO بانتظام إحصائيات تظهر منها بعض أنماط عمالة الثباب.

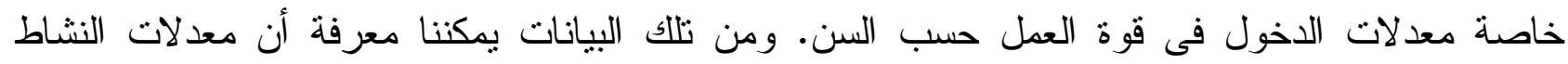

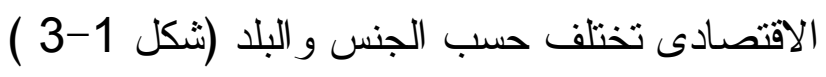

يظهر من نوزيع النسب المئوية للفتيان و الفتيات تحت سن 15 سنة أن معظم العمل يتم فى قطاعات رئيسية

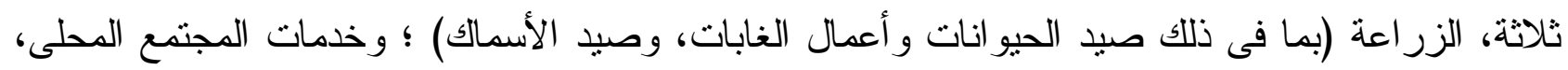

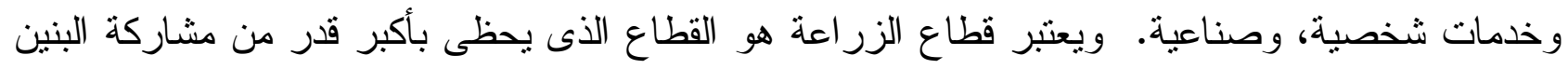

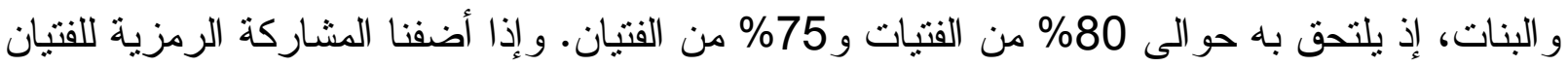

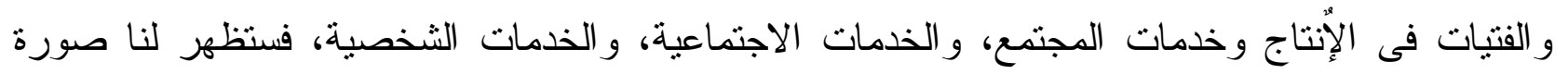

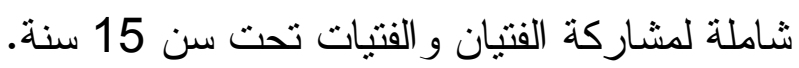

أطلقت منظمة العمل الدولية ILO مؤخر اً مبادرة خاصة تنتهدف تحسين قياسات الأنشطة الاقتصادية

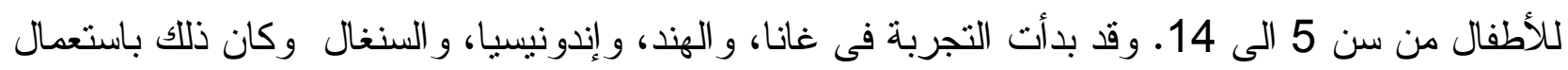

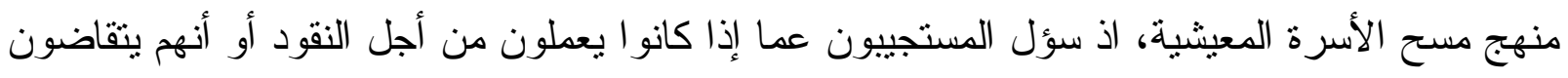

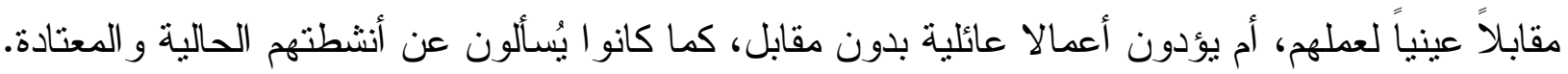

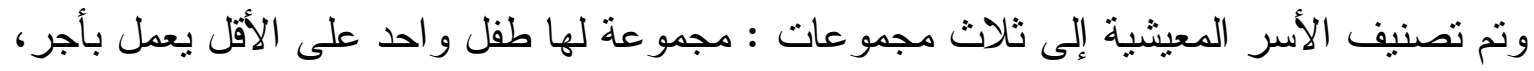

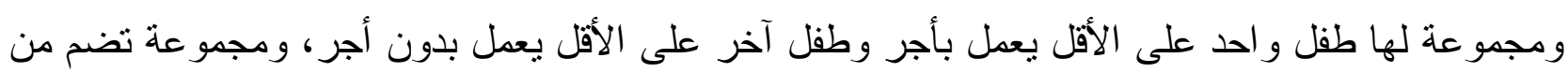

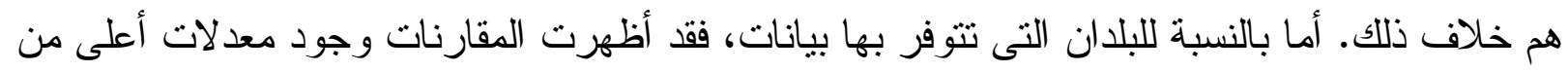
الأنشطة الاقتصادية مقارنة بالماضى.

و أما النتيجة الرئيسية لتلكك المبادرة فهى أن نوعية البيانات عن استعمال الوقت كانت محبطة. فقد وجد أن

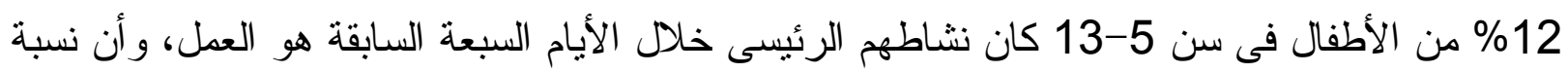

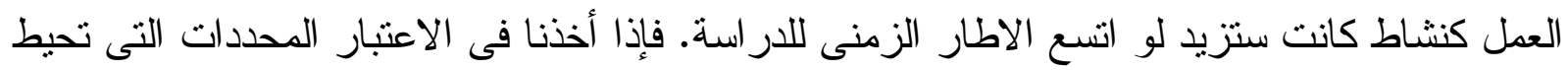
بجمع البيانات فإن الدر اسة قد وجدت نسبة المشاركين فى النشاط الاقتصادى من الفتيان اكبر منها بين الفتيات

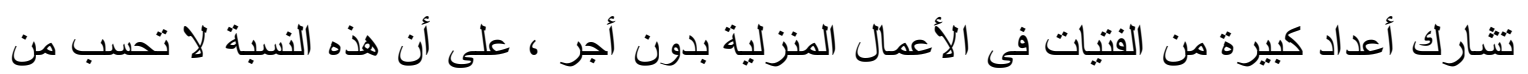
الناحية الفنية فى إحصاءات قوة العمل تزيد معدلات النشاط الاقتصادى للأطفال فى المناطق الريفية مرتنين عن المعدلات بالمناطق الحضرية ويرجع ذلك إلى حد كبير إلى مشاركة أطفال الريف فى الأعمال الزر اعية لئل 
أكثر الأطفال العاملين ينخرطون بالقطاع غير الرسمى ، وأساساً فى مشروعات خاصة بالأسرة

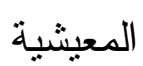

بين الأطفال العاملين تلاميذ وغير التلاميذ، فأما التلاميذ فيعملون فى الغالب بعيداً عن النظرة التقليدية

لقوة العمل

يعرف المر اهقون عادة على أنهم المجموعة العمرية بين 10-19 سنة، وهى فنرة تضم فئات من الثباب

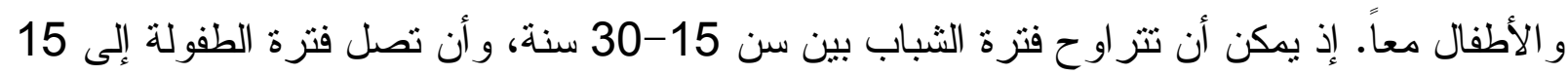
سنة.وقد ركزت معظم بحوث وبر امج تطور المر اهقين على السلوكيات الجنسية و الإنجابية

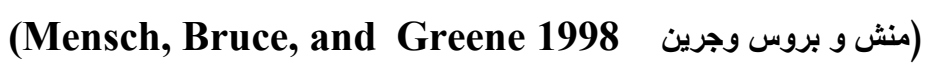

غير أن التحاق كل من المر اهقين الأصغر سناً (10-14 سنة) و الأكبر سناً (15-19 سنة) بقوة العمل آخذ فى البروز كعنصر هام فى قضايا التتمية, وقد حدد المؤتمر الخامس عشر لمنظمة العمل الدولية

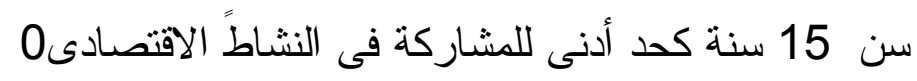


شكل (1) معدلات النشاط الاقتصادى حسب المجموعة العمرية والجنس - مصر

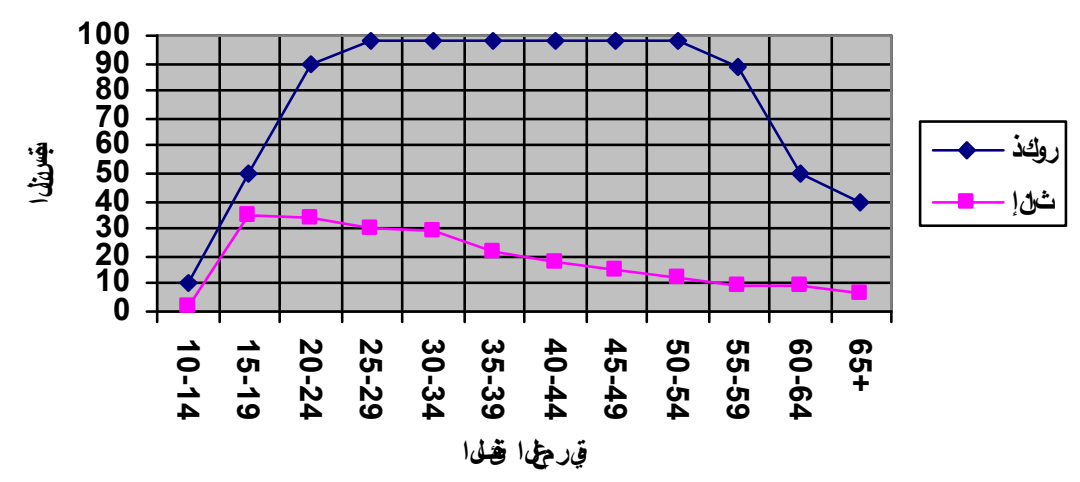

المعدلات الكلية للنشاط فى مصر منخفضة بالنسبة لكل من البنين و البنات على حد سو اء-

فهناك فجوة نوعية بين الجنسين ولكنها لبست كبيرة. فبالنسبة للبنات، تصل المشاركة فى قوة

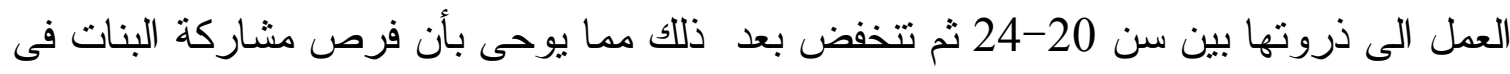

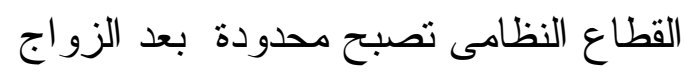

شكل ( 2 ) معدلات النشاط الاقتصادى حسب المجموعة العمرية و الجنس -نيجيريا

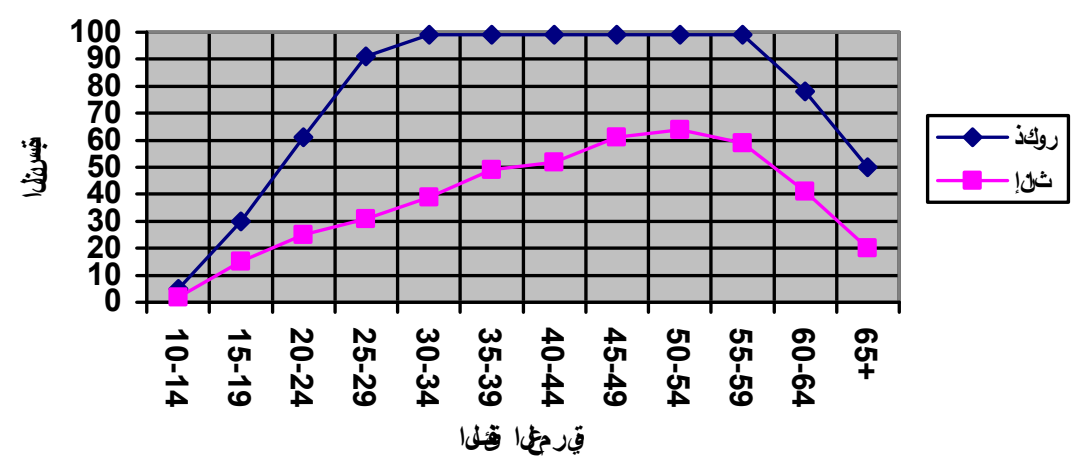

Thailand شكل(3 ) معدلات النشاط الاقتصادى حسب المجموعة العمرية والجنس - تايلاد

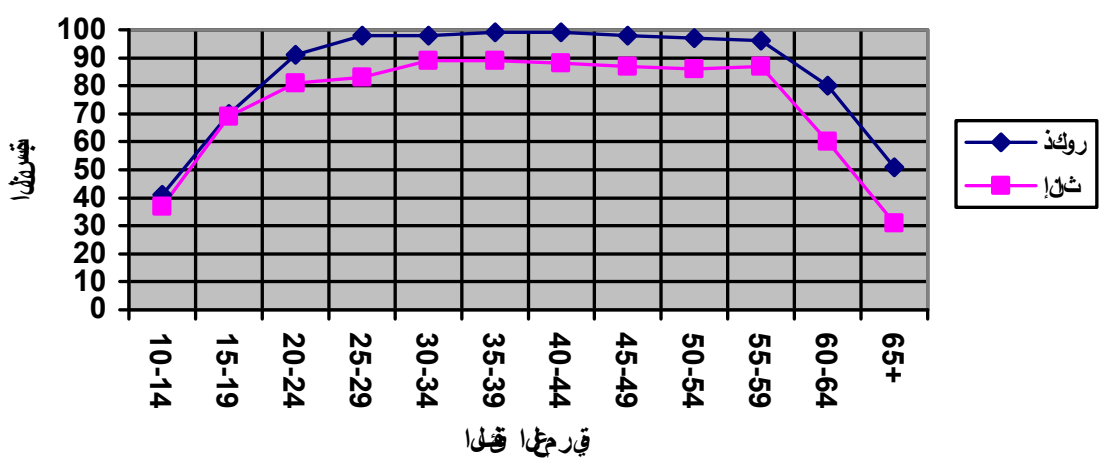

فى نيجيريا تتثابه صورة الالتحاق بقوة العمل خلال المر اهقة مع الصورة فى مصرُ. ولكن فجوة النوع الاجتماعى تتضاءل ولا تتسع مع مرور الزمن. وفى تايلاند، فإن فجوة النوع خلاد

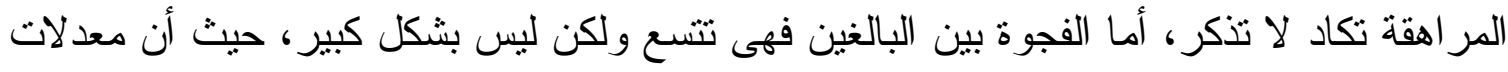
التحاق الرجال و النساء ترتفع وتتخفض فى نفس الوقت طو ال حياتهم. الهصدر : مكتب العمل الدولى 1993 ، 1994

age group = فى الرسوم البيانية : المجموعة العدرية

$$
\text { period = العدة }
$$


ومع الاعتر اف بالقيود على البيانات، فإنه من المهم أن نفرق بين خبرات العمل لدى المر اهقين الصغار و الكبار، وكذلك بين مواقع المر اهقين الذكور و الإناث فى سوق العمل. وتتسب معان

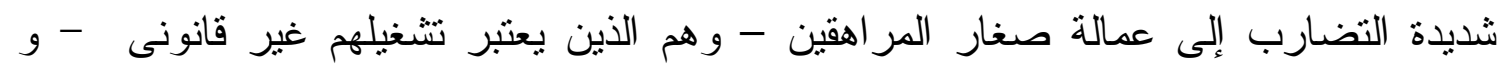
المر اهقين الأكبر سناً الذين يمكنه فى معظم الأحو ال الالتحاق بسوق العمل بطريقة قانونية.

أما بالنسبة لعمالة المر اهقين فإننا لا نعرف إلا القليل عن دوافعها ومداها. ويعد الفقر أهم الأسباب الظاهرة لعمل المر اهقين. فهم يعملون لضمان استمرار الحياة بالنسبة لعائلاتهم

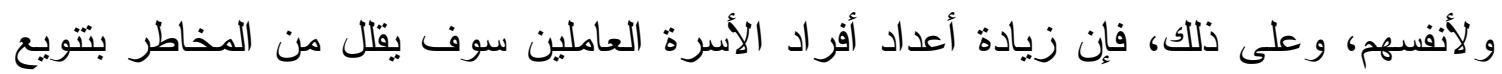

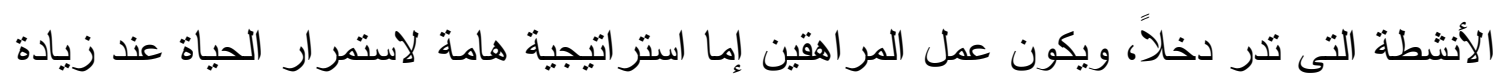

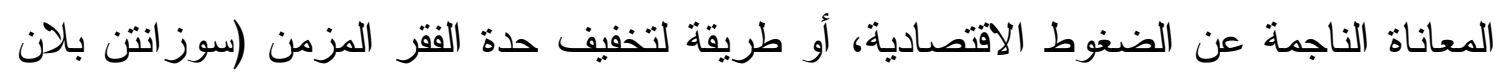

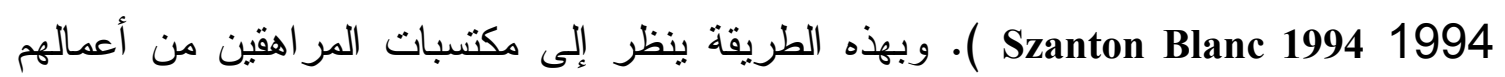
على أنها وسيلة لزيادة دخل الأسرة والحد من تفكلك الأسرة. وقد وجد في دراسة الفة لأطفال

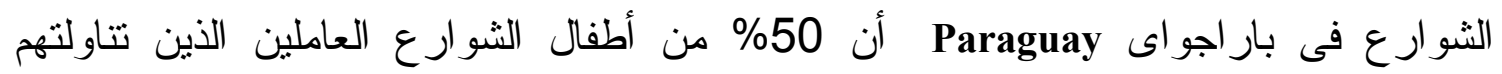

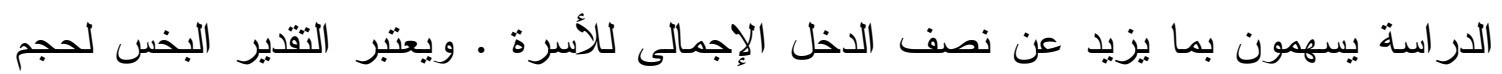

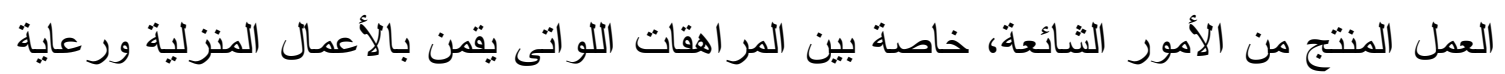

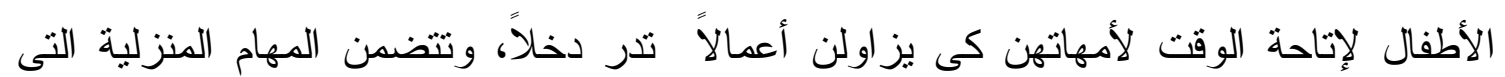

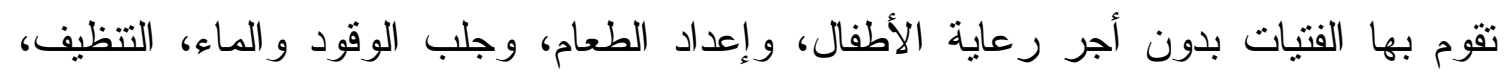

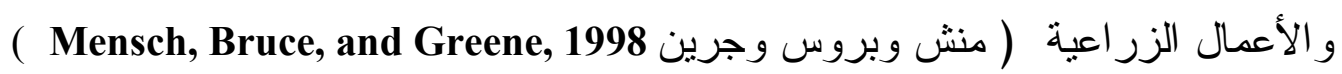
إن بطالة الثباب لها دلالات متعددة بالنسبة لسوق العمل، والأسر الفقبرة، وكذلك بالنسبة

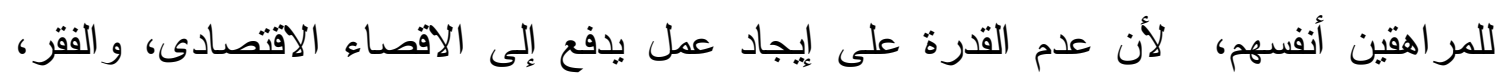

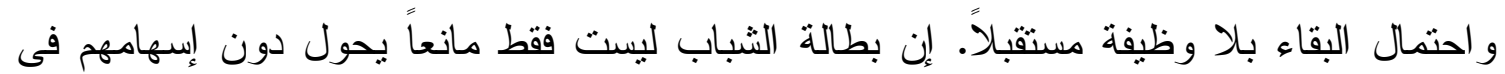

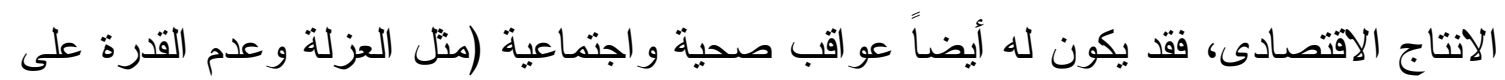
توفير الاحتياجات الغذائية). وحيث أن العمل هو وسيلة هامة كى يطور الثباد البهاب أدواراً ومسئوليات كناضجين، فإن البطالة تحول دون تحول الصغار من المراهقة إلى النضوج 
ماهى أوجه قصور بيانات قوة العمل؟

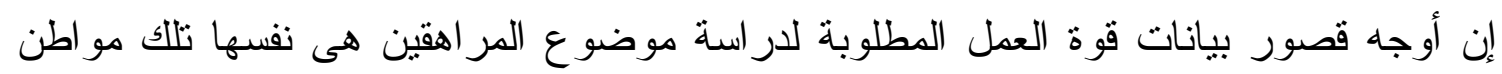

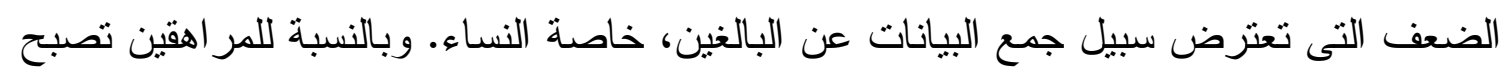

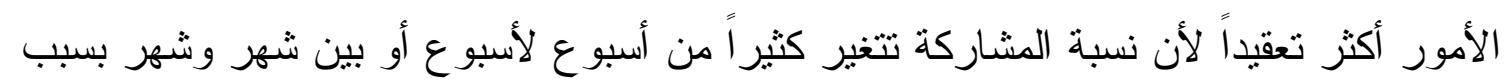

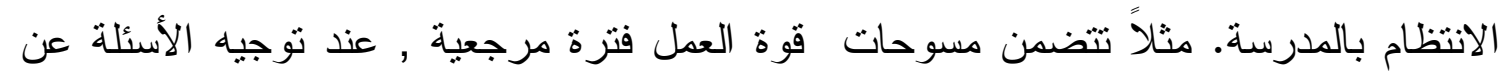

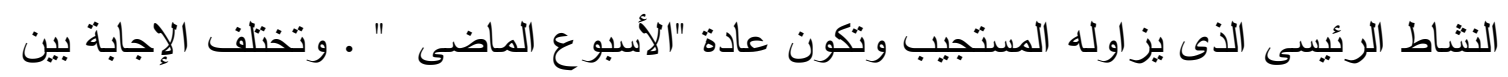

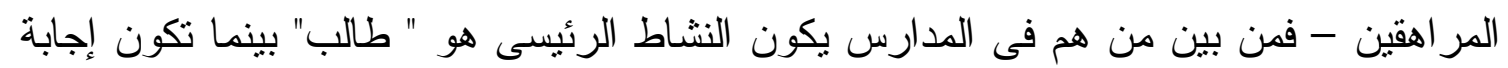

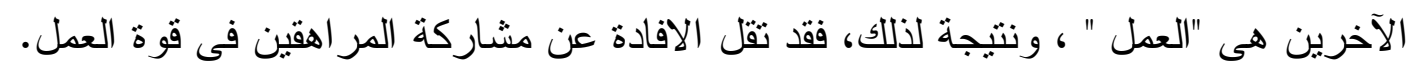

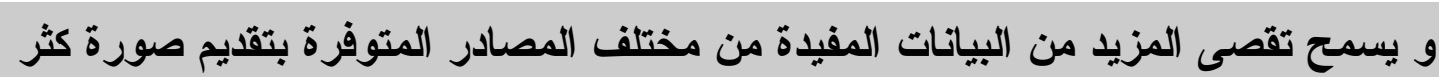

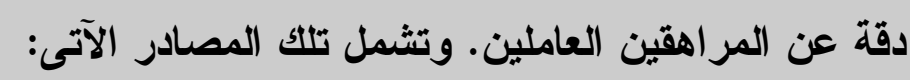
مسوحات عمل الأسرة المعيثية Houshold labor surveys Tراسات استخدام الوقت The-use studies

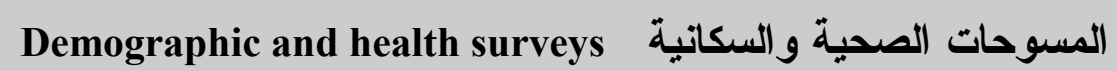

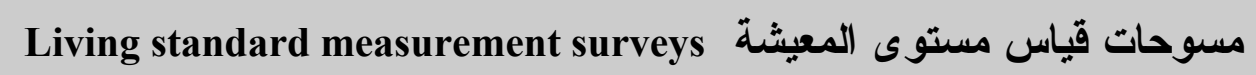

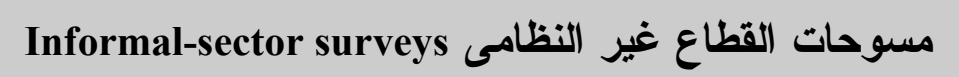

وتوجد لاى كثير من البلاد مصادر بيانات جيدة يمكن أن تعطى معلومات مقطعية-cross sectional فلا يزال هناك الكثير لمعرفته من خلا عل تحليل البيانات الثانوية.

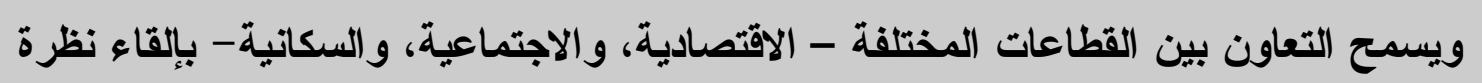

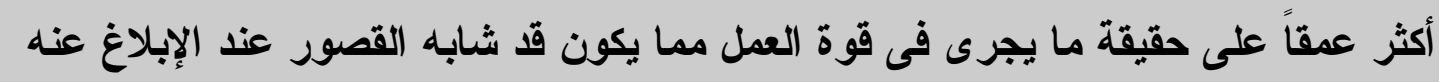

• وبالمثل فإن مسوحات قوة العمل تركز كثير اً على العمل المأجور ، وبرغم ذللك، فإن تعريف

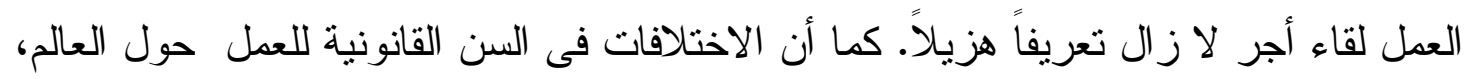

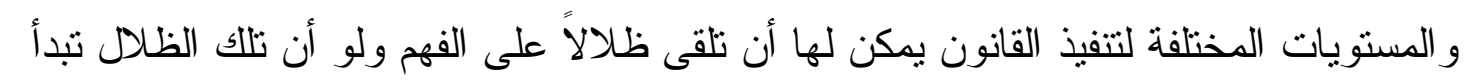
فى الانحسار مع نهاية فترة المر اهقة. 
من الصعب استخلاص نتائج عن الفروق بين الجنسين بسبب بخس التقدير، ففى و اقع الأمر قد تكون الفجوة

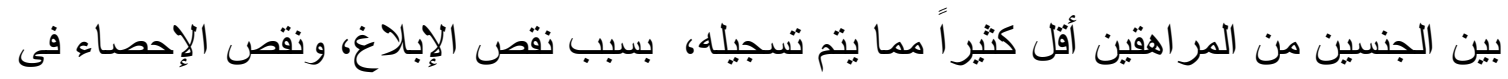
المسوحات.

هل من ليسوا فى المدارس

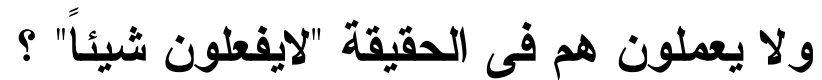

إن عدم التوازن بين قوة عمل المراهقات وبين ترددهن على المدارس يجعل صورة قضاء لهاء

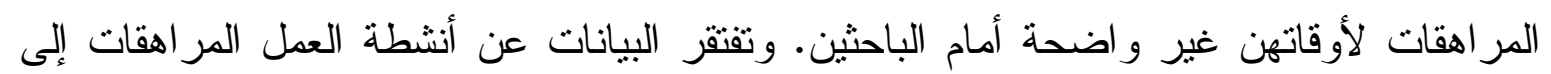

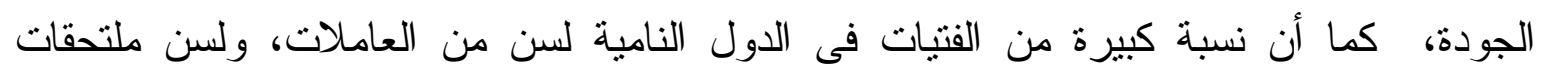
بالمدارس و غير متزوجات، (ثكل 4) ومن الواضح أن تلك الفنيات لسن " جالسات بلا عمل" و هنا

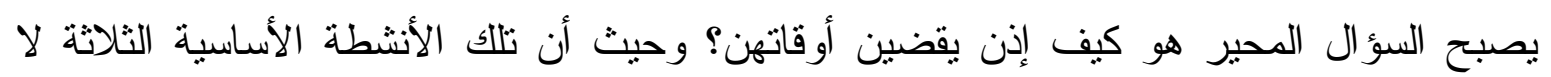

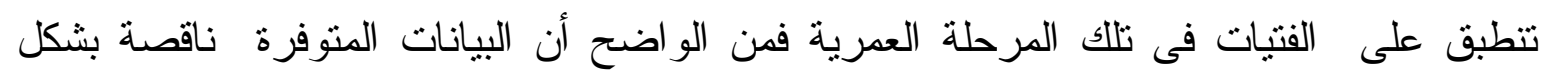

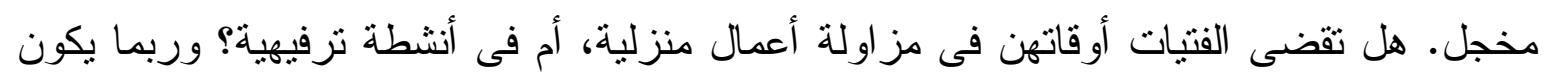

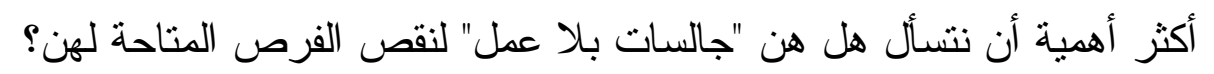

شكل (4)النسبة المئوية للفتيات المراهقات من سن 15-19 سنة اللادى "لا يعملن شيئاً" ( لسن بالمدارس ولسن حو امل وليس سبق لهن الزواج

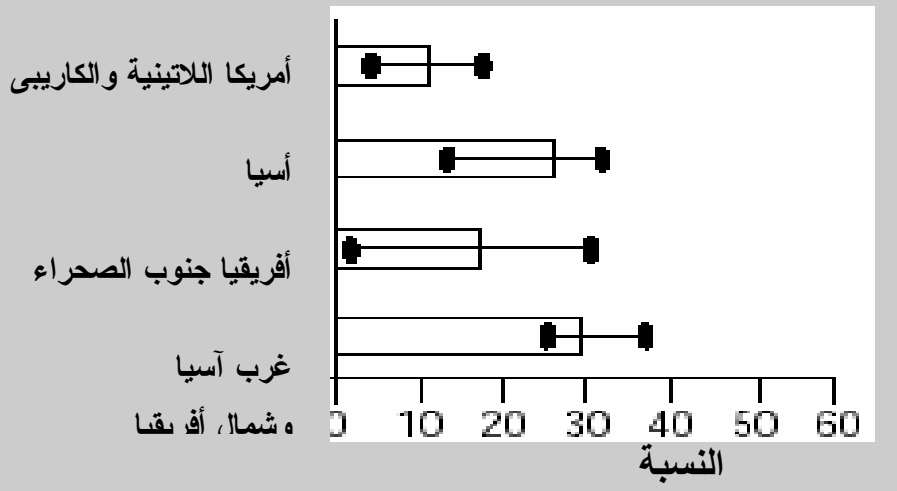

لم يسبق لهن الزواج

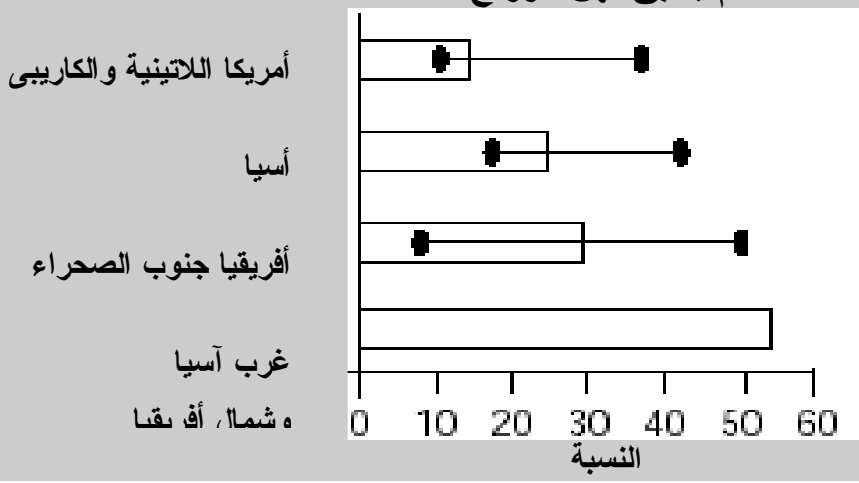




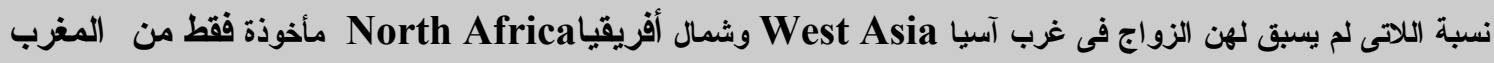

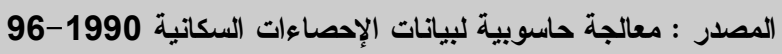
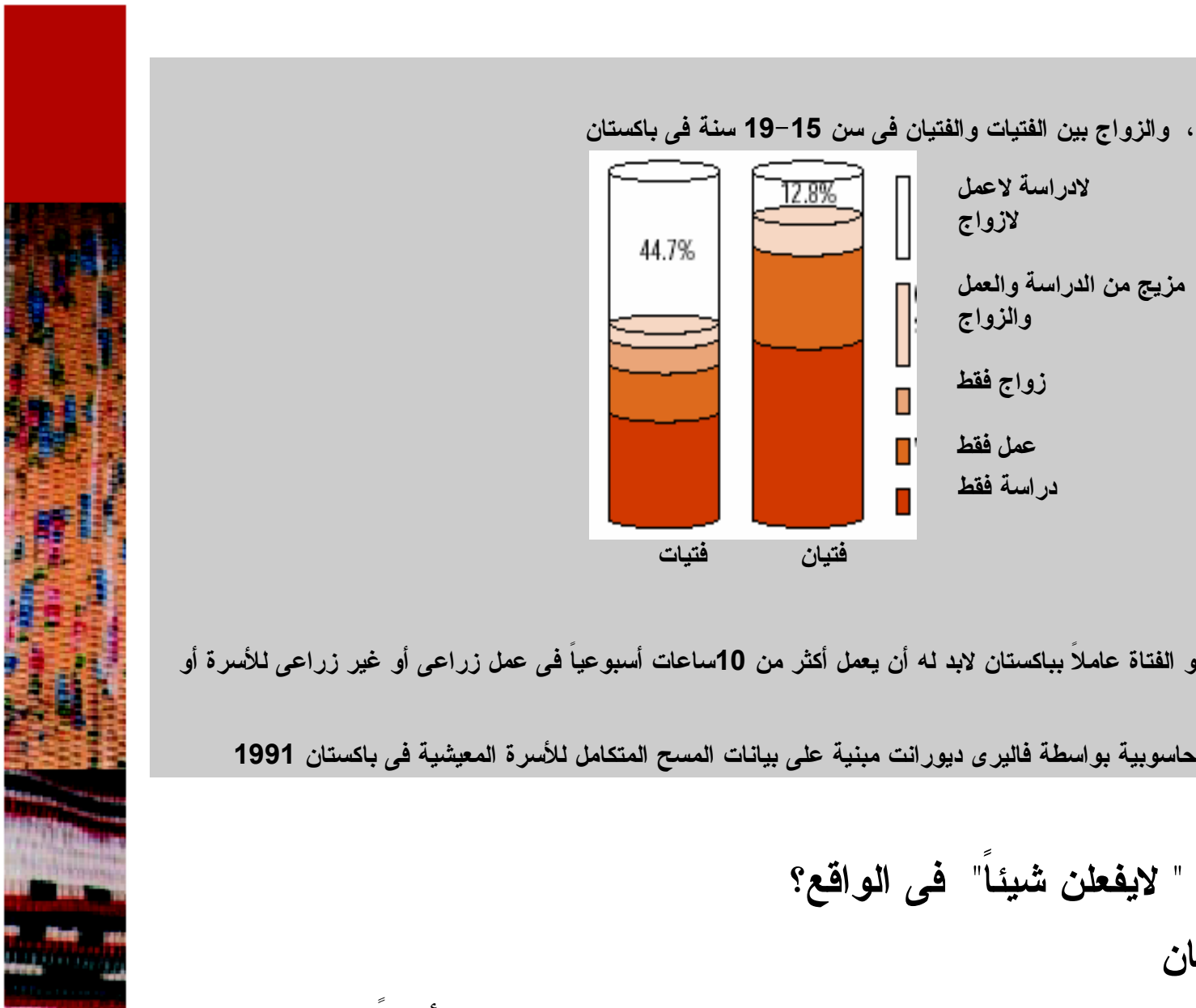

لكى يعتبر الفتى أو الفتاة عاملاً بباكستان لابد له أن يعمل أكثر من 10ساعات أسبوعياً فى عمل زراعى أو غير زراعى للأسرة أو

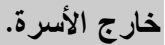
المصدر: معالجة حاسوبية بواسطة فاليرى ديورانت مبنية على بيانات المسح المتكامل للأسرة المعيشية فى باكستان 1991

\section{هل الفتيات " لايفعلن شيئًا" فى الواقع؟ حالة باكستان}

يعتبر وضع المر اهقين فى باكستان غير عادى بالنسبة للمنطقة وبالنسبة أيضًاً لغيرها من البلاد التى تمر بنفس مرحلة النمو، وذلك لأسباب رئيسية ثلاثة، الأكثر أهمية منها هو تنأخر سن الزواج عادة عن السن المعتادة (22 سنة) ، وندرة الزواج قبل سن 15 سنة، وأن 23\% فقط من البنات بين سن 15 و 19 سبق لهن الزواج. وبالإضافة إلى ذلك فإن 32\% من الفتيات فى سن 10-19 سنة هن اللاتى يذهبن حالياً إلى المدارس. و أخيراً فإن عمل الفتيات (بأجر أو بدون أجر) منخفض كذلك. و فيما يبدو، فأن نسبة كبيرة من الفتيات فى باكستان (45\%) "لا يفعلن شيئًا لقضاء أوقاتهن (شكل 5) ـ هذه المجموعة مهمة لأنها: تمنل عدداً كبير اً من الفتيات اللاتى

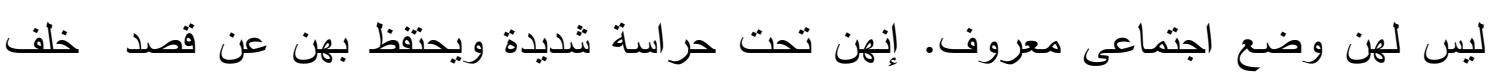
أبو اب البيوت، وهن وحيدات ومنعز لات، وقابلات للنأثز وتقتقدن العلاقات بمؤسسات اجتماعية

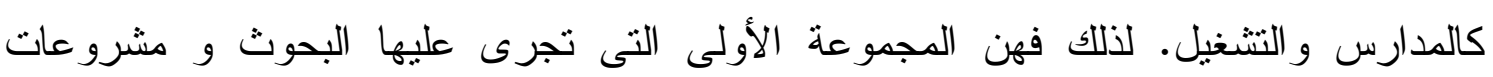


التنخل. إن اكتثاف أن تلك المجموعة غائبة عن الصورة بمثل تحدياً للمعتقدات القائمة عن التحول نحو النضج.

ان معرفة ماذا تفعل الفتيات أمر حيوى بالنسبة للسياسات الايجابية والفعالة والجهود البر امجية لتحسين أوضاعهن.

\section{الأدوات}

اعتمدت المحاولة الأولى للحصول علي تلاك المعلومات النوعبة فى باكستان على مناقثات

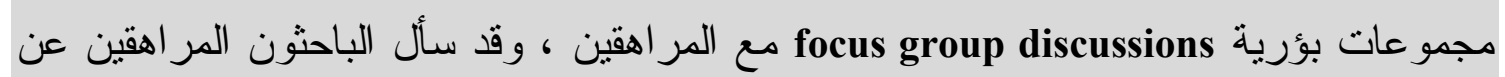

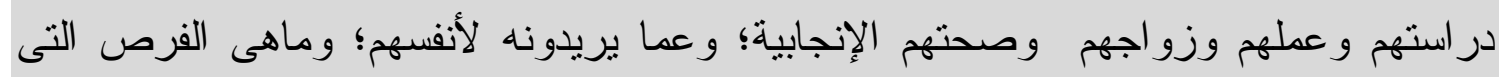

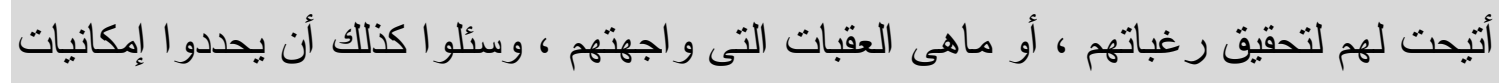

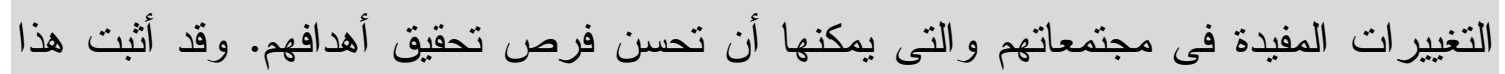

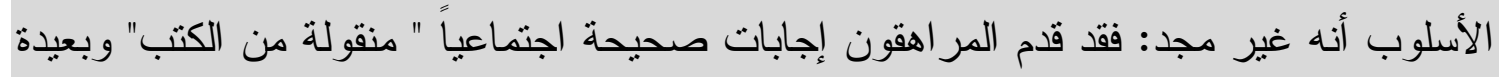

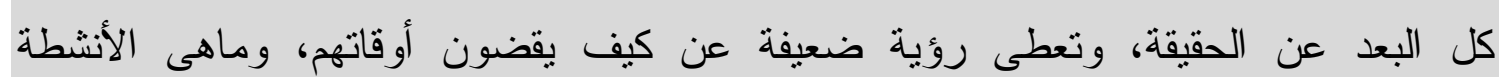

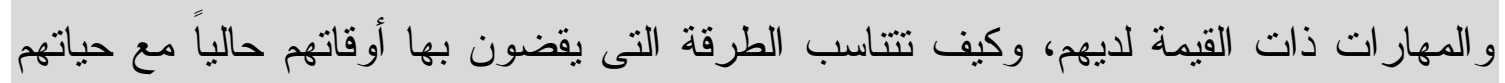
بأكملها.

أعطت المحاولة الثانية لتجميع المعلومات اهتماماً أكبر لبناء المهارات والنطور. وقد سئل

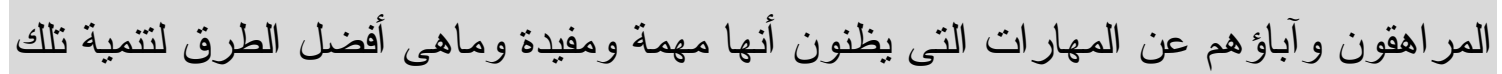

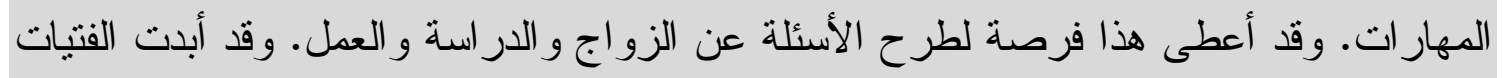

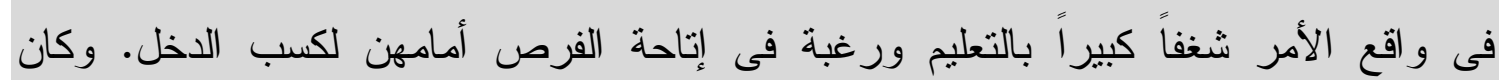

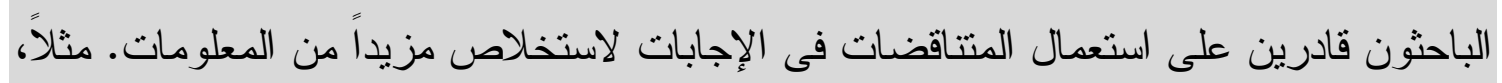

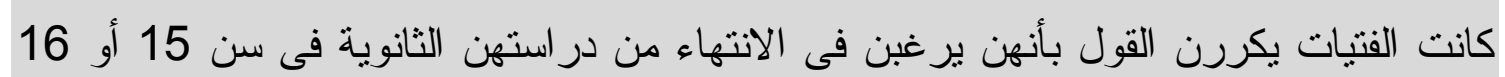

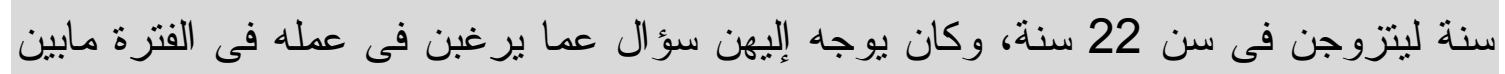

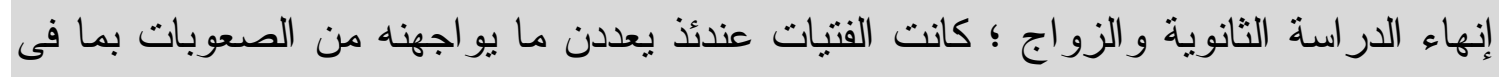

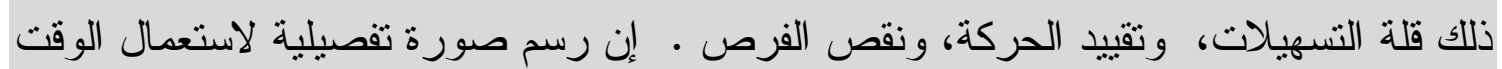

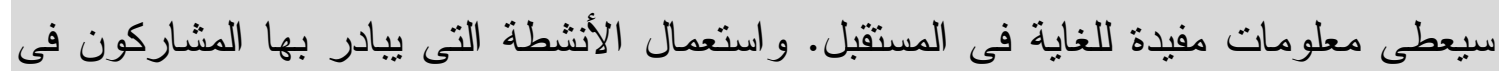

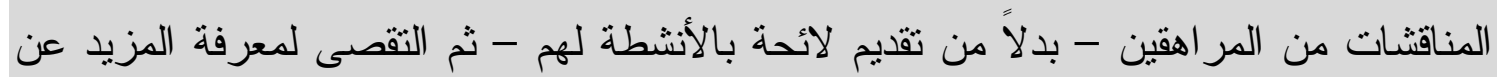


"أوقات الفر اغ" من شأنه أن يقدم الكثير من البيانات الكاثنفة، مثل ما يمكن للاهتمام بالتغير ات الموسمية أن

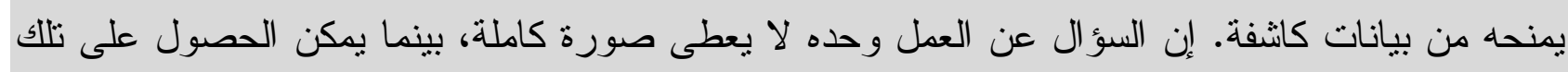

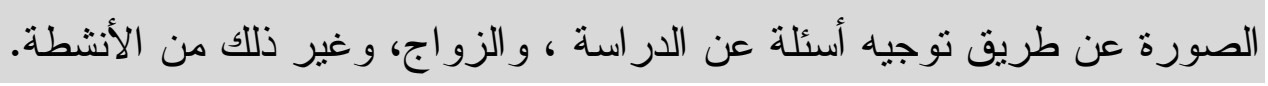

معرفة ما تفعله الفتيات إن معرفة ما تفعله الفتيات هو الركيزة الأساسية لجهود وضع

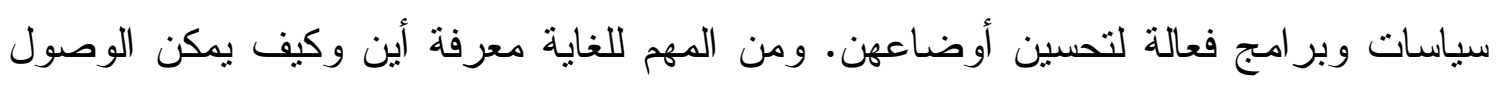

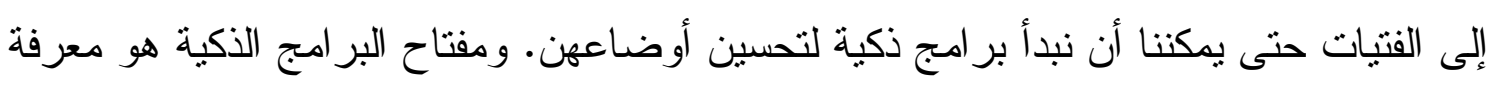

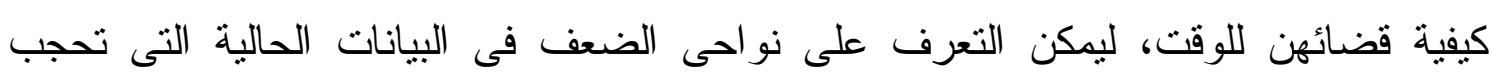

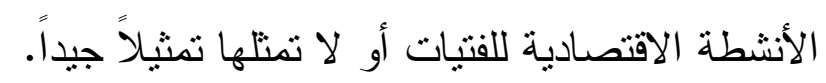

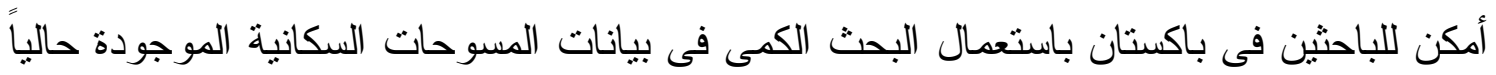

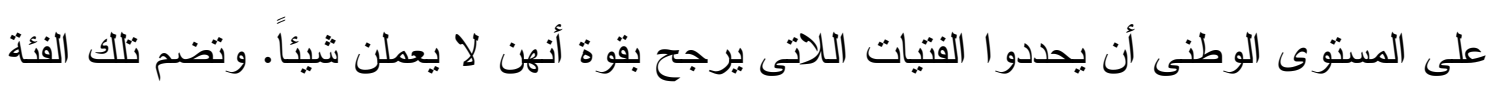
فتيات من المناطق الريفية، وفتيات من مناطق الحدود الثمالية الغربية Northwest Frontier،

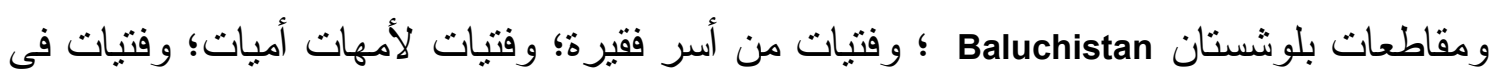

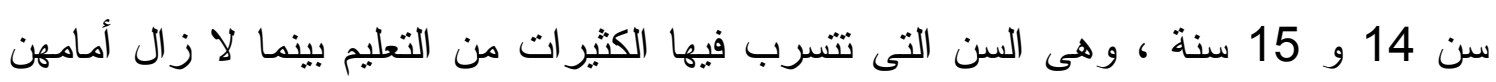

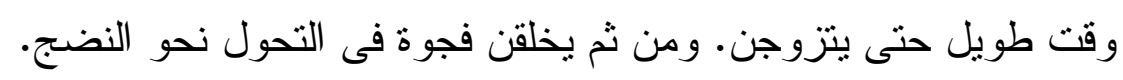

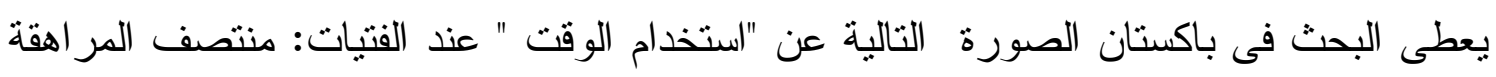

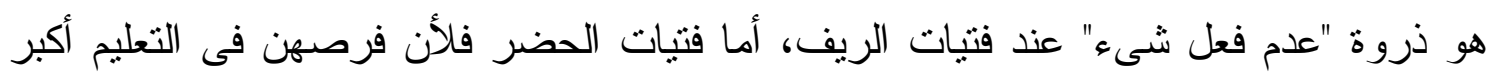

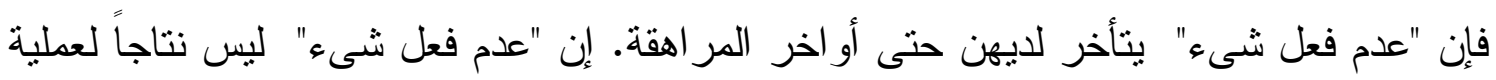

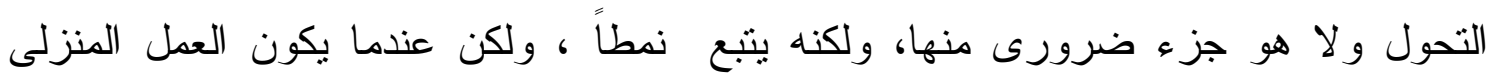

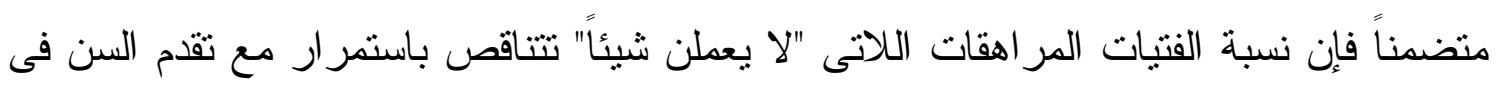

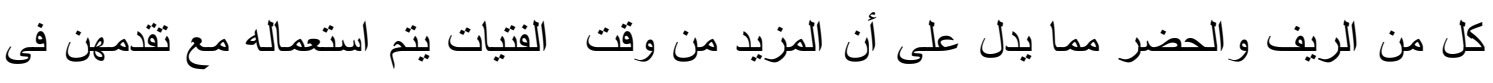
مرحلة المر اهقة.

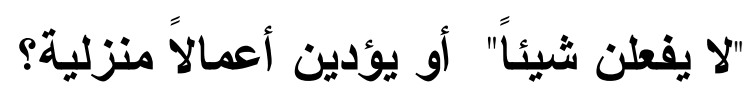

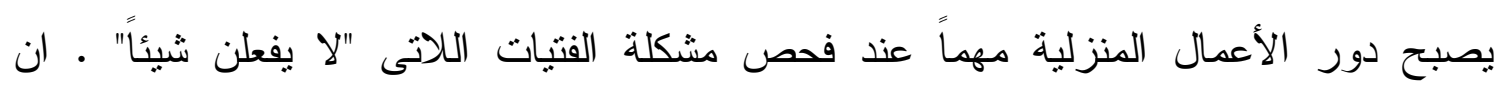
الكثير ات من الفتيات اللاتى لا يفعلن شيئاً فى الظاهر هن فى الو اقع يفعلن الكثير من الأعمال

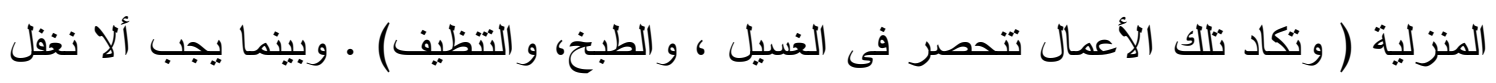

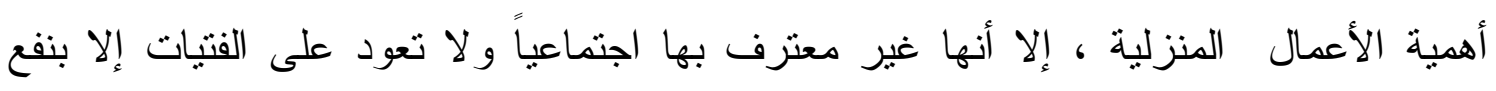

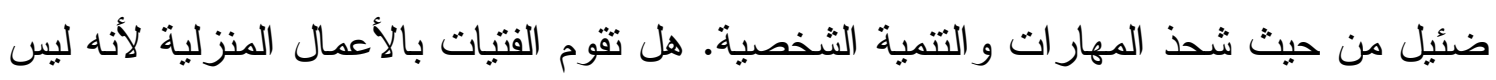


لديهن شىء آخر يقمن بعمله؟ أو أنهن غير قادرات على إيجاد فرص أخرى بسبب انشغالهن بالأعمال المنزلية؟

\section{قيمة وقت الترفيه}

و الموضوع الآخر المهم هو هل الترفيه نثاط له اعتبار أو أنه مدكن إغفاله عند إجراء تقييم كمى دئه

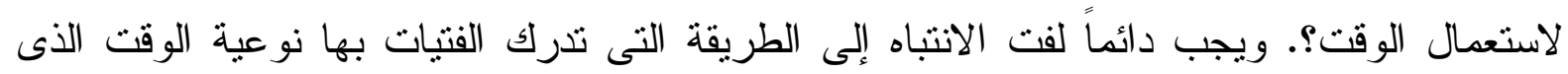

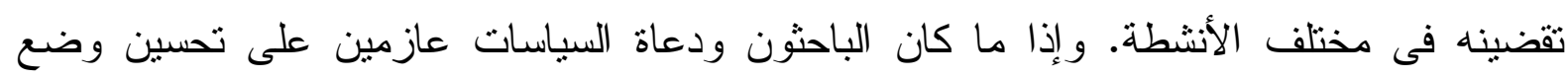

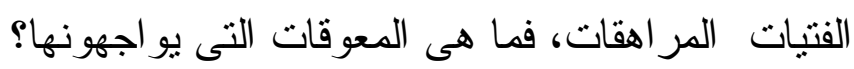

\section{يصعب فى الواقع أن نجد فتيات "لايفعلن شيئا" فالقتيات الأكثر عزلة هن الأكثر انشغالاً}

\section{ليس صحيحاً أن الفتيات" لايفعلن شيئاً"}

يصعب فى الواقع أن نجد فتيات "لايفعلن شيئًا لأن الفتبات الأكثر عزلة هن الأكثر انشغالاً (على الأل الأقل من وجهة نظر الو الدين) ، ولذلك، كان من الصعب تحديد أماكن تو اجد فتيات "لايفعلن شيئًا" .

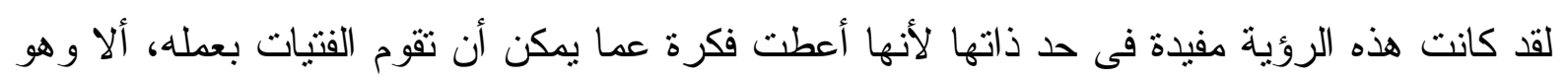
أعمال المنزل. و هناك رؤية أخرى قدمتها مناقثات المجموعات البؤرية focus group discussions وهى أن فنتيات

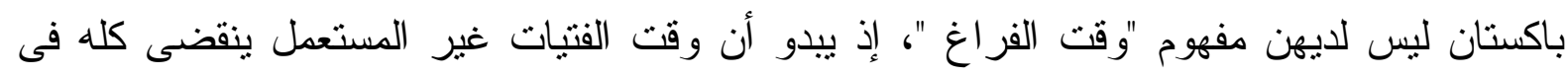

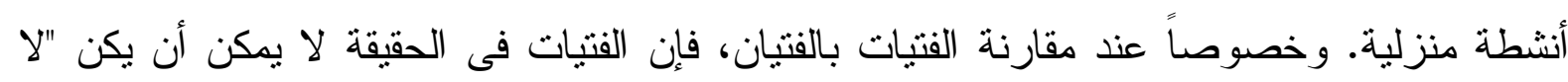
يفعلن شيئًا" 


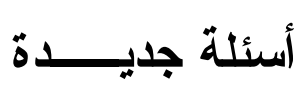

تنقى هناك أسئلة هامة من أمثلنها: لا زال يوجد غموض حول كم من الزمن مر على الفتيات

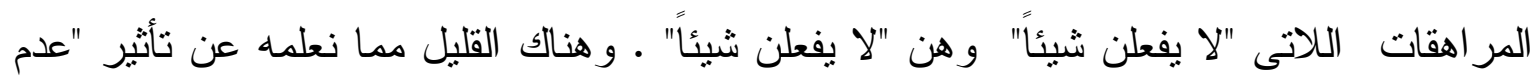

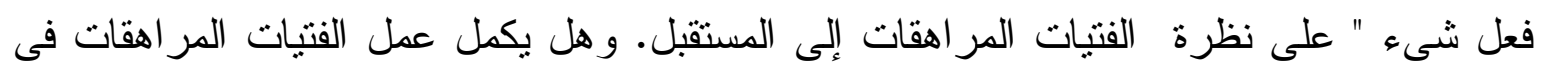

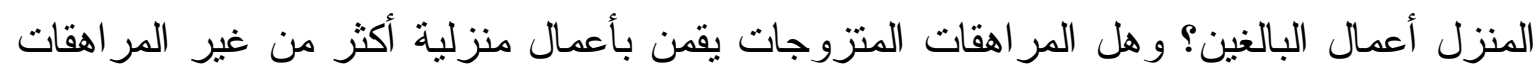

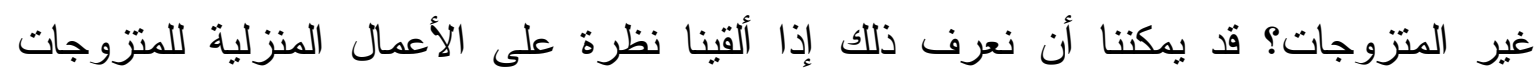

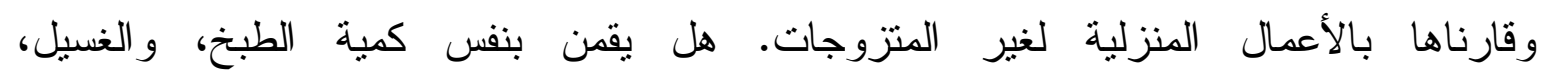
و التتظيف....وما إلى ذلك؟

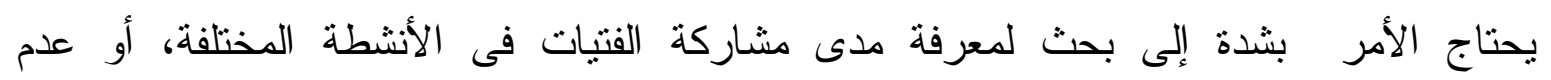

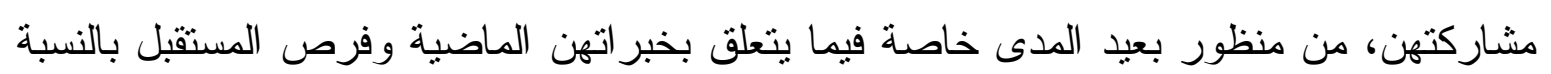
لهن.

\section{هل يفطلون شيئًا:}

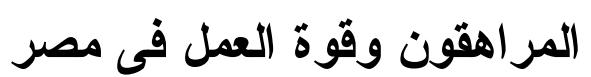

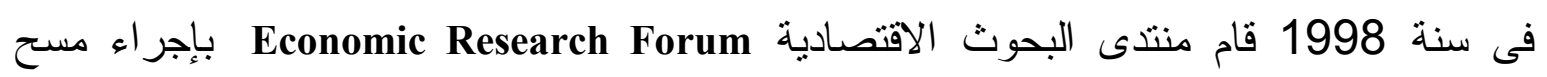
ميدانى ممثل لسوق العمل بالتعاون مع مجلس السكان Population council كجز اء من مجهود

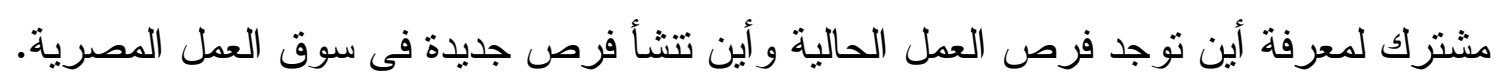

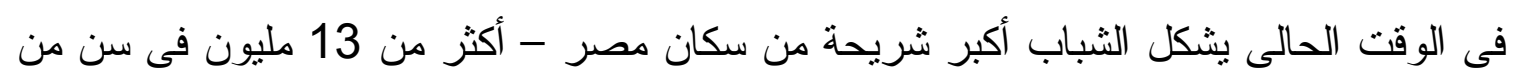

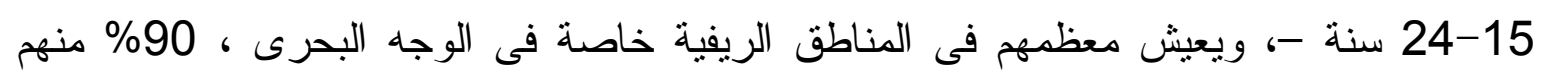

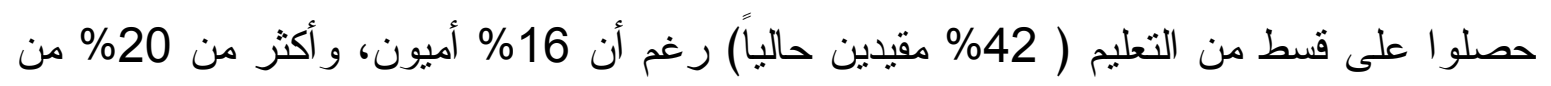
الأميين من الإناث. 32\% من الثباب الــ13 مليون - تقريباً 4,2 مليون - يعتبرون حالياً جز عاً

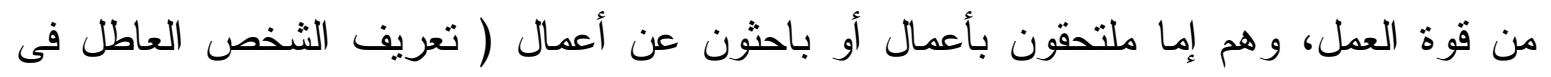

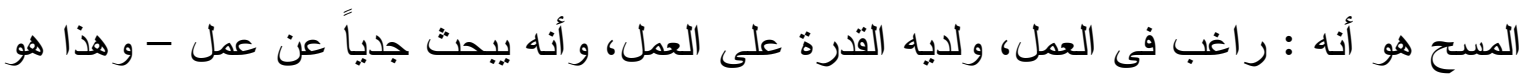

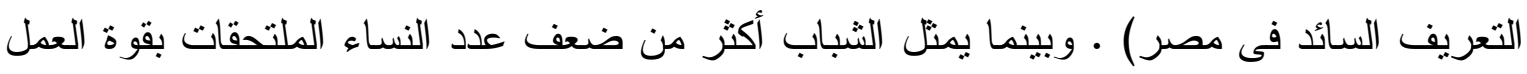
(43\% و19\% على التو الى)، فإن الفجوة بين الجنسين تضيق بين الثباب عنها فى مجموع القوة العاملة. ولكن توجد نواحى تمييز خطيرة بين الجنسين حيث أن المتعطلات من الفتيات ثلاثة

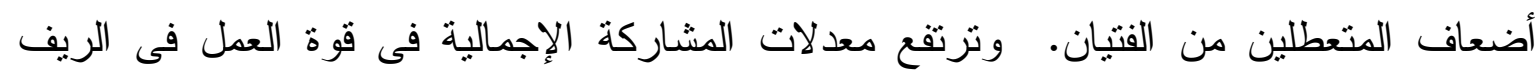

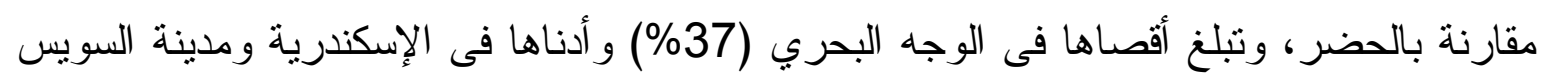


، وتبلغ نسبة البطالة أعلى معدلاتها بين الثباب من حملة المؤهلات المتوسطة وخاصة فى المناطق الريفية.

اتجاهات العمل نظير أجر

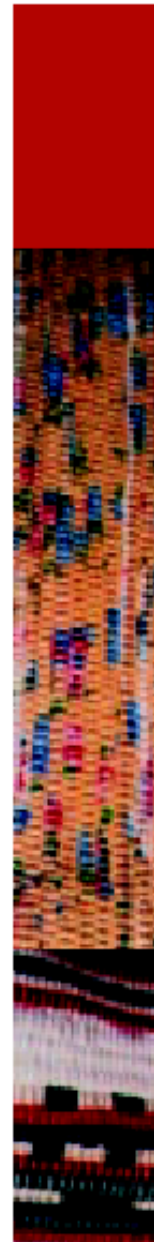

بالنظر إلى من هم فى سن 15-24 سنة فى قوة العمل يلاحظ المرء أن:

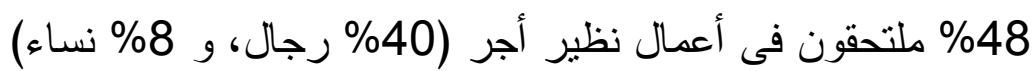

بين سنتى 1988 و1998 زاد العمل نظير أجر بمقدار 12\% بين الثباب ، ونقص بمقدار

21\% بين الثابات، مما زاد فى الفجوة بين الجنسين بمقدار 28

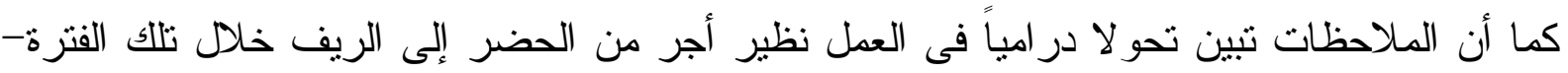

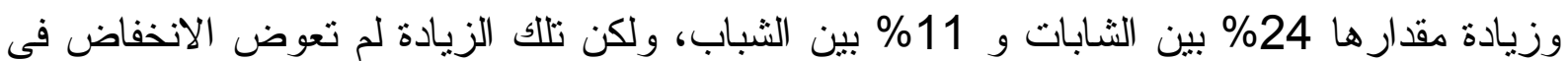
المناطق الحضرية مما يفسر النقص الإجمالى فى التحاق الثباب بقوة العمل.

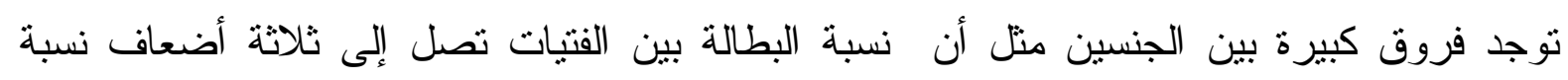
البطالة بين الفتيان

أين تتواجد فرص العمل ؟

توضح النظرة إلى التوزيع القطاعى sectoral distribution للثباب على الأعمال نظير أجر أن

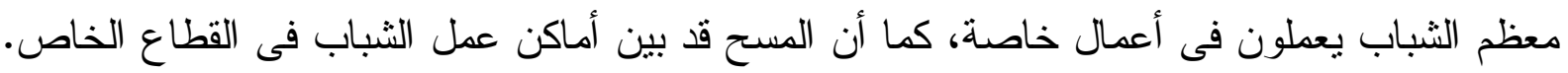

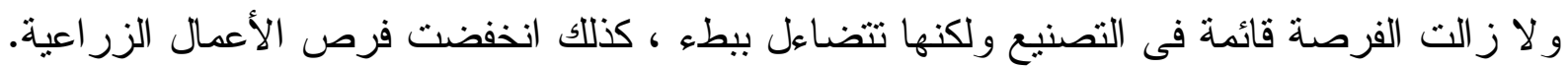

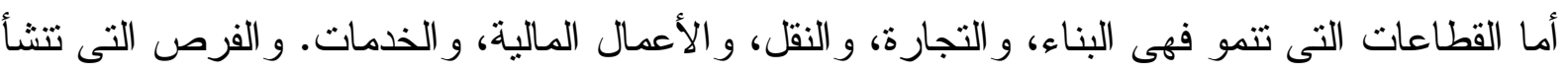

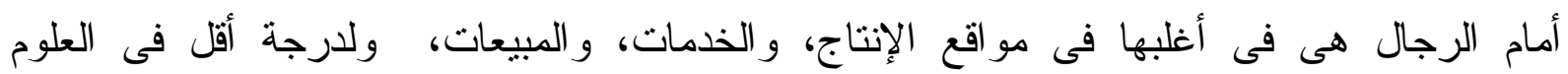

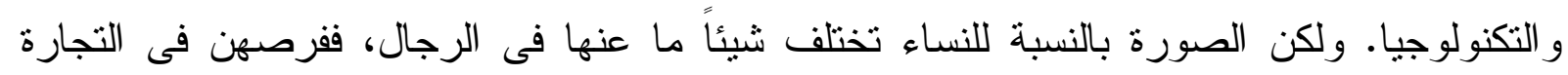

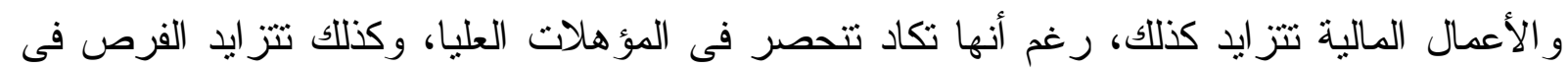

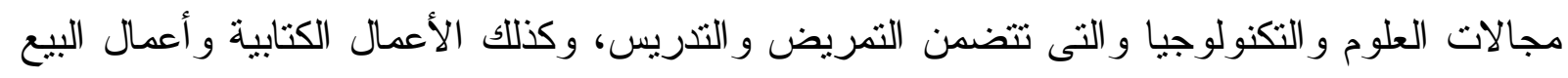

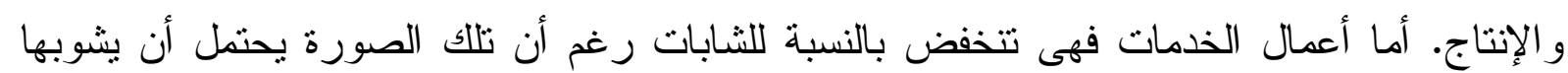
بعض الخطأ الناتج عن التغيير الذى لحق بتصنيف القطاع العام والقطاع الخاص.

\section{فرص العمل: الكم مقابل الكيف}

موضوع الكم مقابل الكيف من الموضوعات الهامة عند النظر فى القطاعات النامية، فقد زادت تكليفات

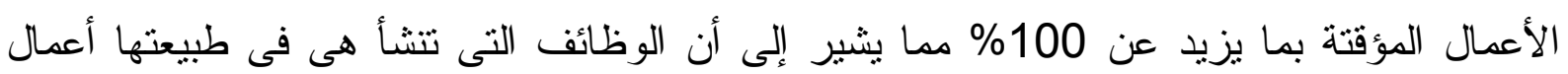
مؤقتة؛ وتوجد فرص أقل للوظائف التعاقدية (الدائمة طبقاً لعقود) ، وقد الخفضت الون مستويات الاستفادة 
بينما زادت ساعات العمل الأسبو عية، ومن الواضح أن معظم فرص العمل الدستجدة تتنسب إلى الفرع غير

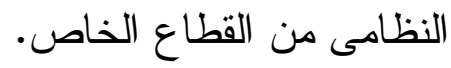

\section{ماهى السن التى يعمل فيها المراهقون فى مصر؟}

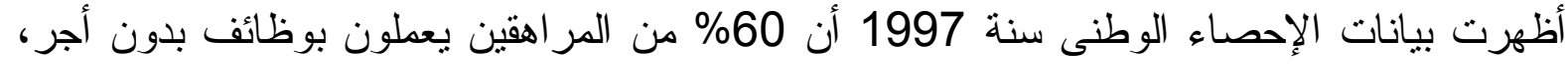
وأن 35\% من هؤلاء العاملين بدون أجر نقل سنهم عن 15 سنة ( الحد الأدنى القانونى للعمل)

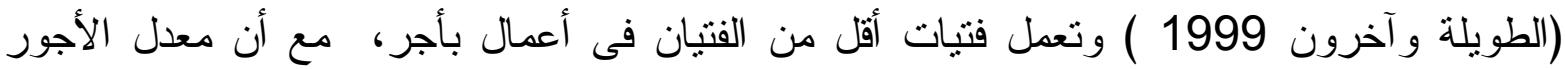

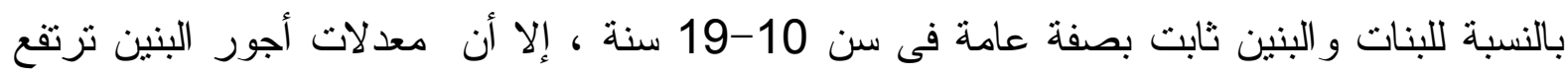

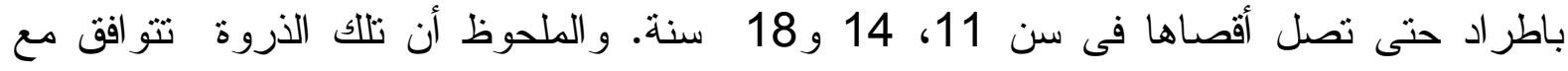

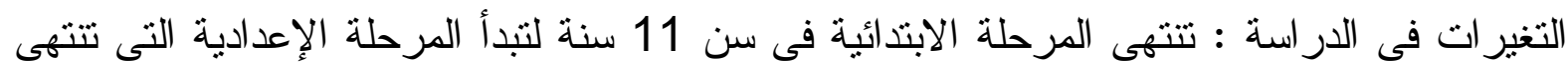
فى سن 14 لتبدأ المرحلة الثانوية التى تنتهى تقريباً فى سن سن 18 سنة.

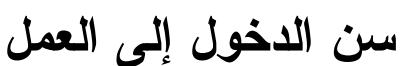

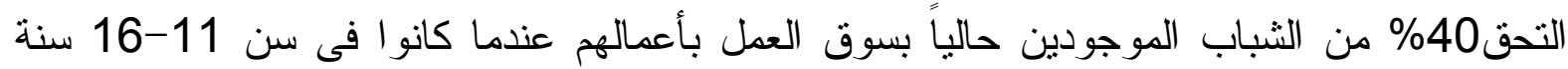

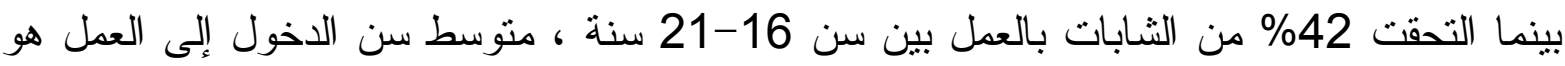
إذن حو الى 10 سنو ات للثبان و 17 سنة للثنابات.

توجد صلة واضحة بين ضعف الأداء المدرسى والتسرب من التعليم - لا يترك الطلاب الدراسة للبحث عن عمل أو للزواج، لكنهم يتسربون لإحساسهم بالإخفاق فى التطليم

العمل والدراسة : هذا أم ذاك؟ حتى حوالى 20 سنة مضت كان الاعتقاد السائد فى مصر أن الأطفال الذين يعملون لمساعدة عائلاتهم

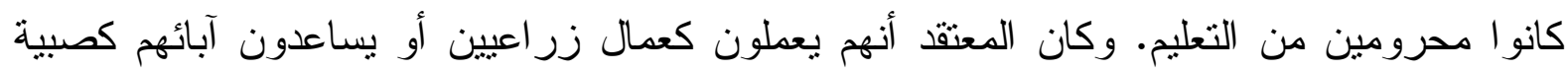

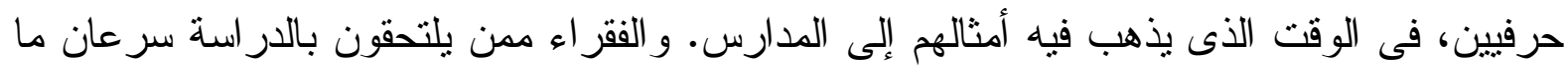

$$
\text { يتسربون منها. }
$$

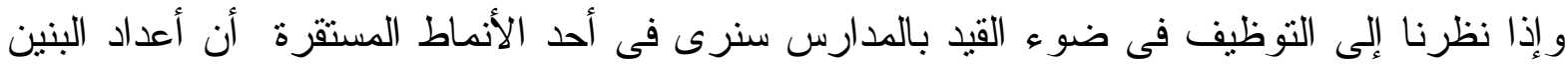

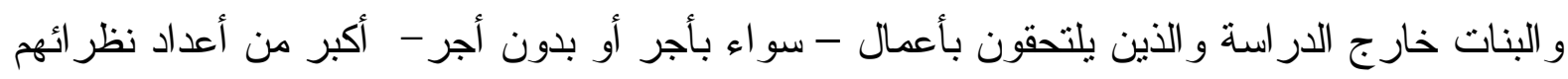

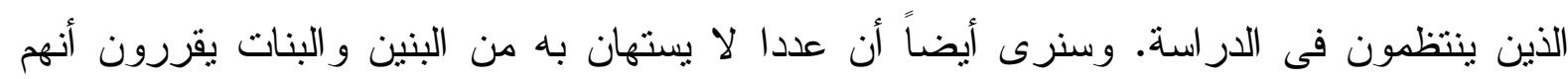


التحقو ابالعمل و انتظموا فى الدراسة فى نفس الوقت، مما يدل على أن العمل والدراسة لا يتعارضان

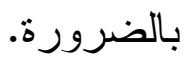

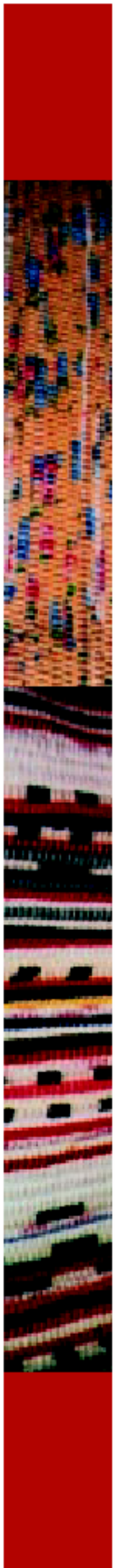

\section{السبب الرئيسى لترك الدر اسة}

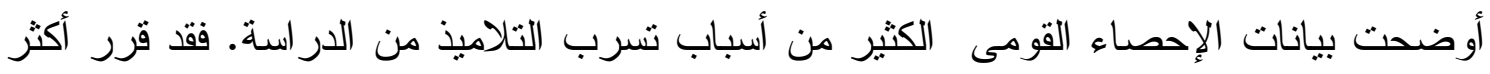

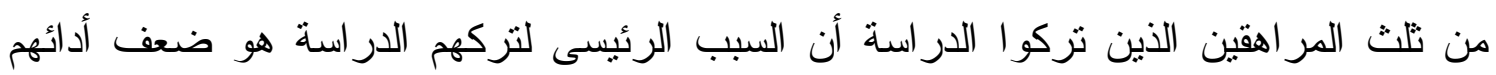

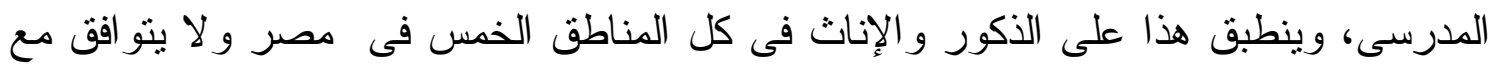

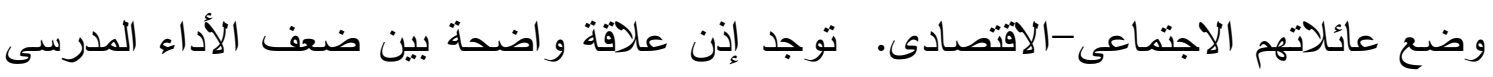

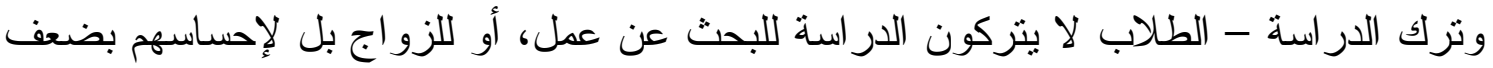

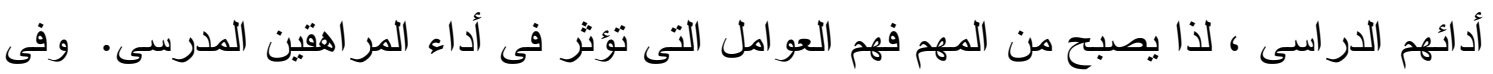
سياق تحليل متعدد المتغيرات multivariate analysis وبعد ضبط أربعة من العوامل المهمة المتعلقة بالأداء المدرسى (النوع gender ، و والمنطقة السكنية، والحالة الاجتماعية-الاقتصادية، وحالة العمل ) لم يوجد فروق بين الجنسين، و لا فروق ذات قيمة بالنسبة لمكان السكن فى الأداء

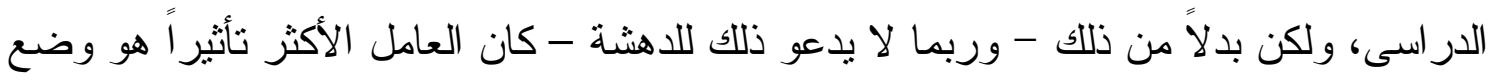

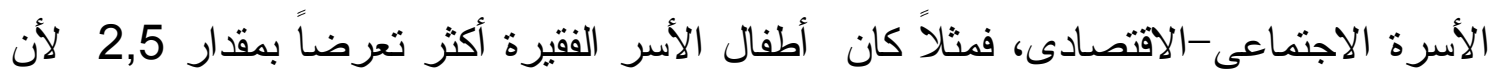

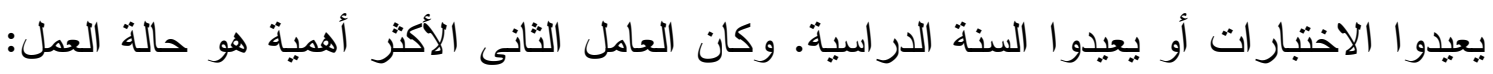

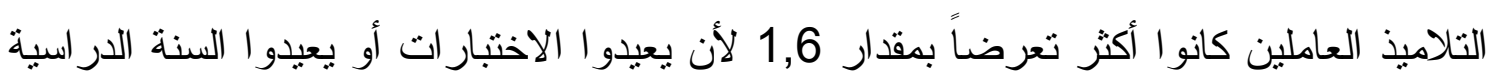

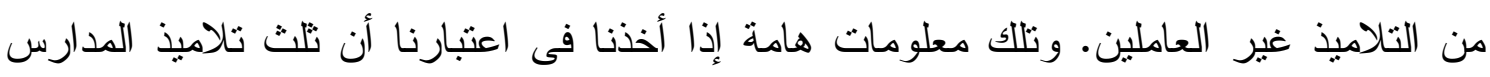
من الذكور ملتحقون بأعمال، وأن 10\% من تلميذات المدارس مشاركات فى قوة العمل كذلك.

\section{عormative environment عمل البنات والسياسات و البيئة المعيارية}

\section{ما هى أوجه التوتر tensions بين العمل والار اسة؟}

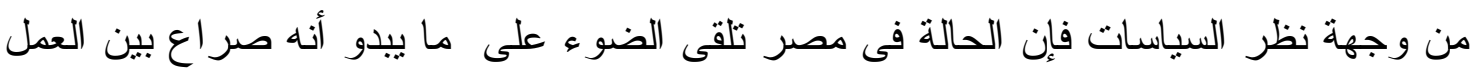

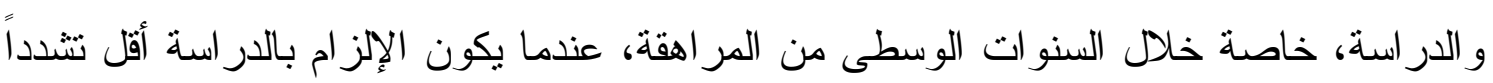

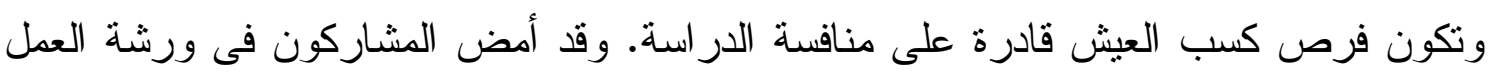

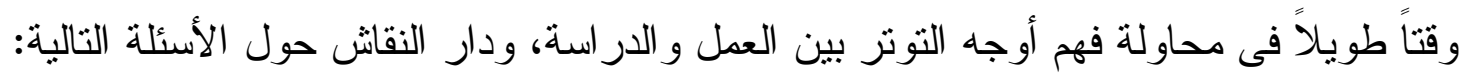

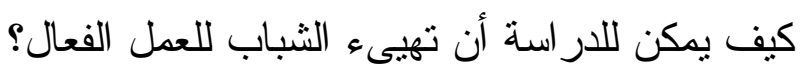

هل توجد مبادلات ذات مغزى بين العمل و التعليم؟

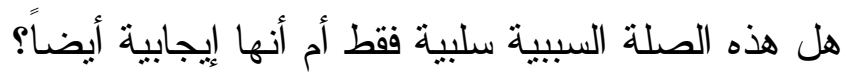


ماهى المبادلات بين العمل و التعليم على الددى القصير و الطويل؟

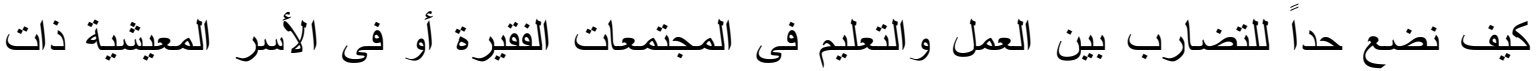

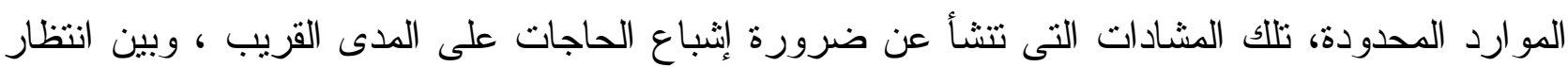
الفو ائد التى تجنى من التعليم على المدى البعيد باعتباره أحد وسائل تقوية رأس المال البشرى؟ الثقائ

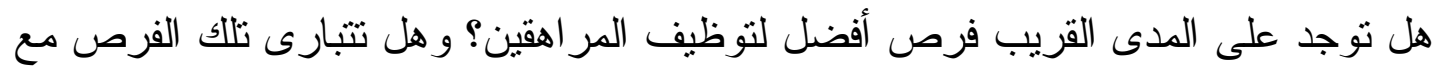

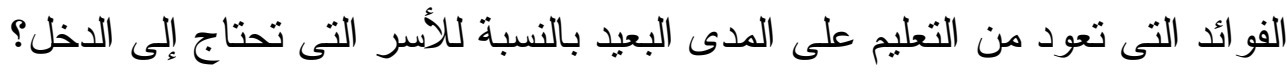

ونظراً للعدد الكبير من الثباب فى القطاع غير الرسمى وما تضعه البلاد فيهم من استثمار ات، فلابد

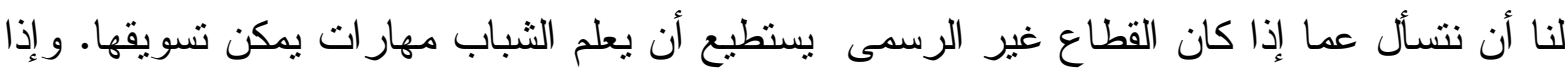

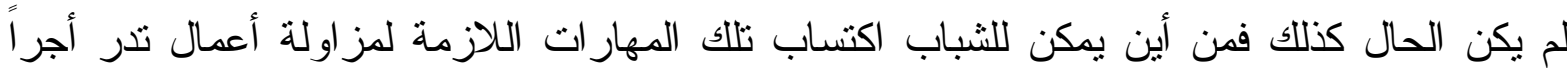
حسنا؟ إن التناميذ الذين يتركون الدراسة يفقدن بالتالى الفرص التى تمنحها الدر اسة إياهم، فى حين أنه من غير المضمون أن يحصلو امن خلال عملهم على خبرات تحسن من فرصهم فى سوق العمل، لئل

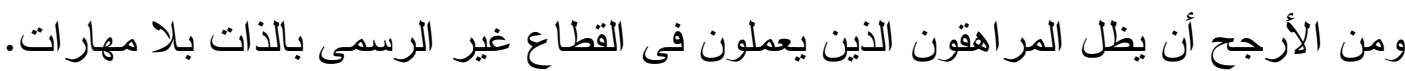

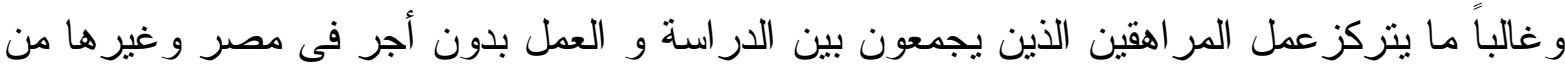
البلدان فى الأعمال اليدوية بالزراعة والتى تعرضهم للمخاطر الصحية (منل ملامسة المخصبات الكيماوية ومبيدات الآفات) بدون أن يكتسبو المهار ات خاصة تعطيهم القدرة على إيجاد فرص أفضل

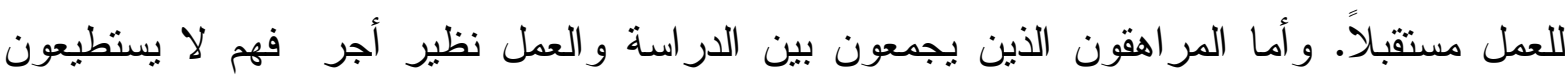
بدور هم اكتساب مهار ات فى الغالب من خلال عملهم كصبية متدربين apprenticeship : لأنهم لا لانيل يمكثون فى العمل طو ال الساعات المقررة، ولذا لا يكلفون إلا بالأعمال التافهة.

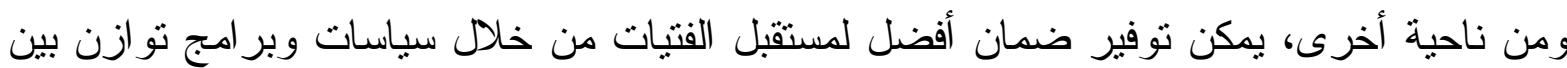
حاجاتهن الحالية لكسب العيش وبين الفرص المستقبلية والمز ايا التى يحصلن عليها من خلال التعليم على الددى الطويل. إن الاستثمار فى التعليم يحسن من فرص الحصول على أعمال مستقبلاً لكل من الفتبان و الفتيات، ولكنه فى كثير من الأحو ال يكون مردوده على الفتيات أكبر من مردود التعليم بالنسبة للفتيان.

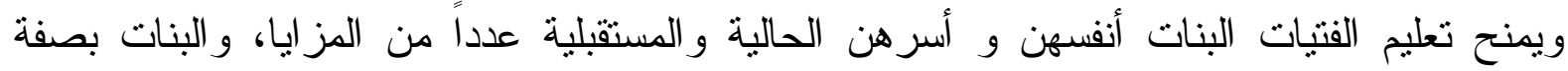
خاصة يحتجن إلى نوع من التعليم يهيائهن للمشاركة الكاملة فى تتمية مجتمعاتهن سياسياً واجتماعياً و واقتصادياً.

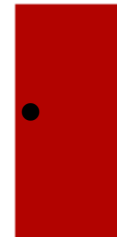

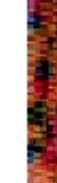




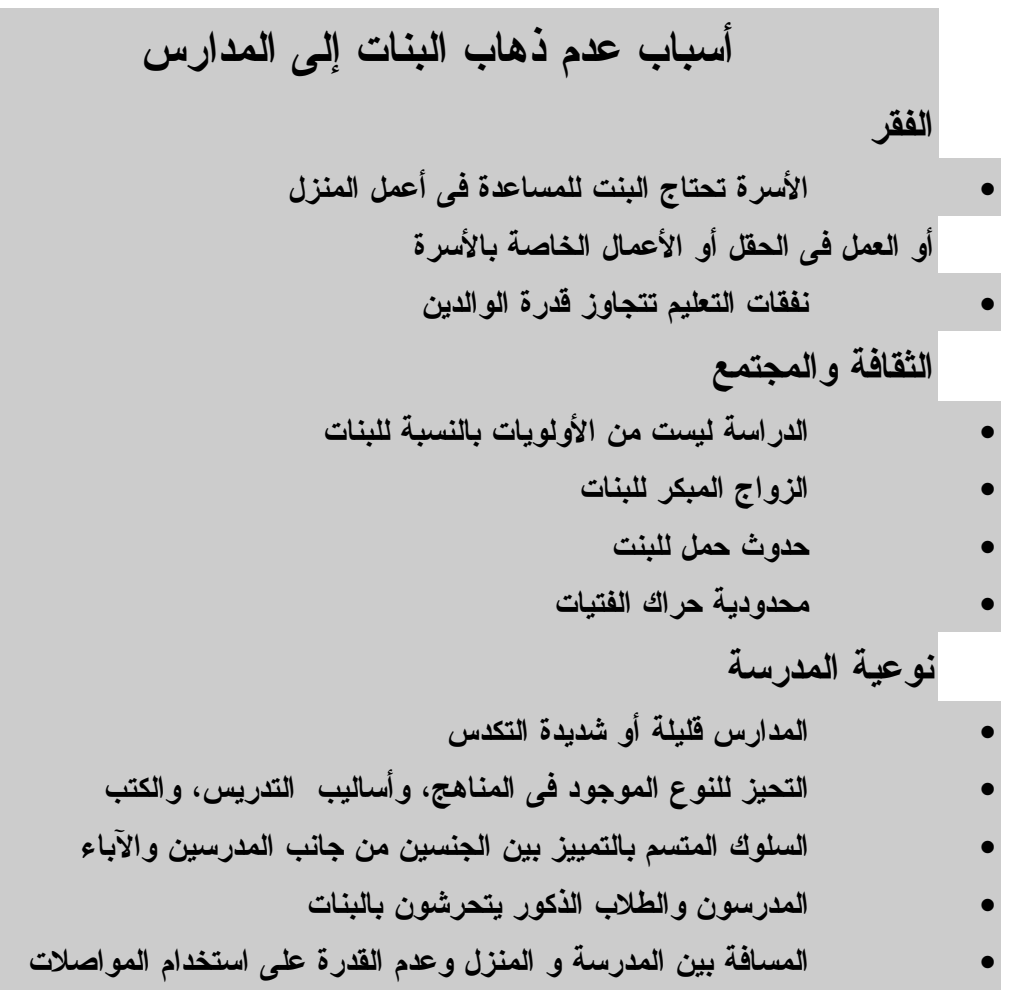

ولكن، فى الدول الأقل نمواً لا زال يوجد 73 مليون فتاة فى سن التعليم الابتدائى لم تتح لهن الفرصة للحصول على التعليم الأساسى ، و13\% فقط من البنات و22\% فقط من البنين هم المقيدون فى التعليم الثانوى. أين إذن تتو اجد البنات طالما هن لسن بالمدارس؟ قد يكن عاملات

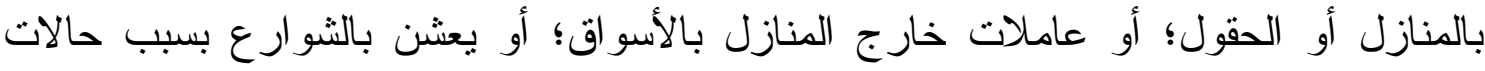

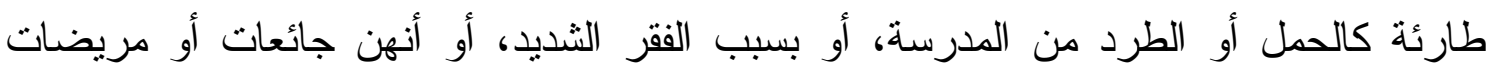
لارجة تمنعهن من الذهاب إلى المدرسة.

و لا يدهشنا وجود علاقة إيجابية للغاية بين التزدد على المدرسة ودخل المثلة الأسرة، خاصة بالنسبة

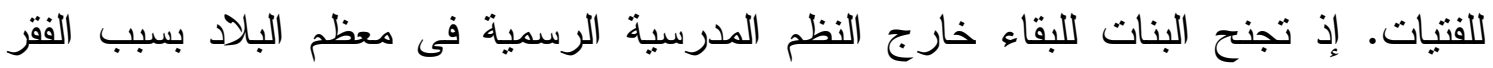

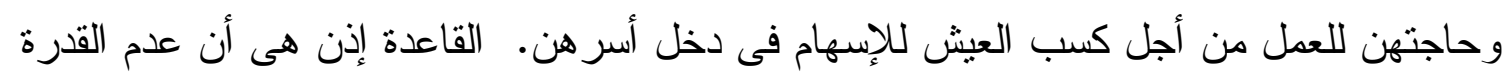

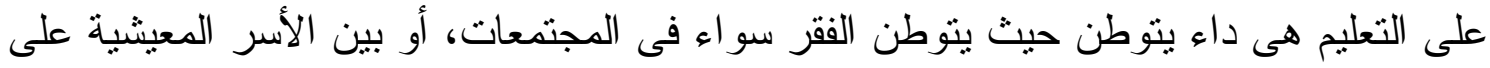

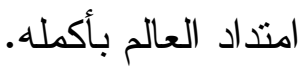

الا أن البيانات التى جمعت فى مصر تثبر الى أنه بالرغم من أن قرار الالتحاق بالعمل بدلاً من

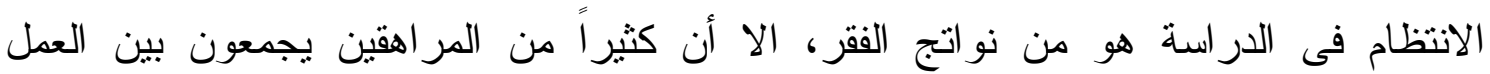

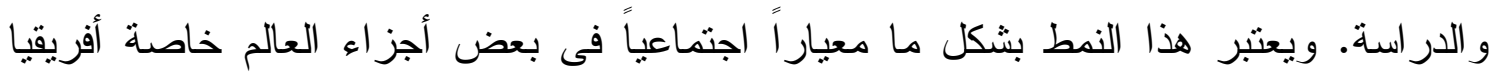

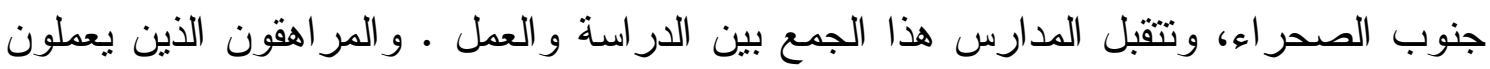




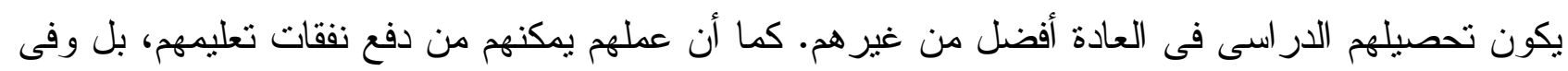

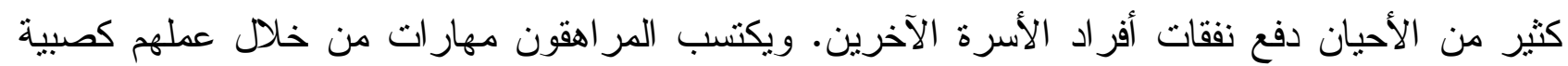
متدربين وكذللك من خلال بر امج تدريب على المهار ات معدة بعناية.

تثير البيانات التى جمعت فى مصر الى أنه بالرغم من أن قرار الالتحاق بالعمل بدلاً من الانتظام فى التى

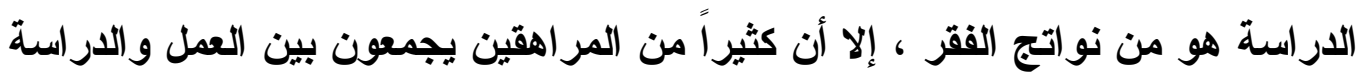

الإقلال من الاتجاه نحو استبدال الدراسة بالعمل أو العكس يوجد العديد من البر امج التى تستوعب احتياجات المر اهقين بالنسبة لكل من الدراسة و العمل،

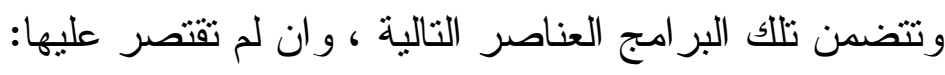
ترنيات مرنة للعمل و الدر اسة

دعم وحو افز افتصادية للآباء ليسمو اللأبناء بالتردد على الددرسة بدلاً من العمل فئل

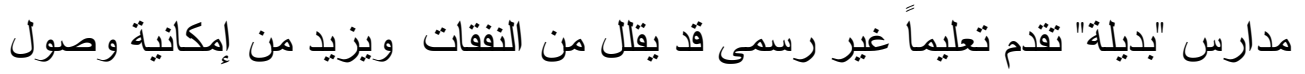
التلاميذ إليه

بر امج در اسية " خارج الأسوار" للمهشين ومن ليست لديهم إمكانيات من الثنباب تعليم ذو علاقة باحتياجات عمل المر اهقين جهود لإز الة الأعمال التى تتضمن الإساءة أو المغامرة بتهيئة بيئة وفرص آمنة.

رعاية بيئة عمل إنتاجي آمنة للفتيات المر اهقات : معابر

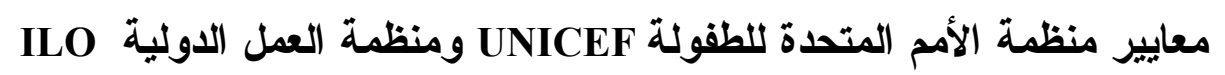

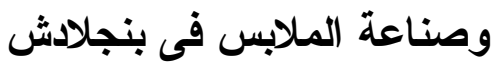

ازدهرت صناعة الملابس فى بنجلادش فى التسعينيات من القرن العشرين فزاد عدد المصانع من 50

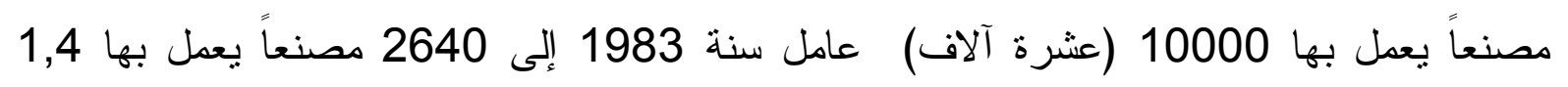
مليون عامل فى سنة 1998 ـ وتشكل الإناث نسبة 85\% من العمال. وبينما كانت الصناعة تتمو

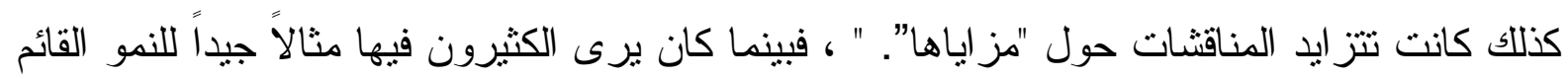

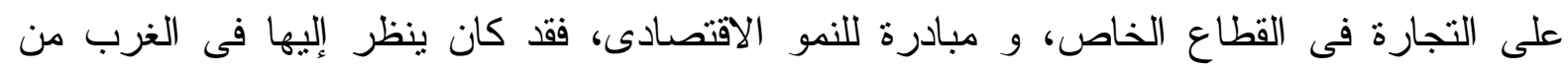

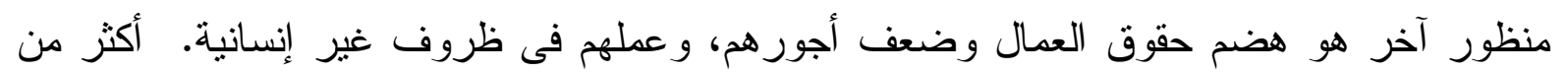


هذا، فإن الأمريكان الذين تفتح أسو اقهم لــ 85\% من صـادرات الملابس من بنجلادش قد تم إقناعهم بأن

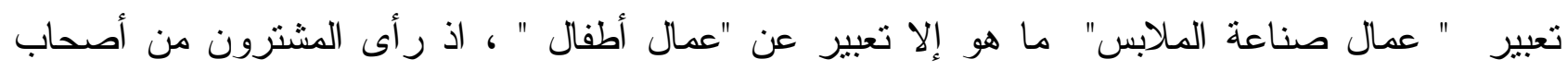

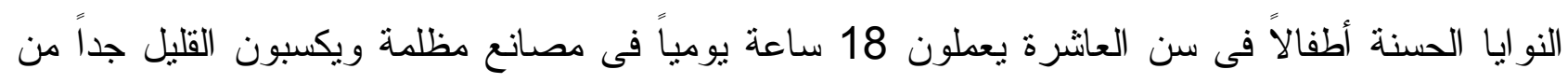

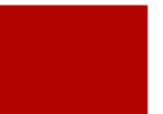

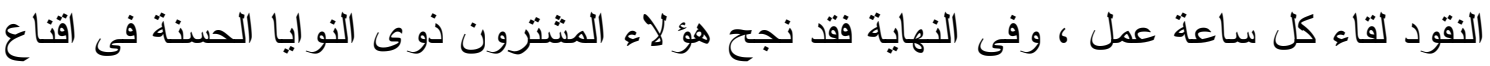

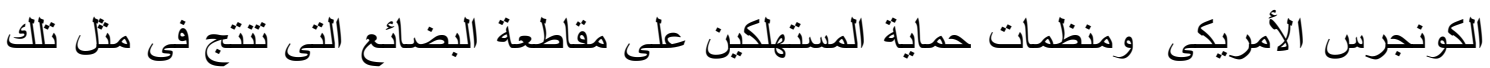

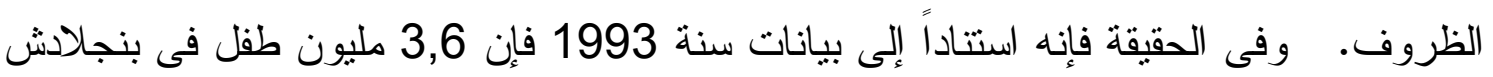

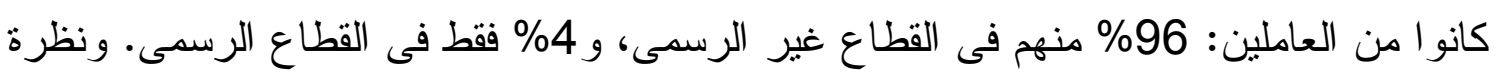

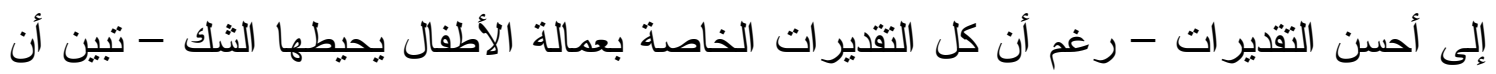

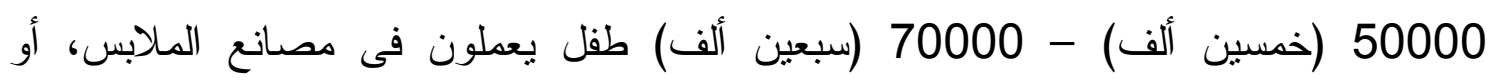
مايساوى تقريباً 5-7\% من قوة العمل فى صناعة الملابس ـ كما أن مديرى تلإن المصانع -

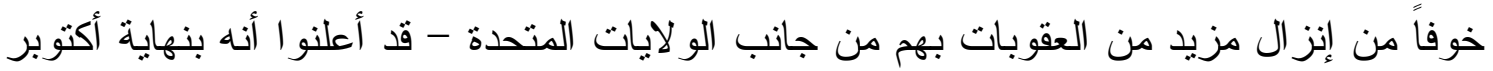

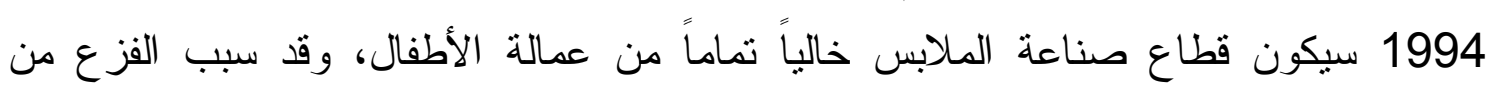

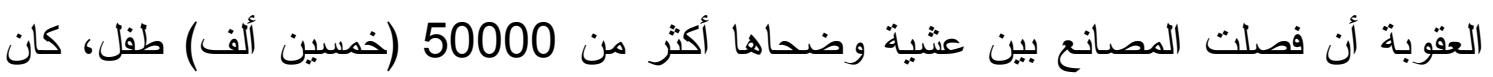

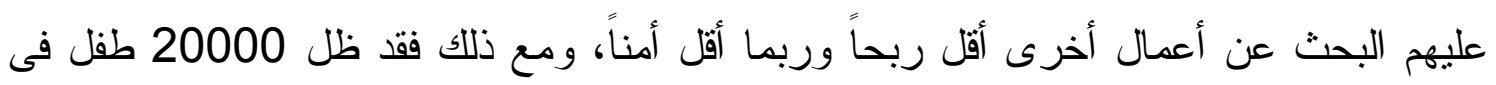

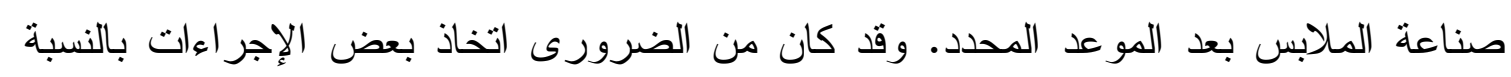

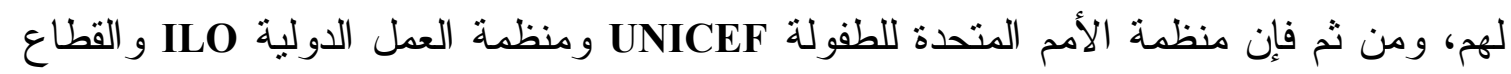
الخاص قد صاغو ا معاً مذكرة تفاهم بهذا الثـأن.

إن توصيات المؤتمرات العالمية التى تمنل إجماعاً على الحد الأدنى لمعايير العمل، هى من أهم الأدوات المتاحة لمنظمة العمل الدولية ILO من أجل تحسين التشريعات و الممارسات فى الدول أعضاء المنظمة ، وكانت الاتفاقية 182 هى أول اتفاقية حول قو اعد عمل الأطفال تحدد ضرورة بذل اهتمام خاص للفتيات. وفى التوصيات المصاحبة للاتفاقية(رفم 146) استرعت منظمة العمل الدولية الانتباه إلى ظروف العمل الخفية وغير المنظمة - منل الوظائف فى القطاع غير الرسمى - و الذى نكون فيه الفتيات بصفة خاصة عرضة للخطر • ومن المنتظر أن تقوم الدول التى صدقت على الاتفاقية بتكوين لجان وطنية نزاقب عمالة الأطفال محلياً فى جميع القطاعات، وتتأكد من أن المداخلات تصل إلى الجمهور المستهدف. 
اتفاقية السن لسنة 1973 سنة 1973 (الاتفاقية 138) حددت الاتفاقية ثلاثة أعمار للحد الأدنى للسن

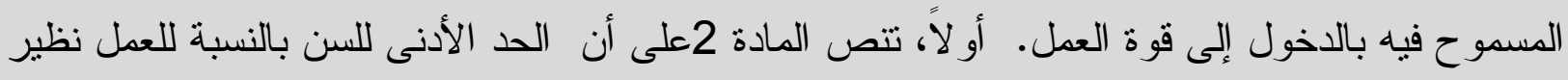

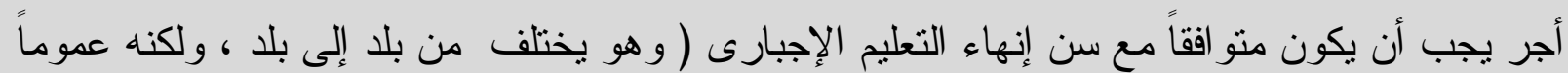

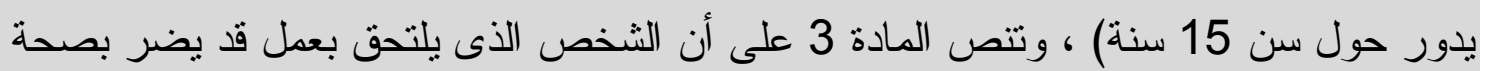

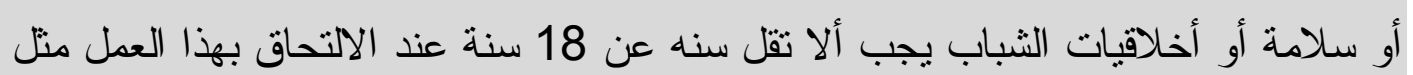

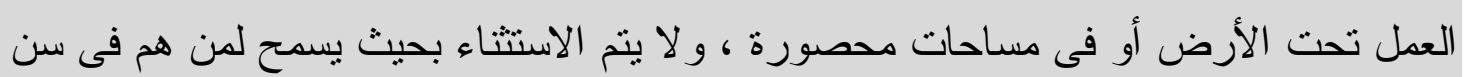

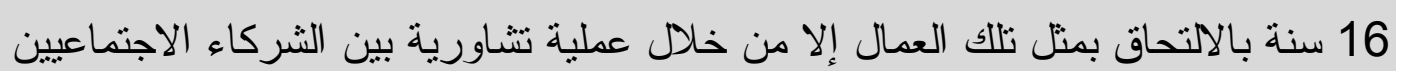

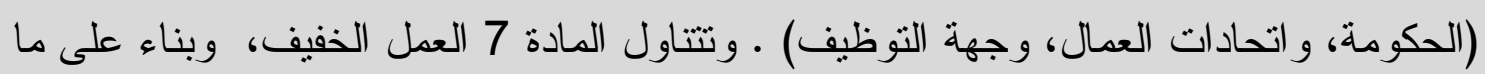

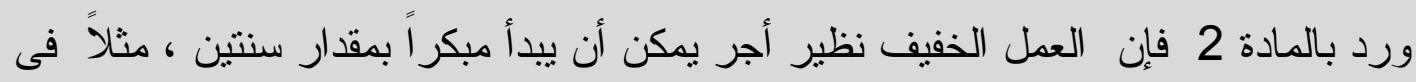

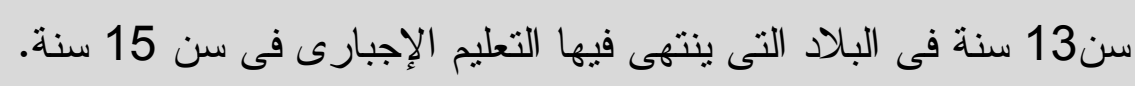

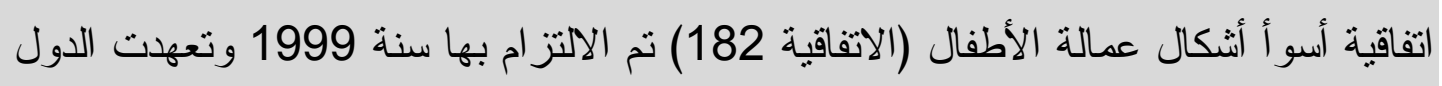

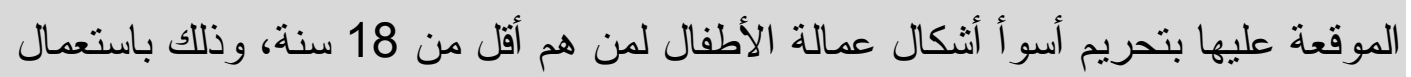
تعريف " الطفل" الذى ورد باتفاقية الأمم الدتحدة لحقوق الطفل. وتقع أسو أ أثنكال عمالة الأطفال

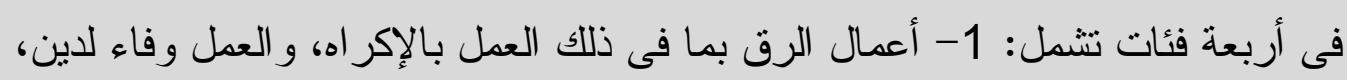

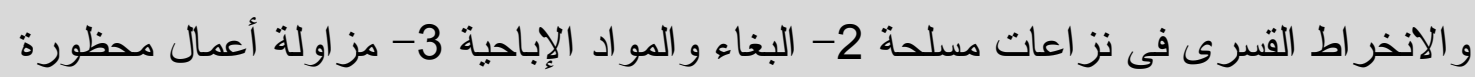

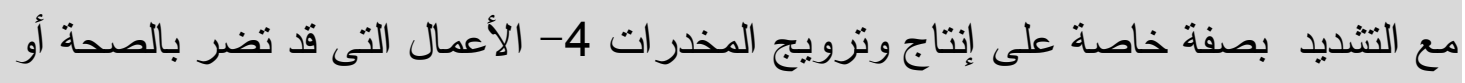
القيم الأخلاقية للأطفال

Theresa Smout. المصدر : موجز قدمته تريز السماوت لوطفات

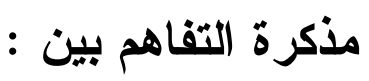

منظمة الأمم المتحدة للطفولة ومنظمة العمل الدولية واتحاد صانعى ومصدرى UNICEF/ILO/BGMEA
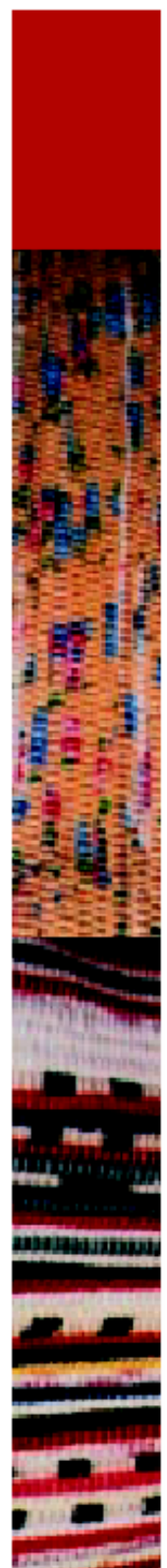
الملابس في ابنجلادش

بدأت كل من منظمة الأمم المتحدة للطفولة ومنظمة العمل الدولية واتحاد صانعى ومصدرى الملابس فى بنجلادش

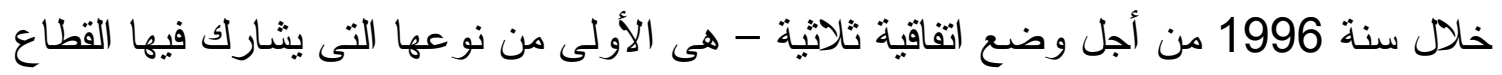

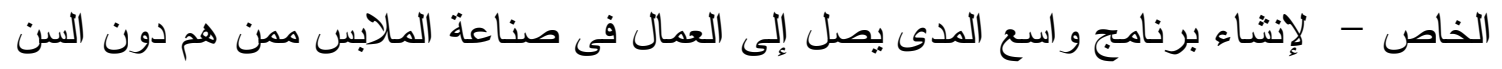

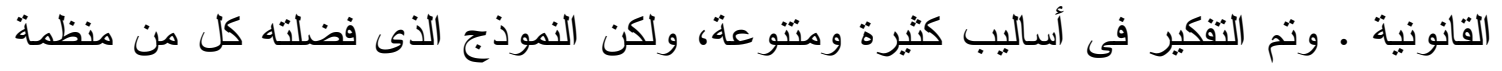

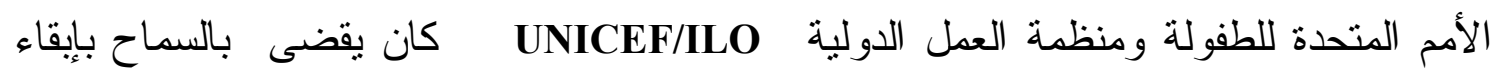


الأطفال عاملين بالمصانع ، على أن يعملو 6 ساعات يومياً ، مع حضور الدراسة لمدة ساعتين أو ثلاث

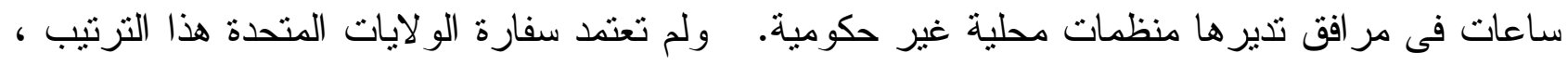
وطالبت بدلاً من ذلك بإخر اج الأطفال من المصانع تماماً.

وفى النهاية فقد تضمنت مذكرة التفاهم الموقعة فى 4 يوليو 1995 الإجر اءعات الات التالية: تجرى منظمة العمل الدولية ILO مسحاً تقديرياً سريعاً لجميع المصانع لتحديد مقدار

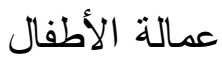

بعد إجراء التقدير يعفى من العمل الأطفال دون سن 14 سنة، على أن يلحقوا ببرامج

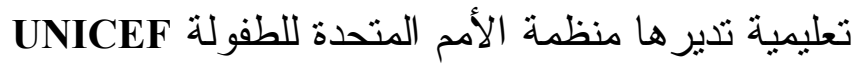

و افق اتحاد صانعى ومصدرى الملابس فى بنجلاديش BGMEA على عدم إنهاء عمل الأطفال أقل من 14 سنة قبل إنهاء التقدير و إنثاء المدارس المنادية

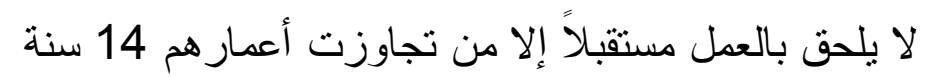

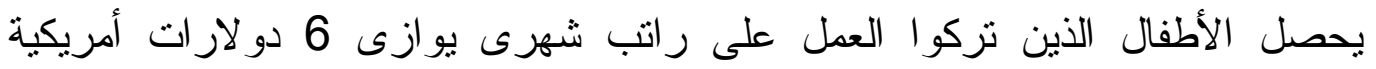

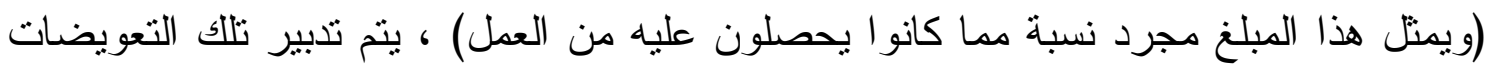

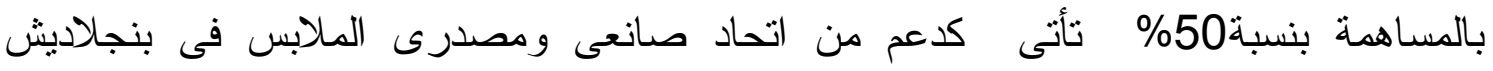
BGMEA منظمة العمل الدولية ILO فى دعم الرو اتب الثهرية.

بدأ هذا البرنامج فى سنة 1996 وصادف صعوبات كثيرة اذ تساءل المنتقدون لماذا تورطت

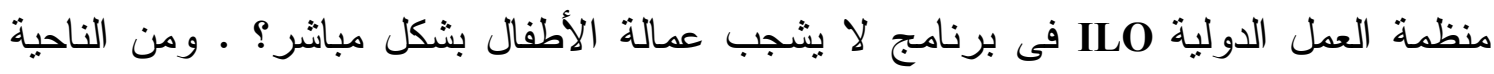

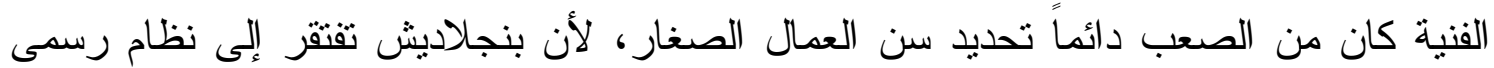

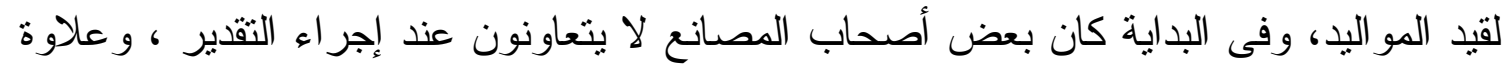

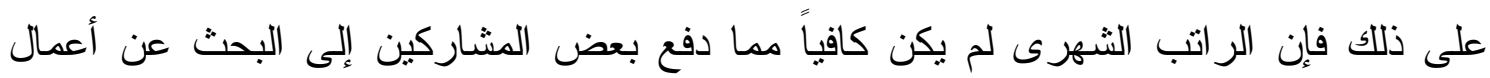
أخرى. و أخير أ فإن بعض مر افق للتدريب على المهار ات وتطوير ها كانت غير كافية بالمرة.

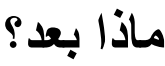

كان الموعد المحدد لانتهاء هذه المبادرة هو سنة 2000 ـ وقد "تخرج" كثبر من الأطفال من

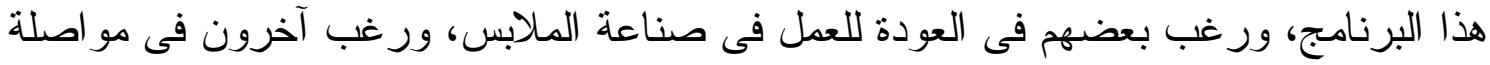

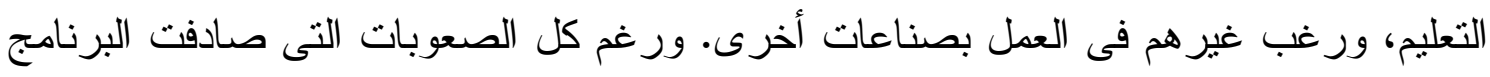
فإنه قد أثتبت أنه من المككن أن يقترن الكسب من العمل بالدراسة . 
كيف تخوض الفتيات المراهقات تجربة العمل ؟ ماذا يضيف العمل الى مراهقتهن؟

مشاهد من ثلاثة بلاد

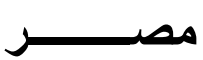

أجرى مجلس السكان دراسات حالة ( كانت لا تزال جارية أثناء انعقاد المؤتمر) عن الثشابات

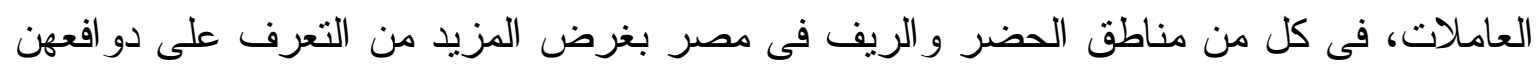

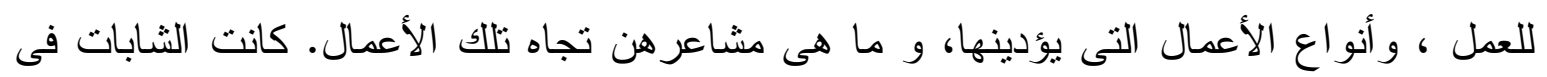

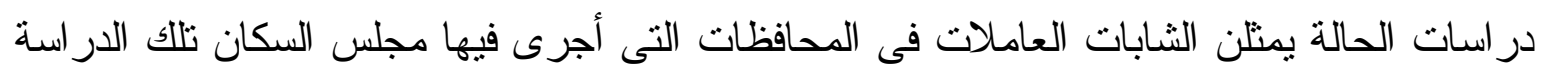

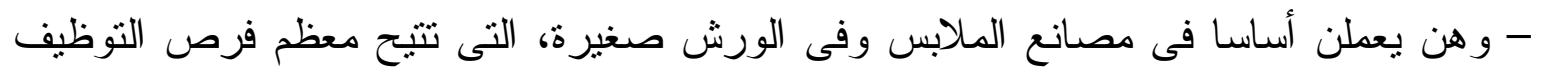
في القطاع الرسمى بالنسبة لكثير من المناطق.

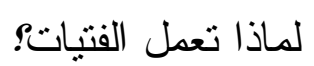
رغم أن العمل فى بحث مجلس السكان كان لا يزال جارياً إلا أن أنماطاً معينة قد برزت بالفعل.

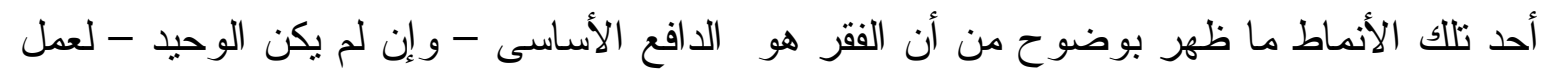

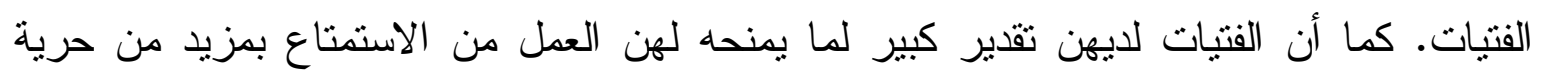

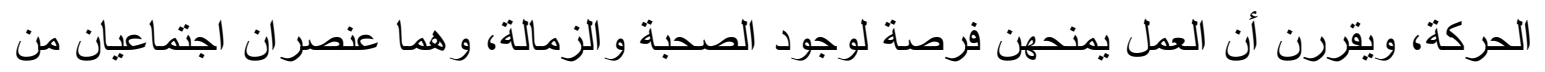

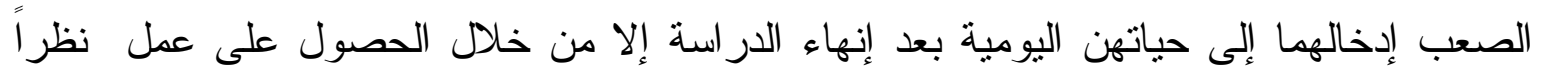

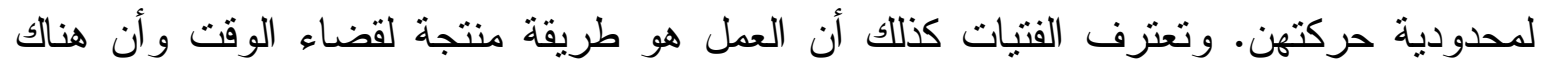
قيمة (ونقود) ترتبط بكونهن "عاملات" مع ملاحظة أن البديل عن العطل هو البقاء فى المنزل طو ال ال اليوم.

ما نوع التدريب الذى تحصل عليه الفتيات وأين يحصلن عليه؟

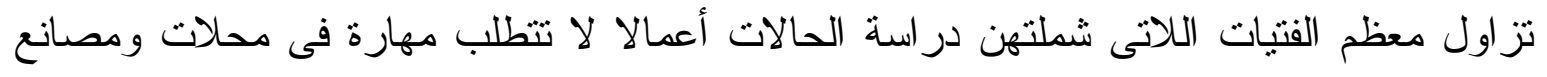

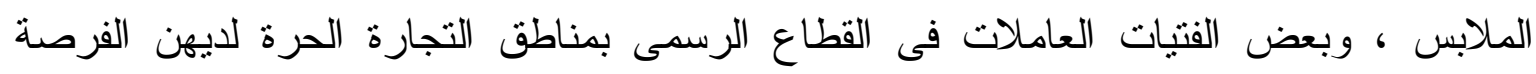
للحصول على تدريب خارج مكان العمل نظير أجر ـ وقليل من الفنيات يندربن في المصانع لأنهن 
يوقعن عقوداً تلزمهن بالعمل فى المصنع لمدة ست سنوات على الأقل مهما كان الأجر أو المعاملة، مما يعتبر نوعاً من عقد الإذعان.

ظروف العمل

عادة ما تكون ظروف عمل الفتيات صعبة، وقد أفادت العاملات بمصانع الملابس أنهن يعملن

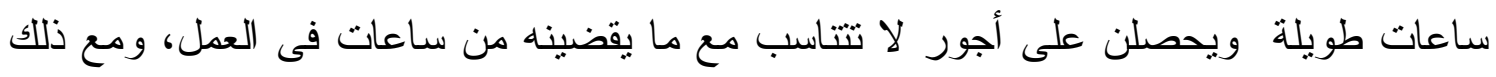

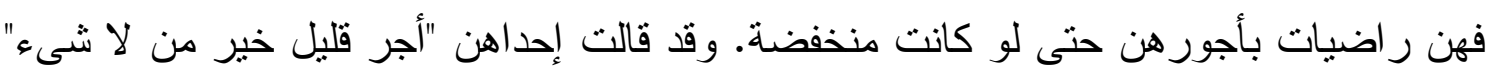

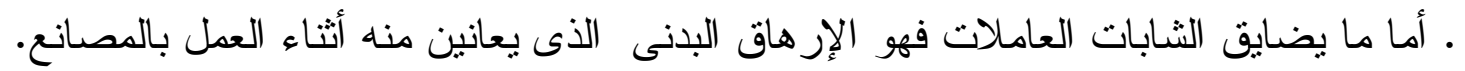

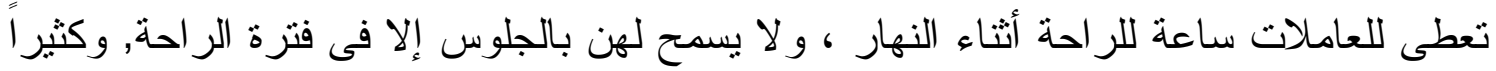

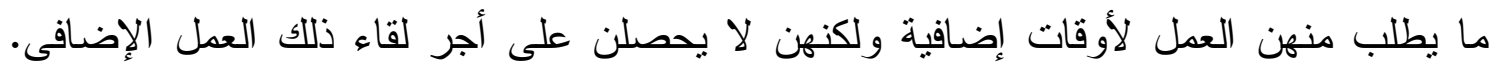

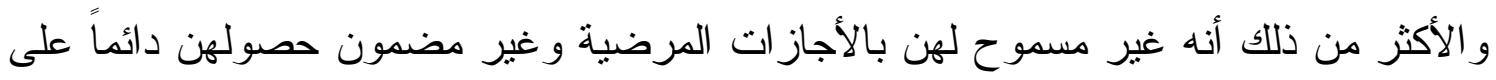

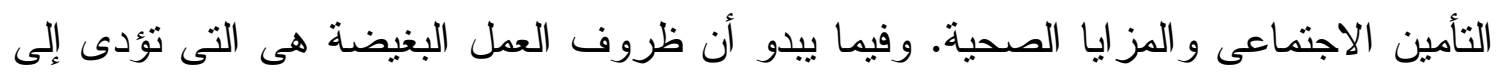

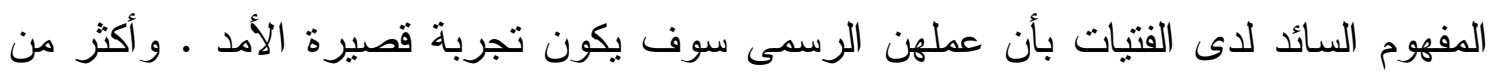

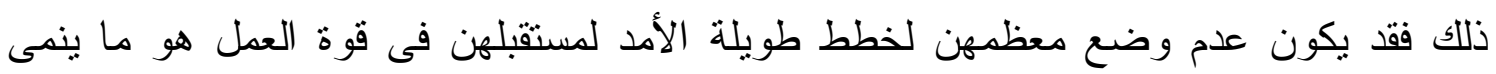

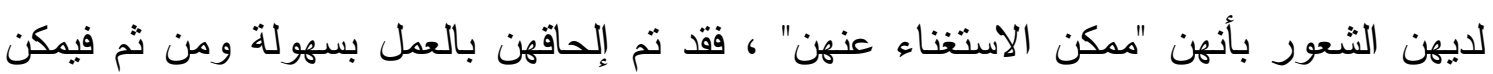
التخلص منهن بسهولة أيضاً.

\section{الحد من الخيارات المتاحة للعاملات:

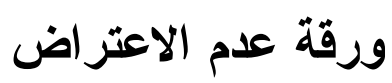

قام مجتمع رجال الأعمال فى بور سعيد بناء على طلب مديرى المصانع بإنشاء آلية لا نسمح

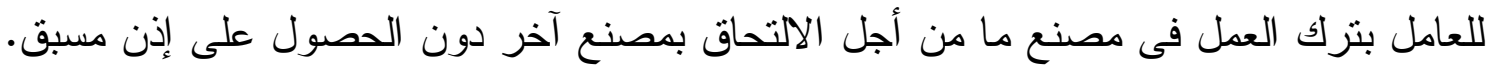
وقد أفادت النساء فى دراسات الحالة أنهن ونظير اتهن من العاملات يثقبلن ظروف العمل وأنه العها

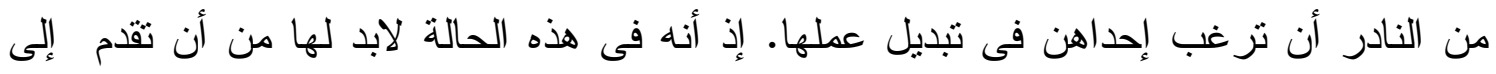

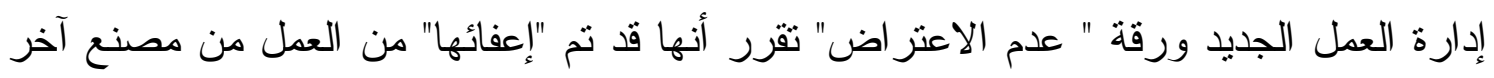

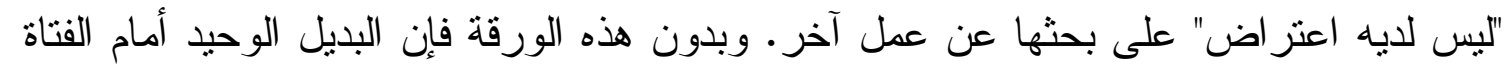

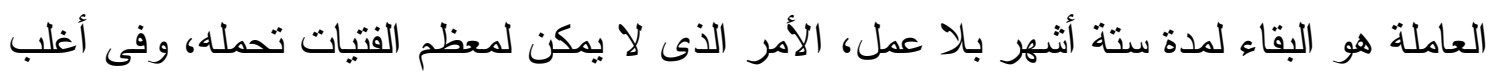
الأحو ال فإن أصحاب العمل الحالى برفضون طلب لعدة إصدار مثل تلاك الورقة. 


\section{حقوق العمال}

معظم العاملات اللاتى شملتهن دراسات الحالة على غير وعى بحقوقة كهن كعاملات، و اللاتى يعرفن

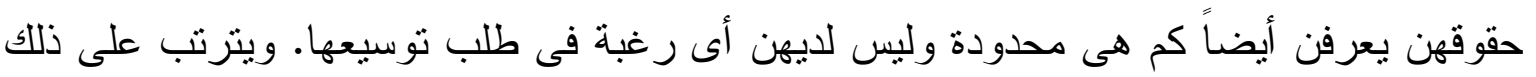

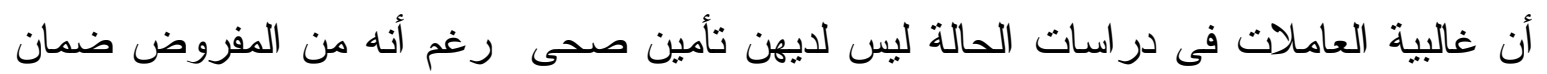
وجود هذا التأمين مع العمل. و التحرش الجنسى هو أيضاً من الانتهاكات الأخرى لحقوق العاملات، رغم أنه شائع الحدوث أثناء

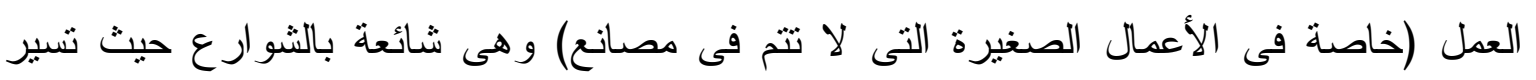

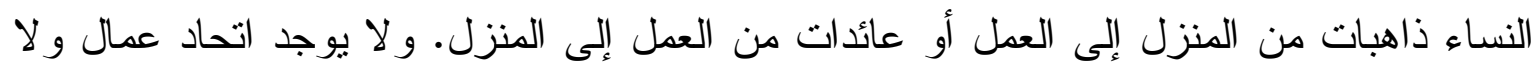

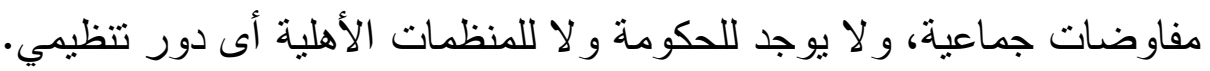

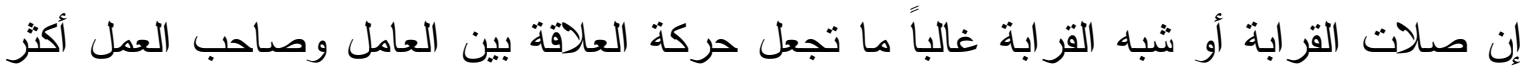

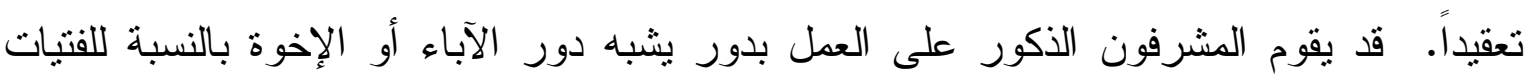

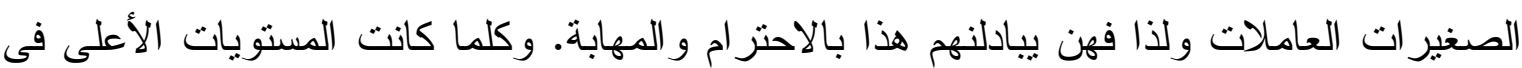
العمل أكثر أبوة كلما قلت رغبة العاملات فى مساءلة رؤساءهن.

\section{تقييم العاملات لتجربتهن}

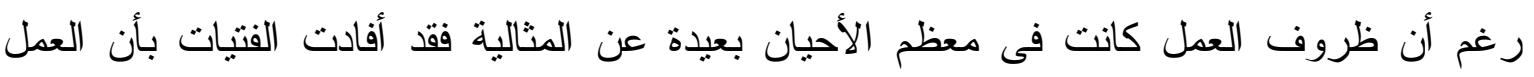

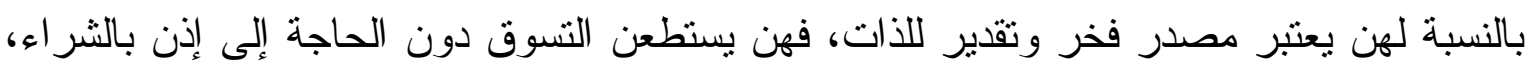

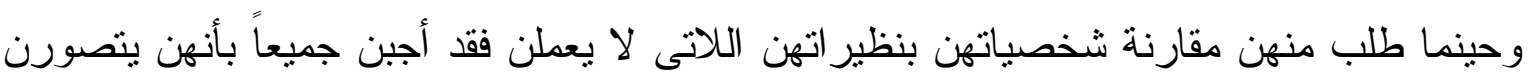

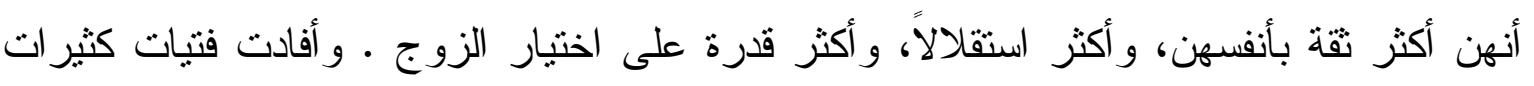

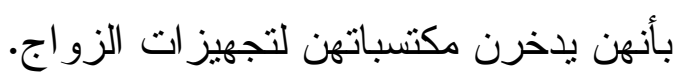

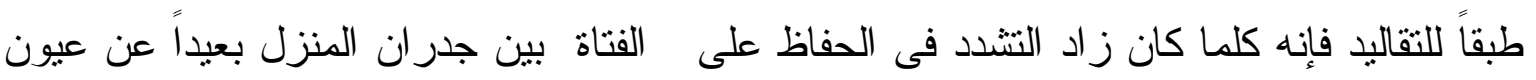

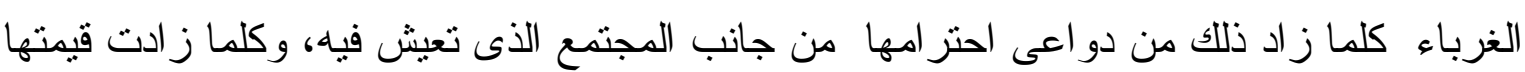

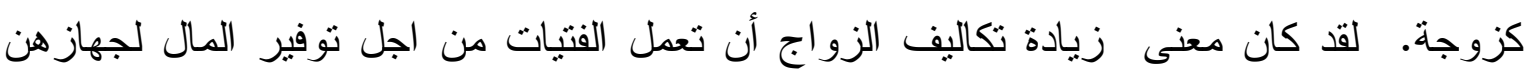

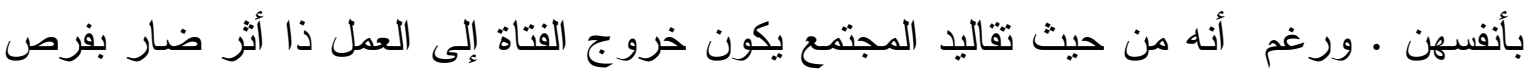

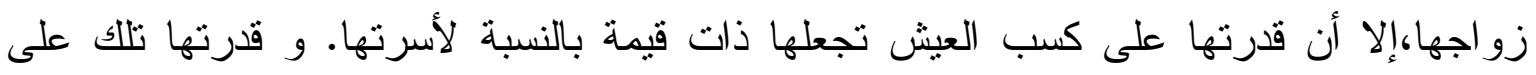

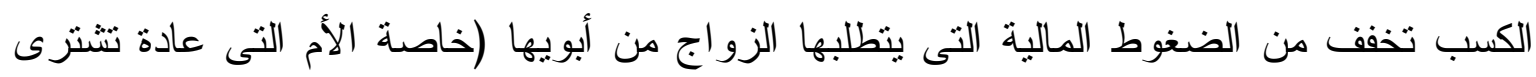

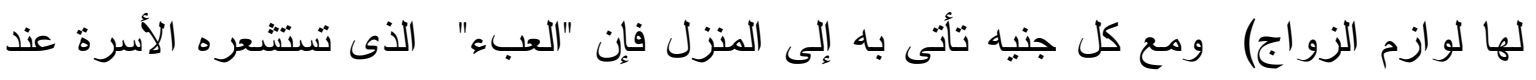
تزويج البنت سوف ينحول إلى " منفعة".

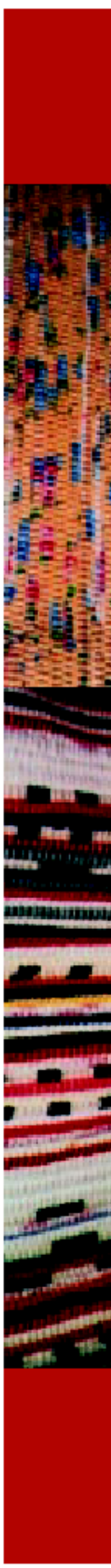


إ عطاء نقود للأبوين /الإخوة/الأخوات قد يضفى الثرعية على رغبة الفتيات الخفية فى الاستمرار فى

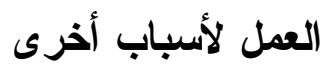

من غير الواضح فى تلك الدراسات ما إذا كان العمل برفع "سن الزواج" للفتاة ، وفى الحقيقة فإن

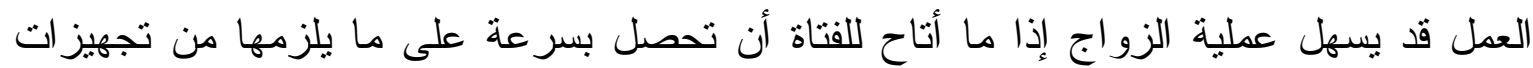

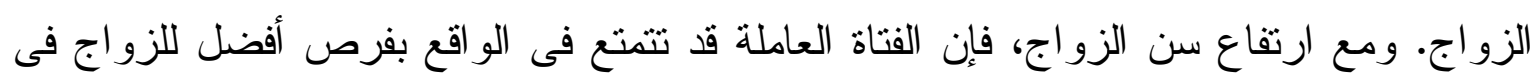
سوق الزواج الر اكدة.

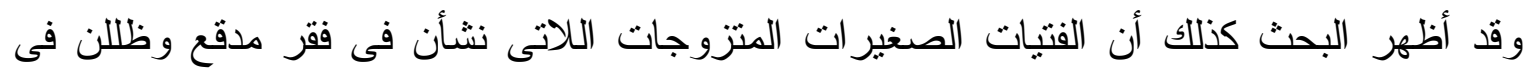

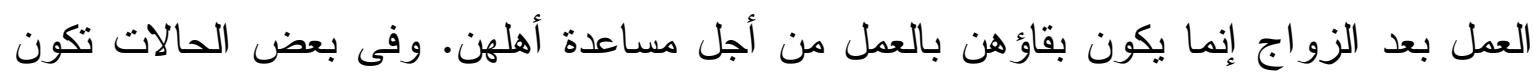

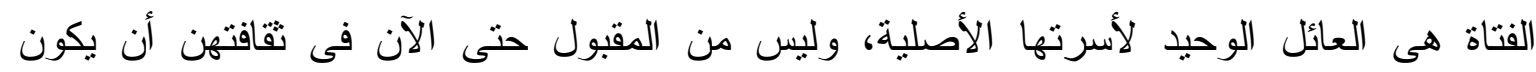

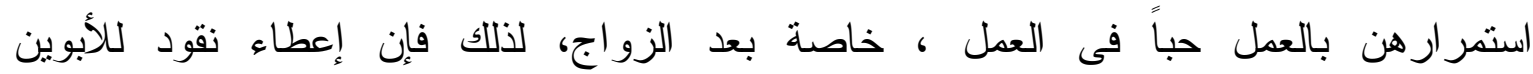

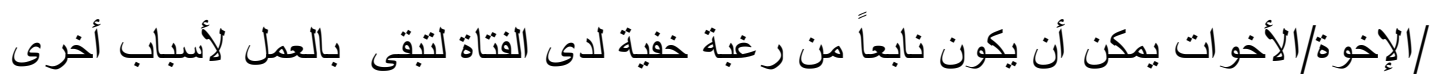

\section{الأردن}

تعتبر مشاركة الإناث فى قوة العمل فى الأردن منخفضة، وكان نمو مشاركتهن بطيئًا

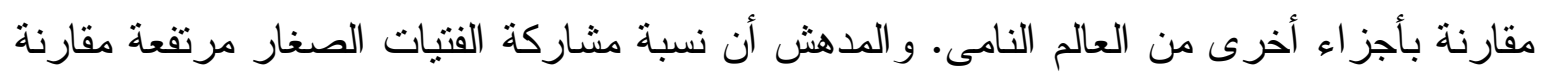

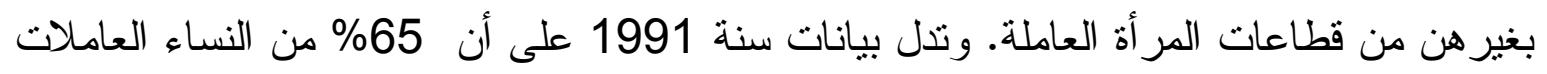

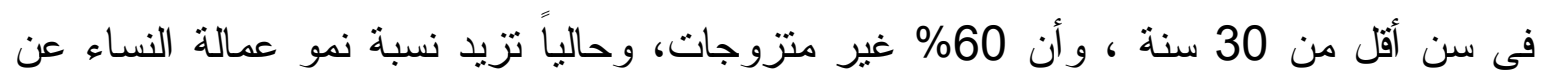

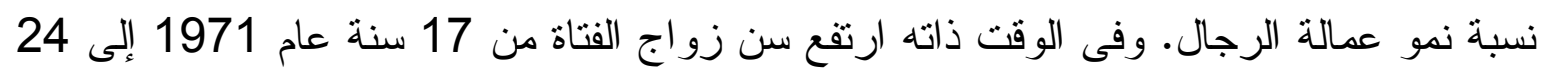

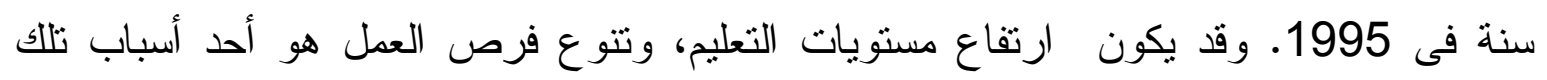
الظاهرة.

وبشكل تقليدى، تقع أدوار وهويات النساء الأردنيات ضمن واحد أو أكثر من الفئات

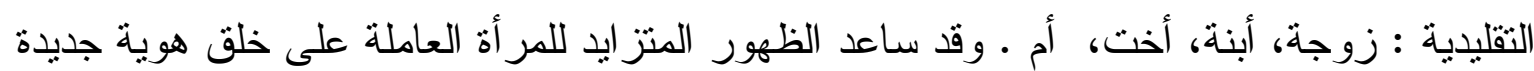

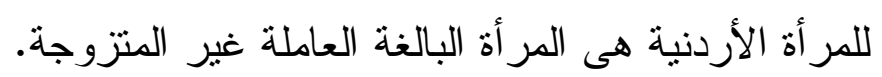

نسبة مشاركة الثابات مرتفعة مقارنة بمشاركة غيرهن من شرائح النساء العاملات

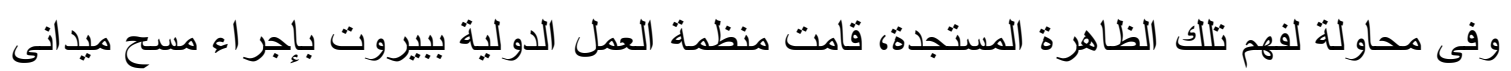
لأصحاب العمل فى 36 من مؤسسات القطاع الخاص، و عمل استبيان على 302 أسرة فى 14

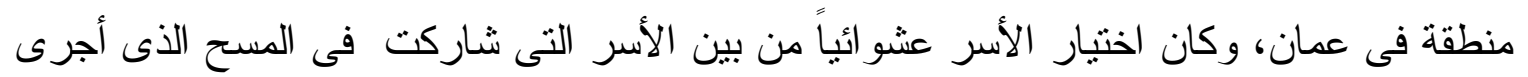


بالأردن سنة 1991 عن العمالة و البطالة و الفقر ـ وشارك فى الاستبيان من هم بين سن 20-30 من غير

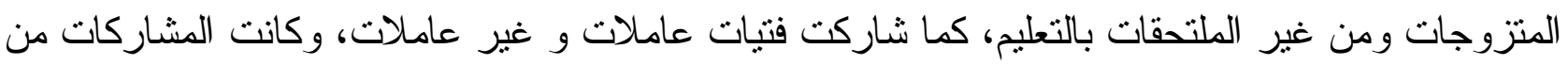

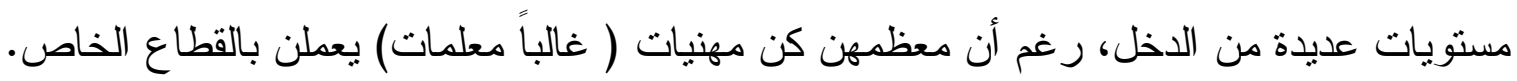

\section{يضفى التعليم على الفتاة المكانة والهيبة بينما لا يمنحها العمل مثل تلك المنزلة:}

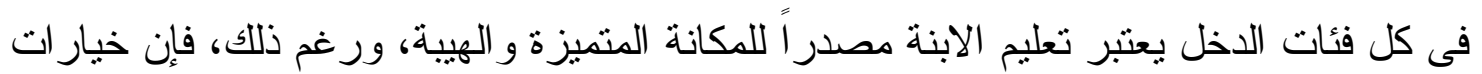

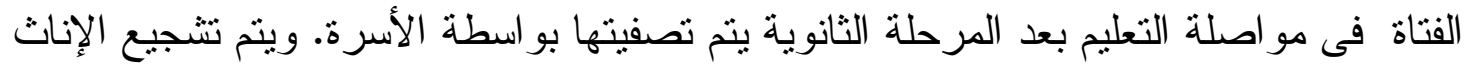

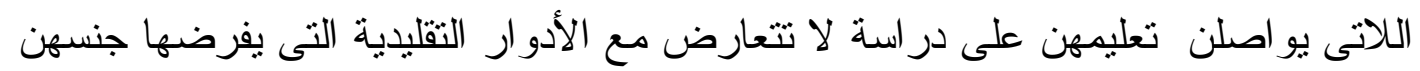

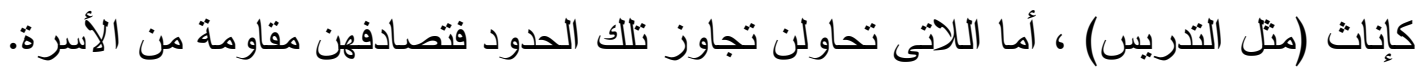
وفيما يمنح التعليم الابنة منزلة خاصة، لا يمنحها العمل متل تللك المنزلة، فالعمل يعتبر تهديداً كامناً للمعايير الاجتماعية التى تتجع الفصل بين الجنسين و الحد من استقلال الأنثى.

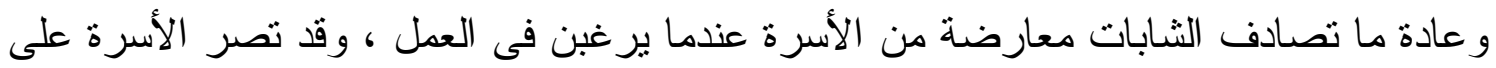

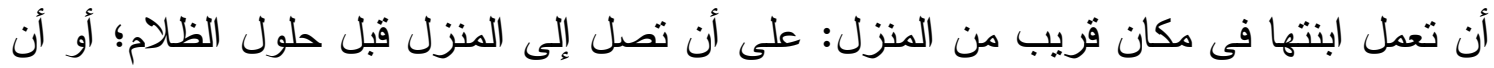
تعمل فى بيئة لا تعمل بها سوى الإناث. و تثقوم بعض المصانع بالتكيف مع تلك المحاذير العائلية

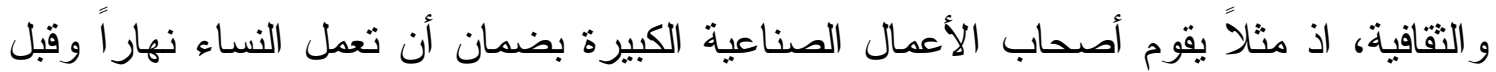
غروب الثمس. ويؤمن آخرون وسائل مو اصلات خاصة لعاملاتهم الثابات، ليجنبونهن استعمال

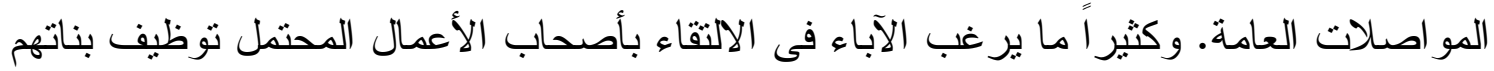

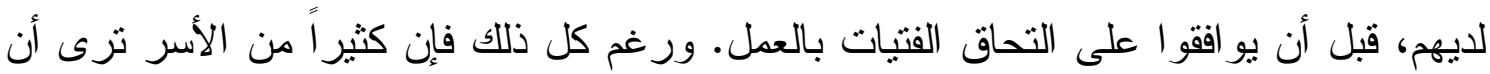

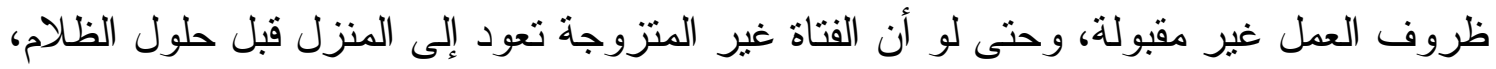

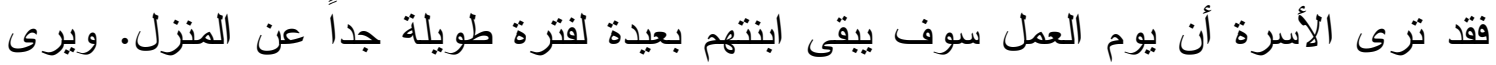

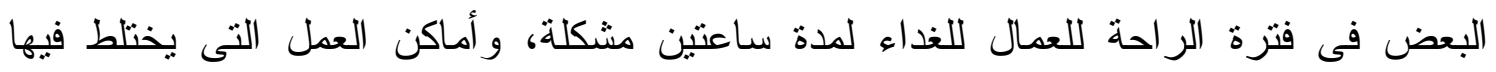

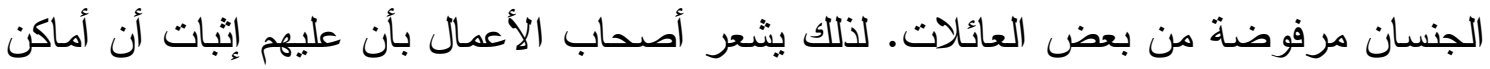

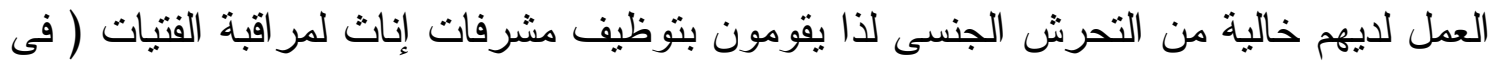

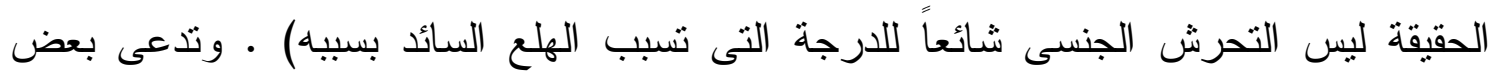

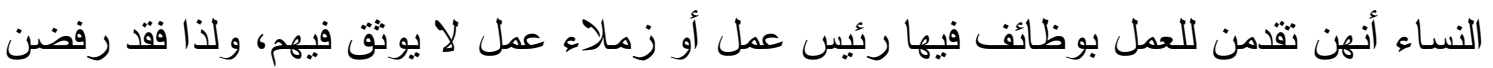
العمل بعد اكتثاف تلك الحقيقة. ومن ناحية أخرى فإن طالبة العمل لو كانت فى حاجة ماسة للعمل فقد يستغل صاحب العمل حاجتها، وتظل عرضة للتحرش فى مكان العمل. إن الميزة المنتظرة بأن تعمل الفتيات فى الغالب فى أماكن عمل مناسبة تماماً لهن ولعائلاتهن -

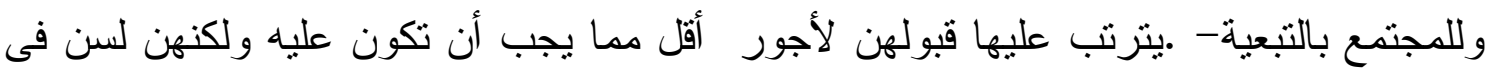

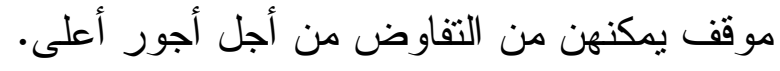


إن قيمة ايجاد بيئة مناسبة لعمل الفتيات تغنى فى الغالب أن الفتيات من الأرجح أن تعمل فى أنى

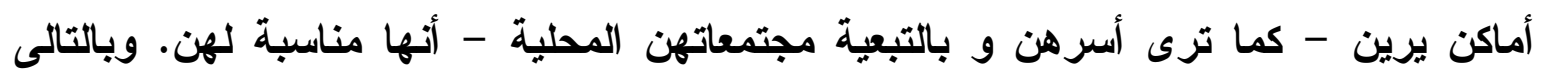

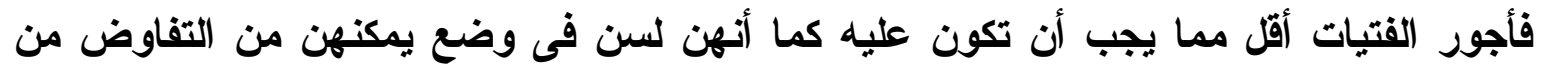

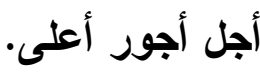

اتجاهات وادراكات و رضا العاملات عن عملهن

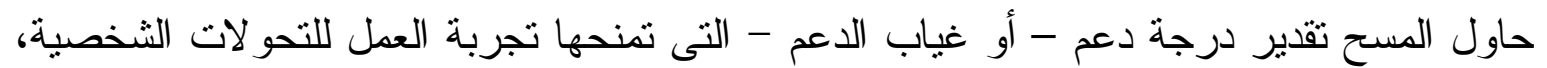

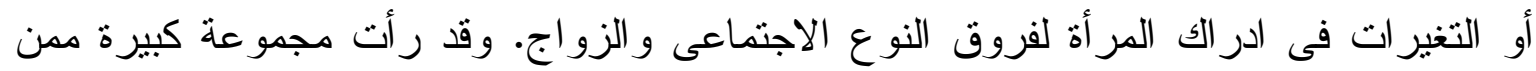

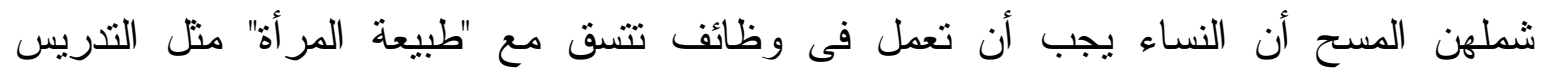

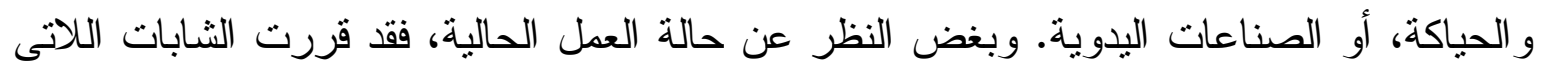

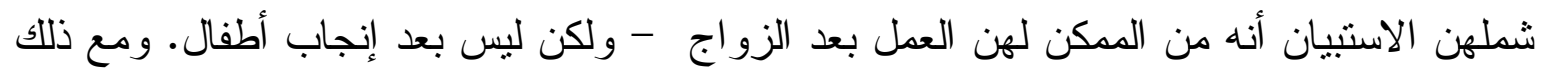
فقد أقرت الكثير ات منهن بضرورة استقال المن الة أة من الناحية المالية.

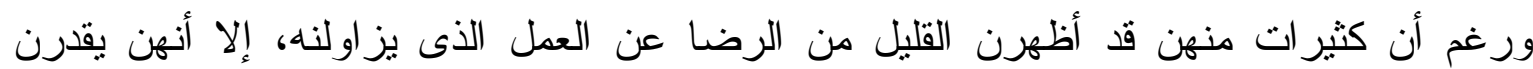

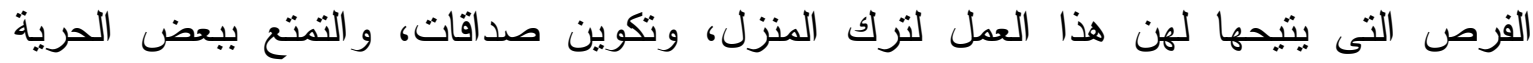

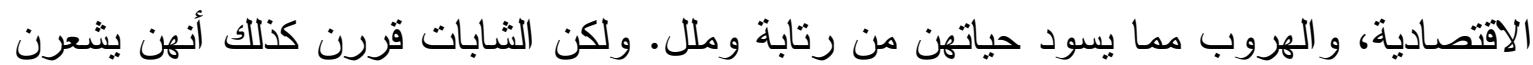

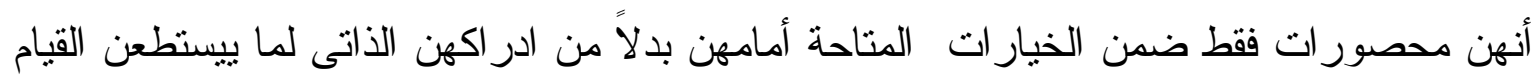

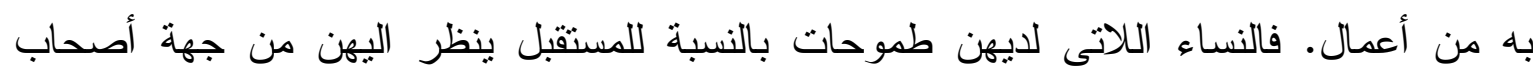

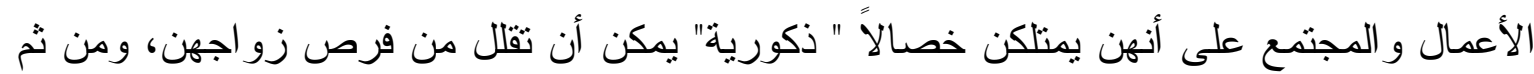

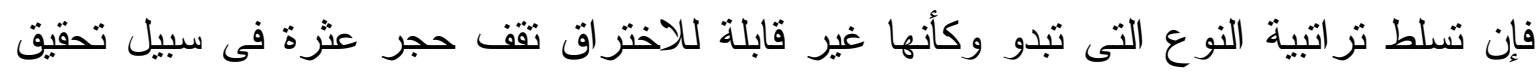

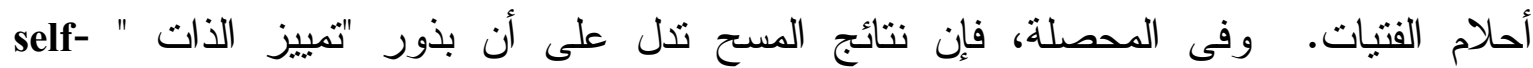
differentiation

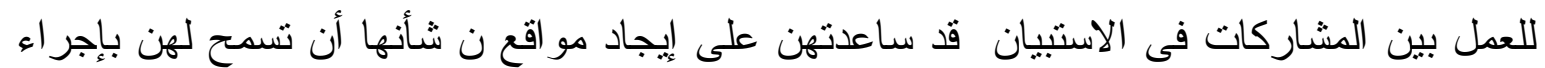
مفاوضات حول السلوك و التوقعات الدعيارية القائمة على النوع الاجتماعى. 


\section{بنجلاديش}

كما لاحظنا من قبل، فإن قطاع إنتاج الملابس فى بنجلاديش قد ازدهر خلال السنوات القليلة

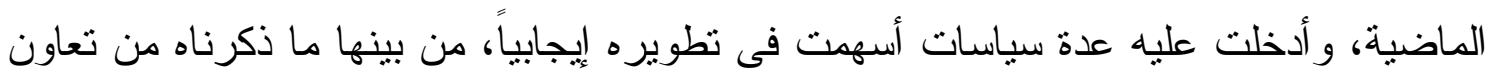

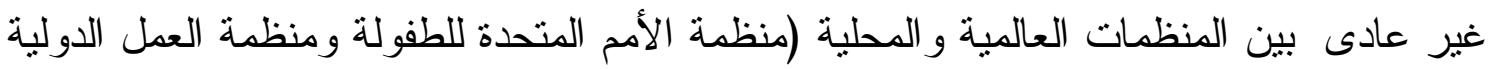
و اتحاد صانعى ومصدرى الملابس فى بنجلاديش

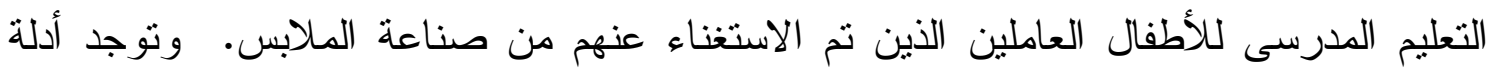

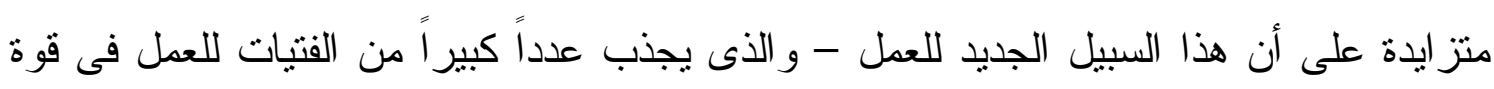
عمل يسيطر عليها الرجال- قد ساعد على خلق مرحلة جديدة من الحياة، هى المر اهقة و التى لم لم الم

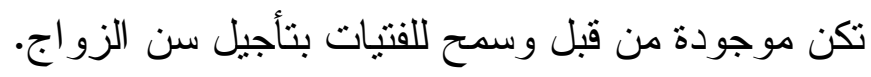

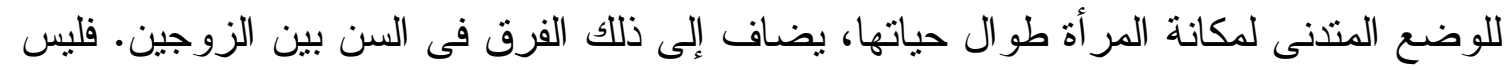

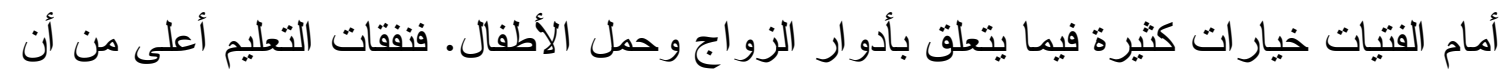

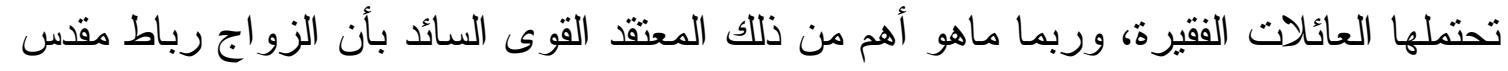

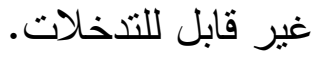

إن للزواج المبكر آثار على كل من الفتيات والأنماط السكانية الوطنية، و بنطبيق التدريب

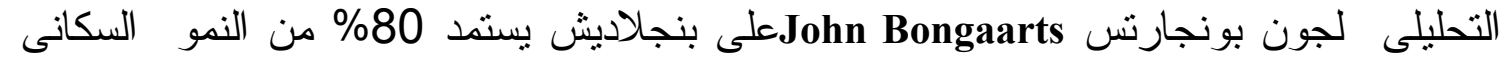

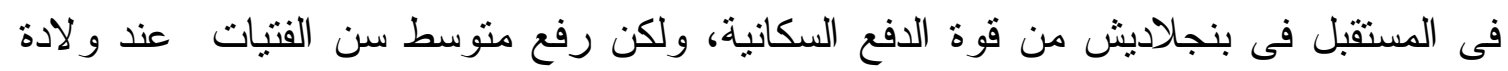
الطفل الأول بمقدار 5 سنوات سوف يساعد على تجنب 40\% من النمو المرتبط بالقوة الدافعة ، ومن ثم فإن تأخير سن الزواج قد يكون له انعكاسات كبيرة على التحو لات السكانية 
عبرت الشابات عن شعورهن بالاتحصار داخل الخيارات القليلة المتاحة لهن بلاًا من ادراكهن الذاتى لما بيستطعن القيام به من أعمال

لقد زادت مؤخراً تكاليف الزواج وارتفعت المهور ـ تاريخياً، لم يكن المسلمون الذين يمثلون 92\%

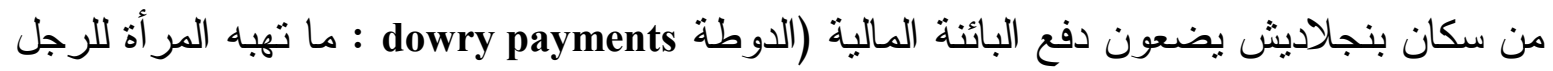

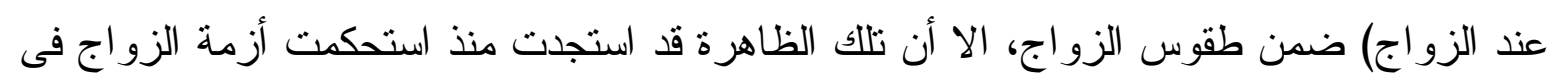

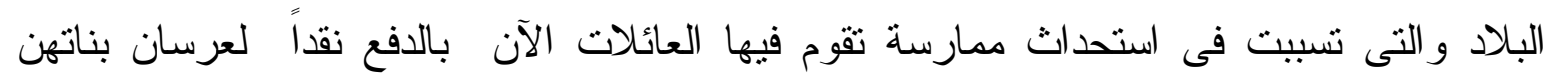

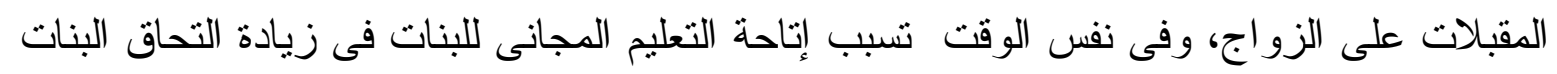

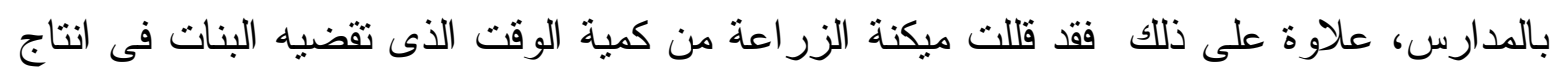
الطعام وتجهيزه. لقد تز امنت تلك النزعات المستقلة مع الزيادة فى فرص العمل فى القطاع النظامى خاصة بقطاع

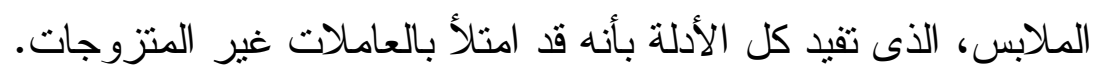

فرص التوفير لاى عاملات الملابس

رغم أن عاملات الملابس لديهن ميل كبير للتوفير من مكتسباتهن، إلا أنه ليست لايهن وسيلة

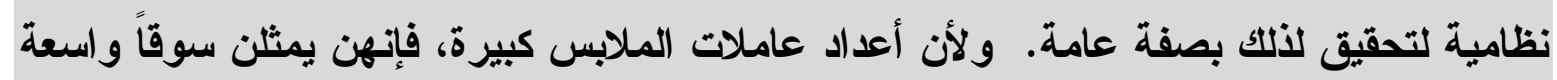

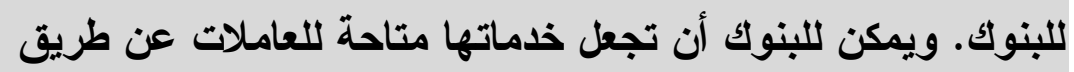

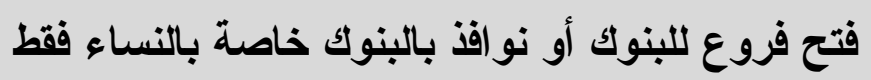

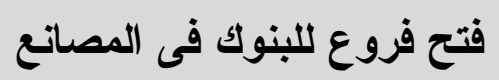
خفض الإجراءات البيروقراطية الخاصة بفتح حسابات التوفير

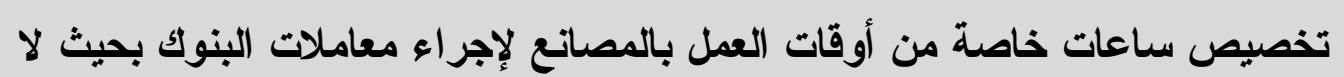
تحتاج القناة إلى إضاعة الوقت فى الذهاب إلى البتك

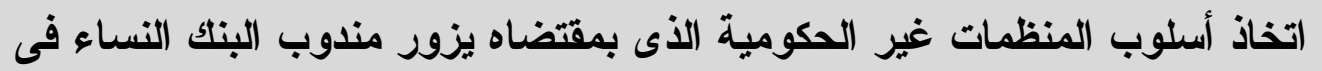
بيوتهن لتحصيل مدخر اتهن.

المصدر : مقترحات تقدم بها يو اخيم فيكتور جومز Joachim Victor Gomes 


\section{من هن العاملات فى صناعة الملابس؟}

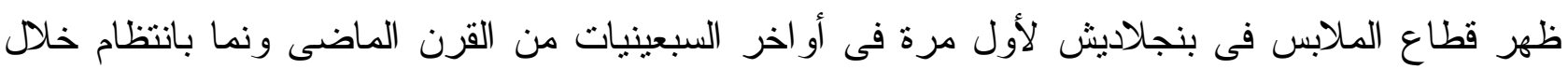

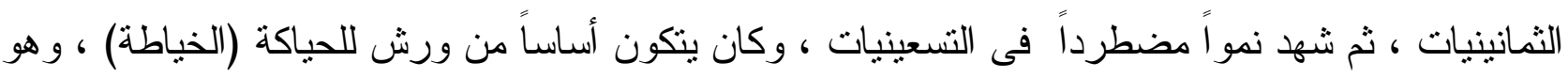

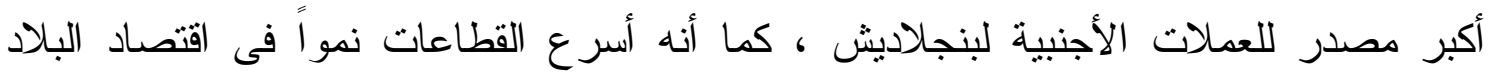

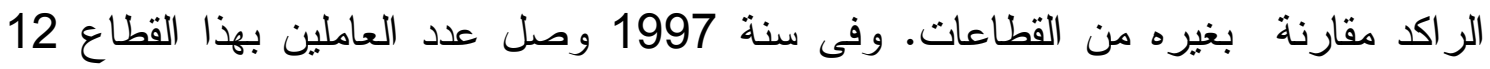

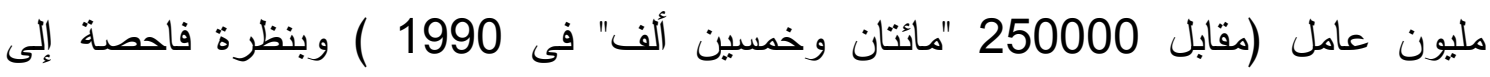
العاملات بقطاع الملابس سنجد أن: 78\% تحت سن 25 سنة

87 مهاجر ات من مناطق ريفية من بنجلاديش

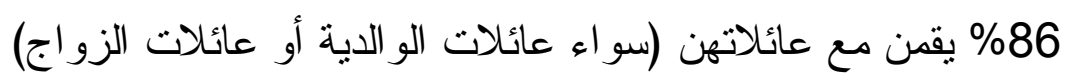

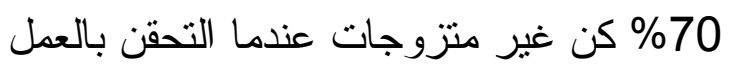

ورغم أن دخل الفتبات من العمل منخفض للغاية فإن لديهن ميلاً شديداً للادخار ، والأمر المثير

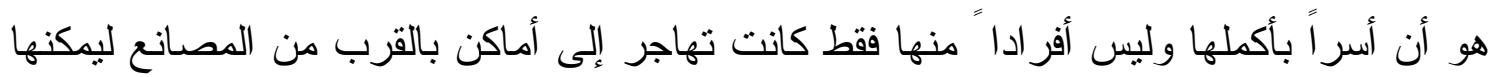

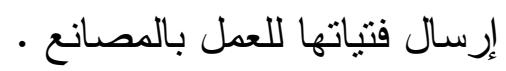
توجد دلائل على أن العمل يؤجل الزواج ليس فقط بين العاملات بالصانع ولكن أيضاً بين الفتيات

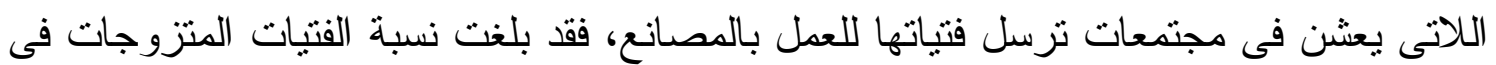

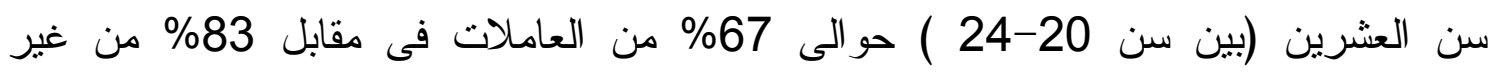

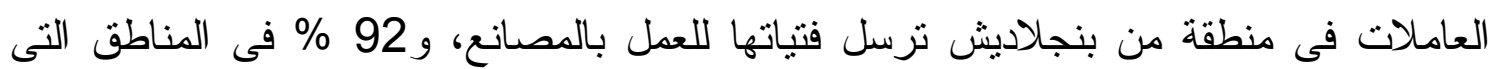

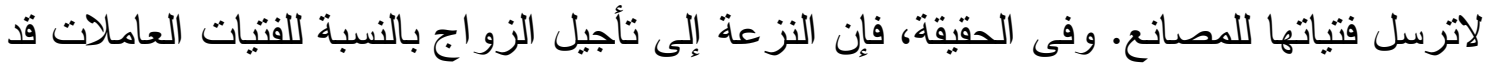

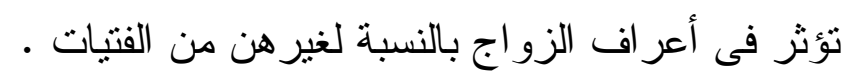

\section{ادرالك الفتيات للعمل}

أفادت الفتيات أن فرص العمل التى حصلن عليها قد منحتهن منظوراً جديداً لحياتهن. وقد

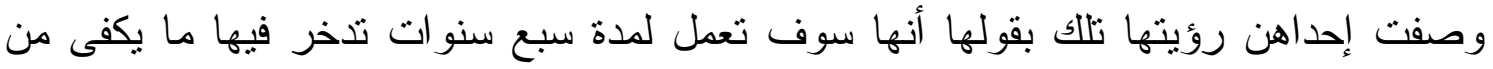

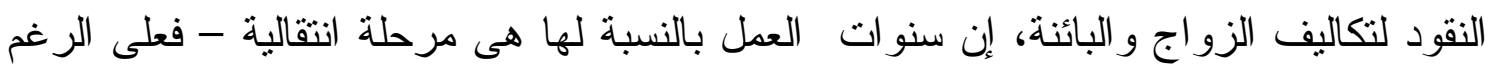

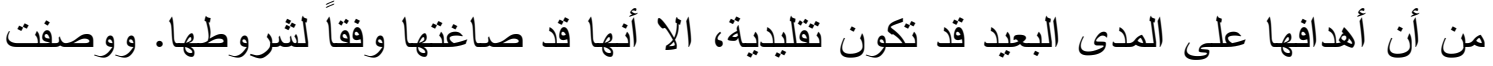
فتاة أخرى كيف أنها أصبحت نستطيع أن ترندى ملابس حديثة وأنيقة (مقارنة بصديقاتها 
المتزوجات) وتستتع كثيراً بحريتها فى الحركة منتقلة بين القرية والمدينة ، ولايها ثقة وجرأة لا تتو افر

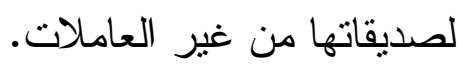

\section{أسس برامج وسياسات التوسع فى وسائل كسب العيش الآمنة والملائمة للفتيات المراهقات الأكبر سناً}

\section{إيجاد النموذج الصحيح من السياسات}

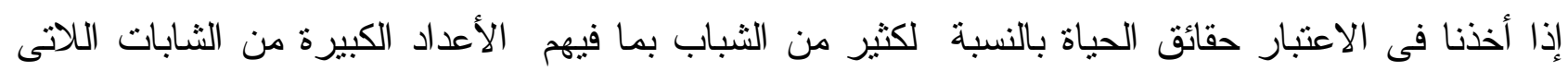

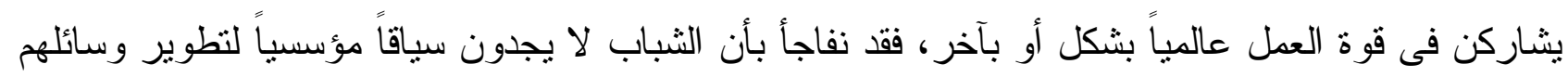

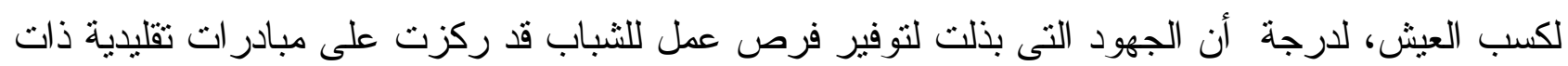

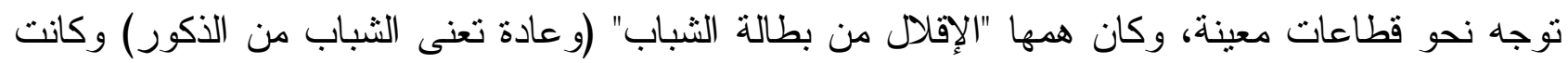

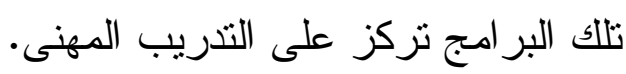
إن نلك الأساليب غالباً ما نكون غير فعالة لا لإبل بسبب كونها ضيقة فقط، ولكن أيضاً لتجاهلها حقائق حياة

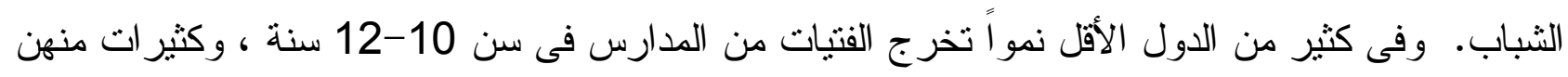

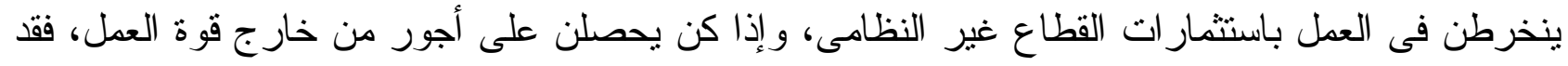

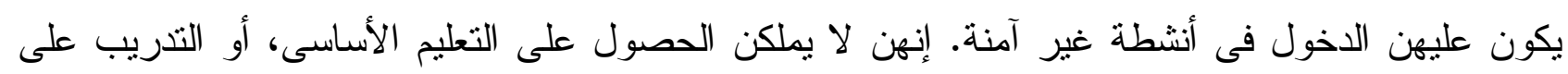

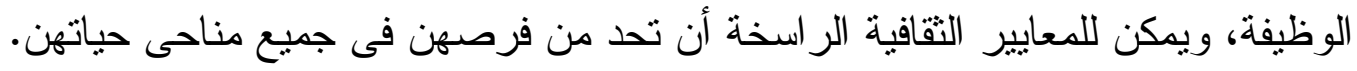

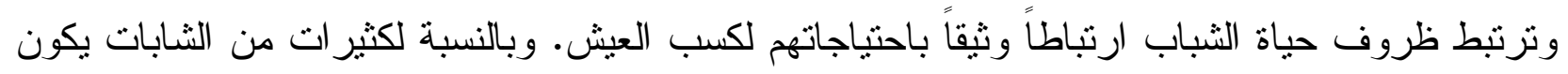

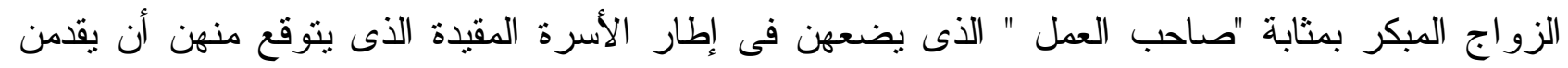

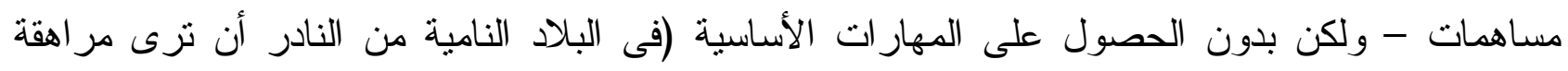

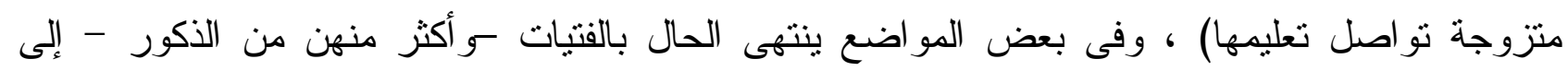

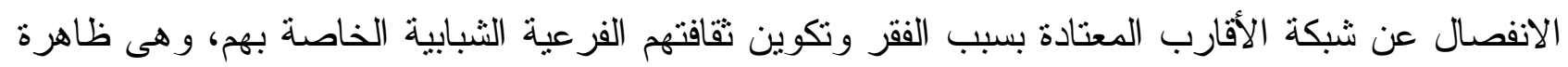
يتم عادة تجاهلها أو استنكارها كلية، وتصوير نلاك الدجمو عات على أنها ببساطة تهديد لاستقر ار المجتمع. 
ما الأى يجعل مقاربة "كسب العيش" جذابةً عند تناول أوضاع الفتيات المراهقات مله

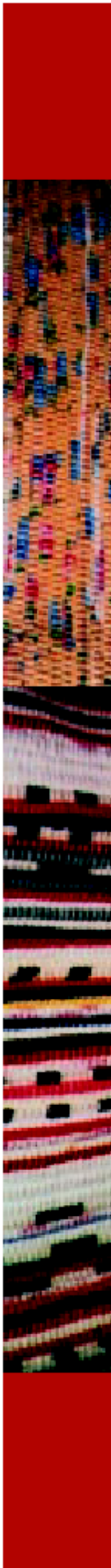

قد يكون لمقاربة "كسب العيش" عند تطبيقها عبر مر احل العمر ميزات معينة بالنسبة

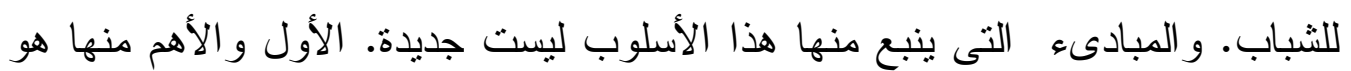
أن أساليب كسب العيش لا تصور عمل الثباب على أنه شىء سلبى بل إن هذا الأسلوب يزودنا بعدسة نرى من خلالها عمل الثباب على أنه دعم لتطوير مهار اتهم، وزيادة معلوماتهم من خلال وسائل التعليم غير الرسمية، ويبنى لديهم الاعتداد بالذات و التقة بالنفس. ويعتبر أسلوب كسب العيش العمل و احداً من مكونات ضرورية عديدة لازمة لعملية تطور فعالة للمر اهقين.

وتسعى مقاربة كسب العيش الى فهم المنطلبات الاقتصادية لتحديد المهار ات التى تلزم للشباب. كما تسعى الى أيجاد رابطة شاملة تصل العو امل الاجتماعية والاقتصادية التى تؤثز فى حياة الثباب. وفى أفضل السيناريوهات فإن ثلاك البرامج تذمج العناية بتخفيف حدة الفقر ( عن كل من أسباب وعائلاتهم) مع البحث عن وسائل ايجاد فرص لأولئك الذين لم يتم إعدادهم للدخول البنية الرسمية للعمل بسبب ضعف مستو اهم التعليمى، ودهار اتهم ومواردهم. وكان التركيز فى البداية على إكتساب المهار ات أكثر

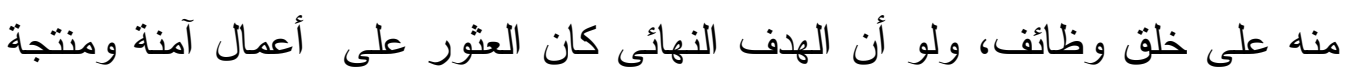
للشباب. وتدرك مقاربة كسب العيش الدور بعيد المدى الذى يلعبه العمل فى حياة الثباب وبالتالى الدور الذى يلعبه الثباب فى الحياة الاقتصادية لبلادهم، فالمسألة اذن ليست مجرد إيجاد وظائف فى لحظة ما.

ويتعاطف هذا الأسلوب أيضاً مع احتباجات جماهير معينة منل أطفال الثوارع و الأسر التى بعولها شباب.

إن التحدى الحقيقى هو أن نضع الفتيات على مسار عمل إيجابى إن إنشاء وسائل كسب عيش للشباب نتطلب إدر الك أن المر اهقين أبعد ما يمكن عن هن أن يكونو ا مجمو عة متجانسة.و الفتيات بالذات لهن احتياجات مميزة لابد من تلبيتها. إن الوضع المثالى هو تقديم فرص العمل و التذريب فى سياق ير اعى تهميش، وحركة، وثقافة، ومهار ات الثباب. ومثل تلك البر امج تبنى على قدر ات الثباب وتتمى الوسائل self التى تزيد من قيمتهم وتوجد لهم صلات بفرص العمل المنتج و التوظيف الذاتى 
e employment أساس دوره فى تتمية الذات، وكما ذكرنا من قبل فإن البحث الكمى quantitative research فى بنجلاديش

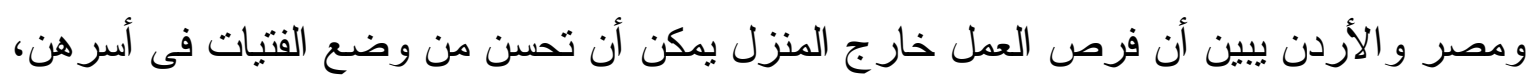

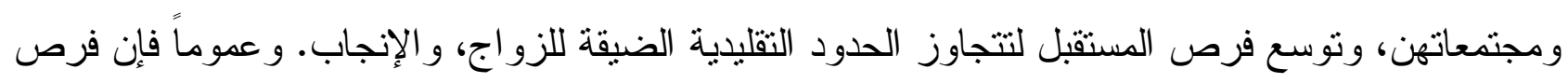
العمل للفتيات تتركز فى نطاق ضيق فى الوظائف التى تتطلب القليل من المهار ات، و التى يسهل الالتحاق

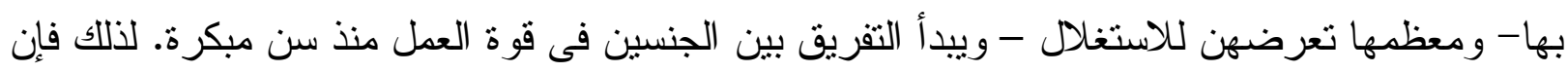
التحدى الحقيقى هو أن نضع الفتيات على مسار عمل إيجابى.

\section{وسيلة كسب عيش مستدامة للشباب: \\ ما الجديد؟}

إن مقاربة وسائل كسب العيش للثباب المستدامة هى تكييف لإطار كسب العيش كما ورد فى تعريف تعاونية الخلاص الأمريكى لكل إنسان CARE (CARE Cooperative for American Relief to Everybody)

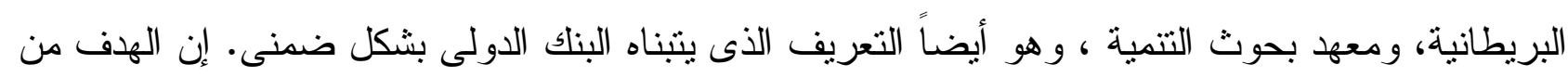

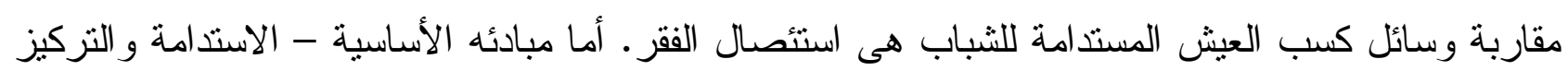
متعدد المستويات القائم على مبادىه الارتكاز الى الناس و الديناميكية و المشاركة و الاستجابة من خلال

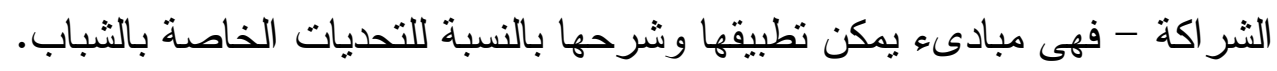

التركيز على الثباب: ندرك مقاربة كسب العيش للثباب أن الثباب ليسو ا فقط متميزين عن البالغين بل أنهم أيضاً متميزون عن بعضهم البعض. لون. إن سياق كسب العبش للمر اهقات الصغير ات يختلف اختلافاً كبيرًا عن السياق الخاص بالفتنان الأكبر سناً، و لابد للسياسات أن تدرك هذا وتتجاوب مع الوضع على هذا لأل الأساس.

الديناميكية: تقر هذه المقاربة بالروابط بين المدرسة و العمل و النطور الاجتماعى و الأسرة ـ و وعلى عكس ما

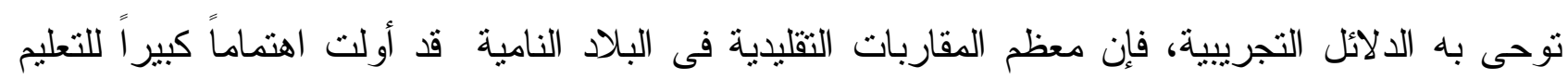

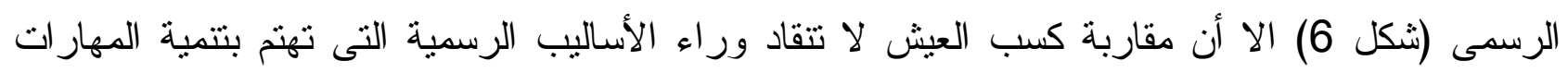

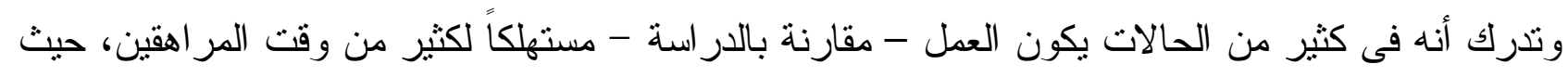
أنه يكون عليهم بدء العمل منذ سن مبكرة، الأمر الذى قد يؤثر سلبياً على تطورهم الاجتماعي و اكتسابهم المهار ات على المدى القريب و البعيد. 
شكل 6: مضاهاة استراتيجيات كسب العيش مع العوامل المتعددة لحياة المراهقين فى البلدان النامية
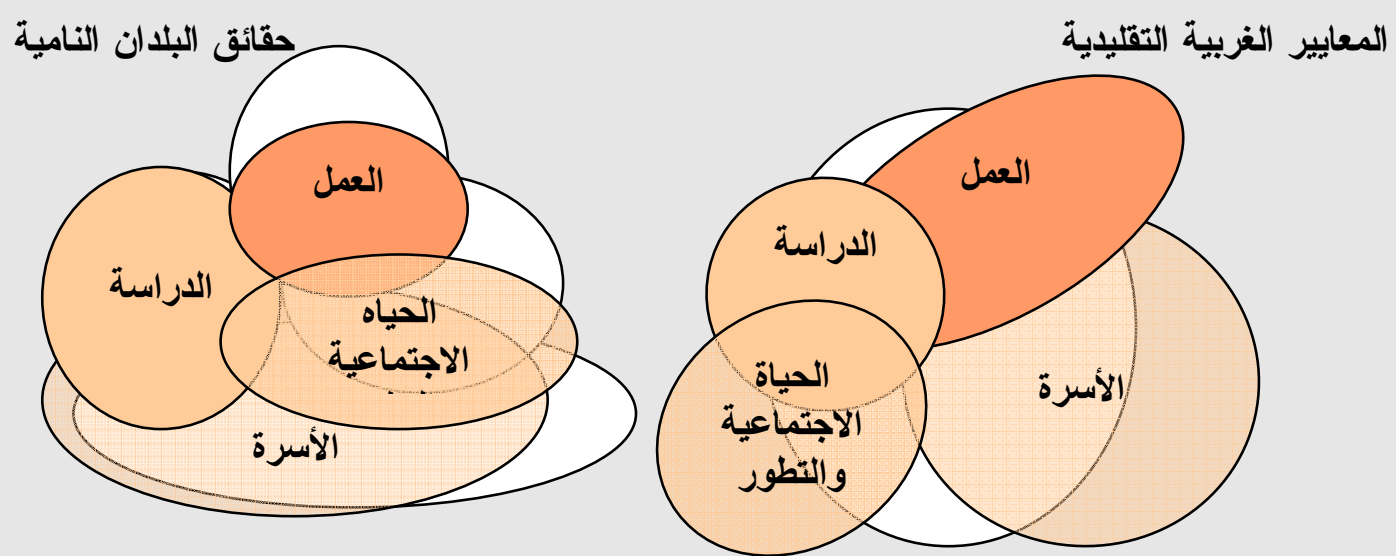

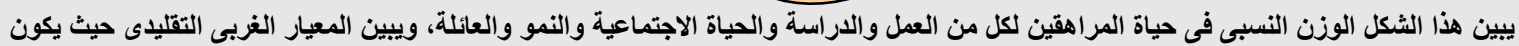

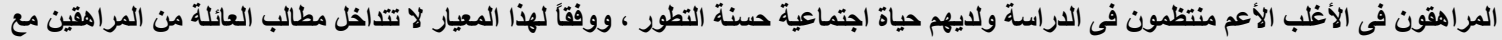

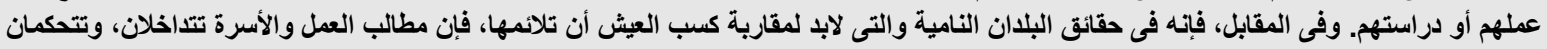

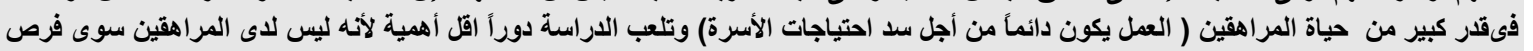

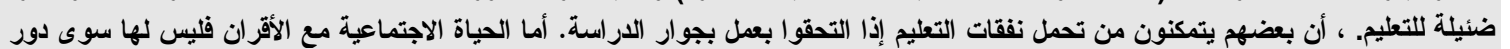

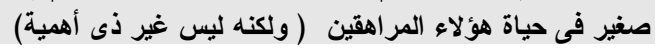

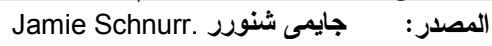

وتأخذ مقاربة كسب العيش فى الاعنبار الروابط قريبة المدى وبعيدة المدى بين المهارات وتطور الحياة

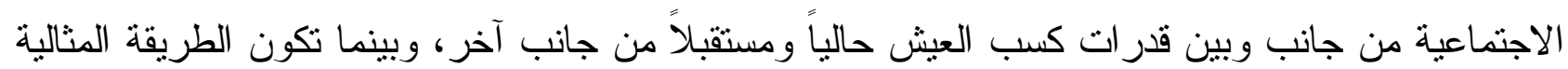

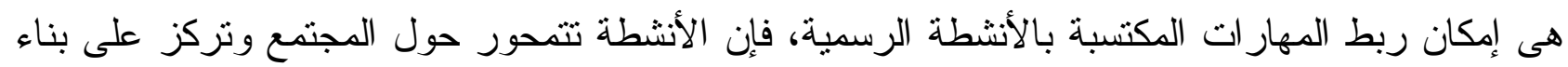

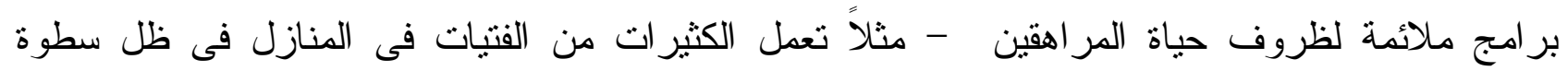

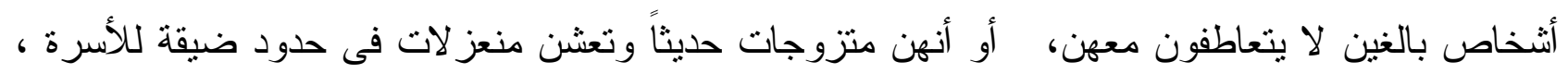
أو يعشن فى مجتمعات شبابية هامشية.

الاستجابة و المشاركة: ينظر هذا الأسلوب للثباب على أنهم فاعلين و ليس مفعول بهم. لقد خضعت سياسة التوظيف فى أفريقيا لقدر كبير من التسييس من جانب الحكومات التى تز غب فئس في ممارسة

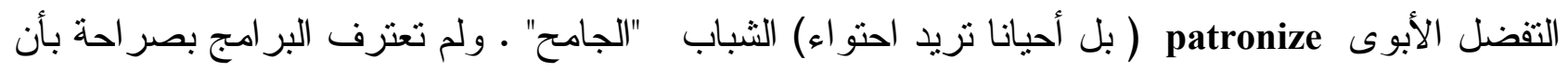

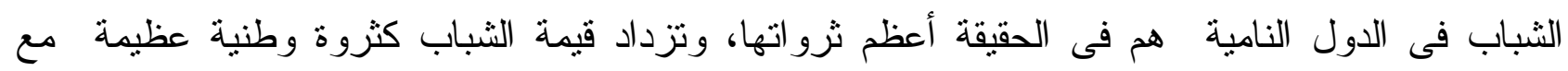

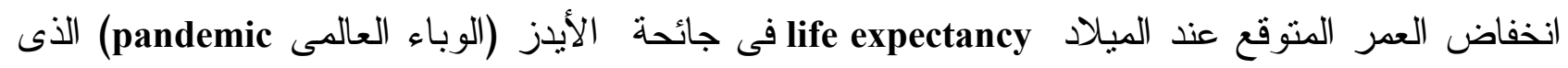

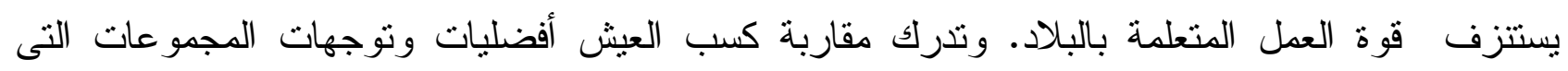

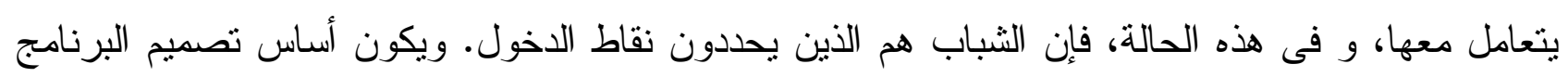

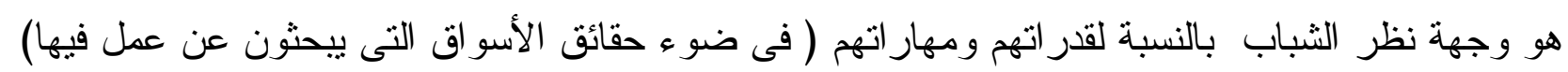

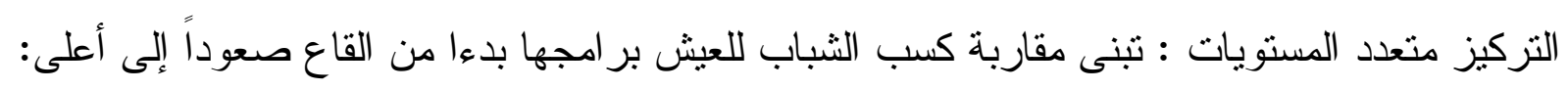




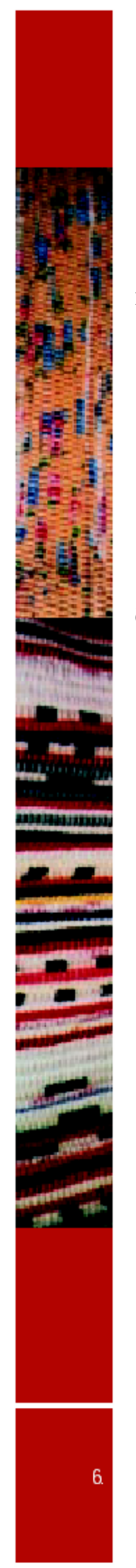

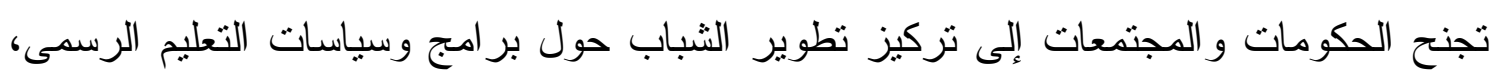

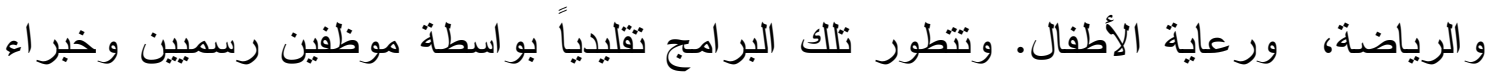

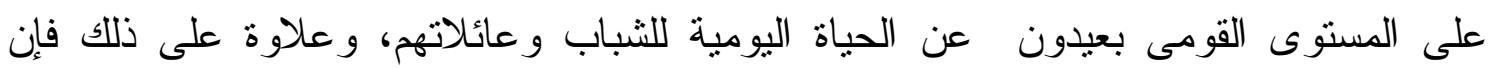

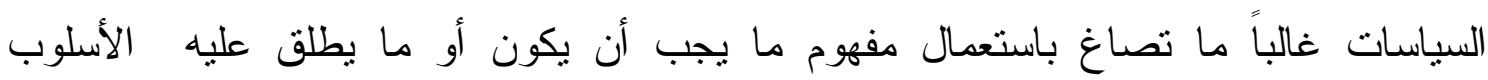
الاستتاجى deductive approach • بينما كسب العيش القابل للاستمرار يستعمل في بناء بر امجه الأسلوب الاستقر ائى المبنى على الهتمع inductive community-based approach

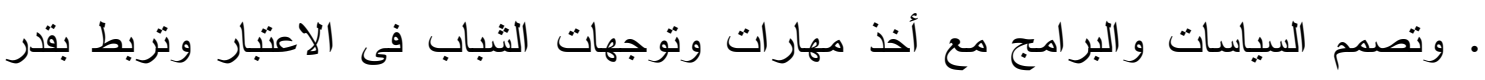

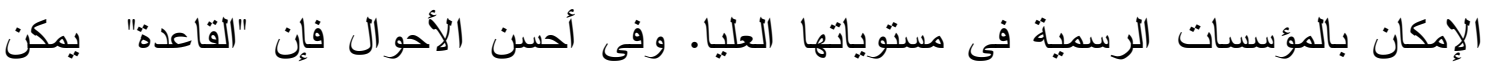
ويجب أن تستعمل لإصلاح التعليم التقليدى ولاعم برامج وسياسات رعائية الأطفال.

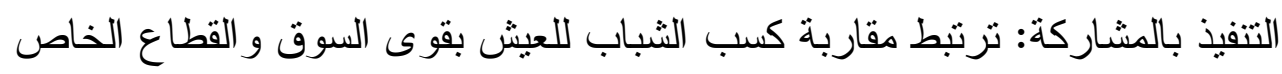

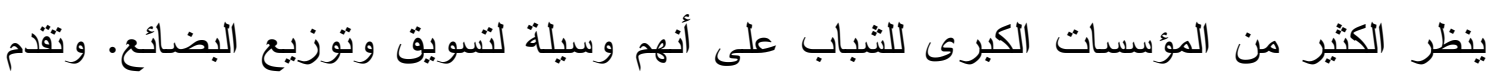

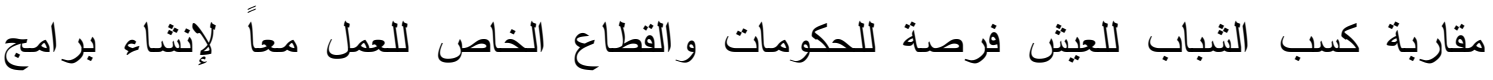

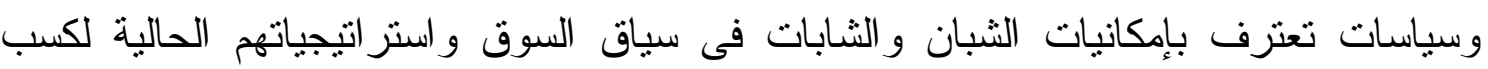
العيش. 


\section{تعريف كسب العيش:}

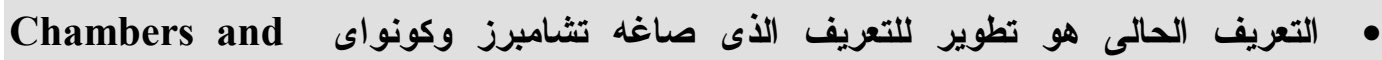
Conway

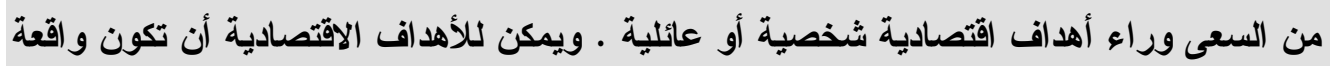

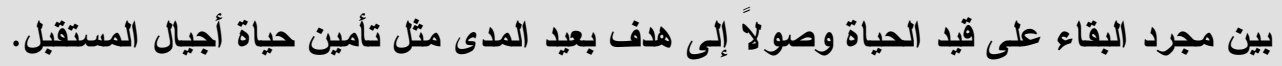
وتنظوى الأهداف المختلفة على اتباع استراتيجيات متباينة تتبع عادة مستويات مختلفة أيضاً من الموارد ونواحى الضعف ودورات الحياة:

• القدرات : تشمل المهارات والصحة الجيدة والثقة بالنفس واحترام الذات والقدرة على اتخاذ القرارات

• الموارد: تشمل الأصول المالية (مثل القروض والمدخرات) والأصول العينية (مثل المنازل والأرض والبنية الأساسية) والأصول الاجتماعية (مثل الروابط والثبكات الاجتماعية وعلاقات

• الفرص : تثمل أنثطة توليد الاخل أو استثمار الأصول ، وقد تشمل التوظيف الذاتى والعمل

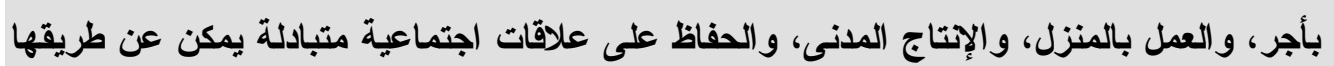

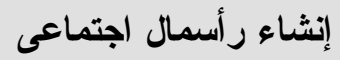

استعمال شبكة لاكتساب المعرفة: شبكة مركز بحوث التنمية الدولية (International Development Research Center IDRC) للحصول على المعارف المتعلقة بكسب العيش فى أفريقيا هدف هذه الثبكة هو الإسهام فى تطوير طرق لكسب العيش نكون قابلة للنطبيق من خلال إجراء بحوث ودر اسات على البر امج و السياسات التى تزيد من القدرات و التأهيل و ربطهما بفرص كسب العيش. و الجمهور المستهدف للثبكة هم الثباب من الجنسين العاملين بالقطاع غير الرسمى الذين لم يتيسر لهم إلا قدر بسيط من التعليم • وبينما يركز أسلوب كسب العيش عموماً على الجماهير المهيشة وليس الجماهير العريضة، فإن الجماهير المهمشة فى إفريقيا هى ذاتها الجماهير العريضة. وتسعى الثبكة كذلك إلى ربط الباحثين بالممارسين فى مجهود لتوليد المعرفة. ومقر الثبكة فى مركز در اسات الثباب بجامعة فندا Venda بالمقاطعة الثمالية من جنوب أفريقيا وقد قامت الثبكة برعاية رسالتى دكتور اه عن كسب العيش لدى المر اهقين، وكلتاهما تبحث فى نماذج لطرق كسب العيش للمر اهقين يمكن استمر ارها. وقد أنتأت شبكة مركز بحوث التتمية الدولية IDRC كذللك للمر اهقين برنامج عمل خاص بها يتكون من: 


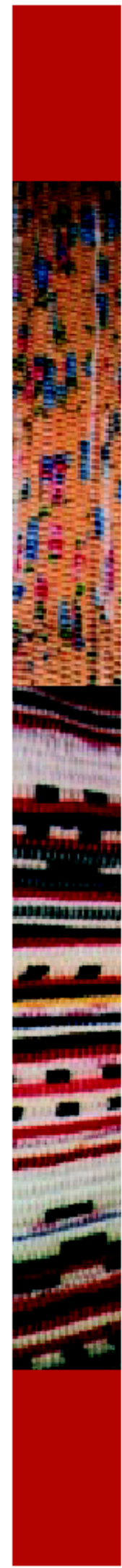

تطوير أدو ات وطرق لتقييم سياسات وبر امج كسب العيش جمع ونشر المعلومات عن السياسات و البر امج الفعالة

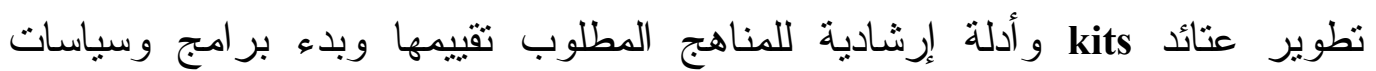
لإصلاحها تطوير القدرات و الوسائل التى تربط بين الباحثين و الممارسين و الخبر اء

بستتد تطوير الأدوات و الوسائل على إطار كسب العيش: البداية تكون بفهم سياق كسب العيش،

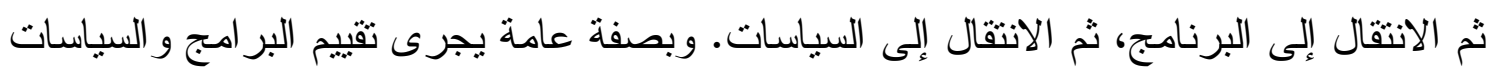

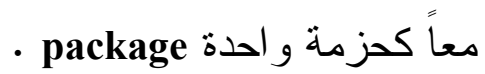
و على الرغم من أن مقاربة كسب العيش يكتسب أرضاً جديدة، فإنه لم ينم تطبيقه بالكامل بعد.

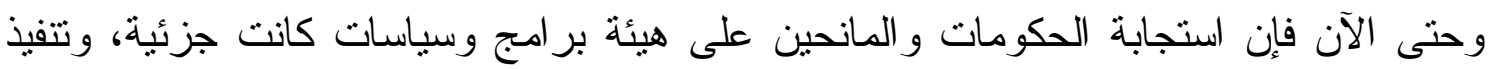

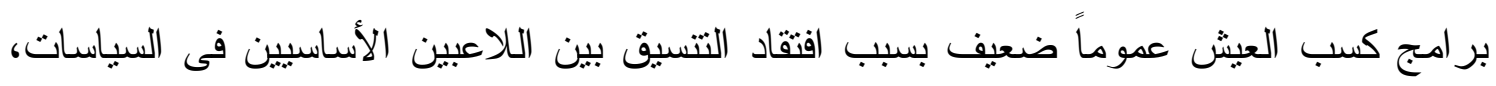

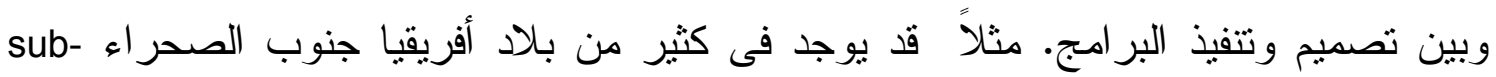
Saharan Africa

سياسات رسمية في مجال الثباب أو سياسة رسمية لكسب العيش، وقد يوجد كذلك عمل غير

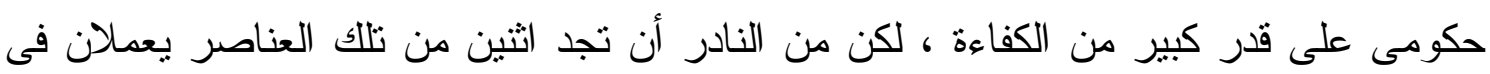

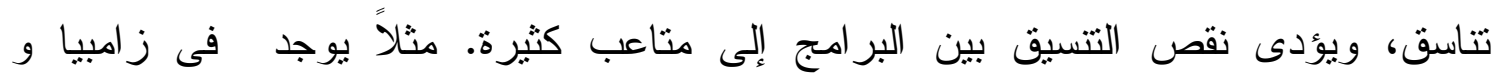

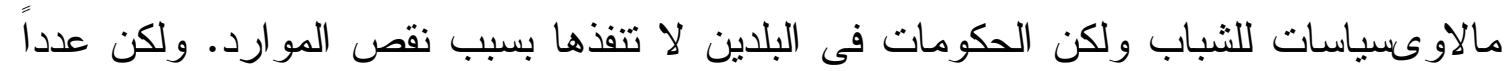

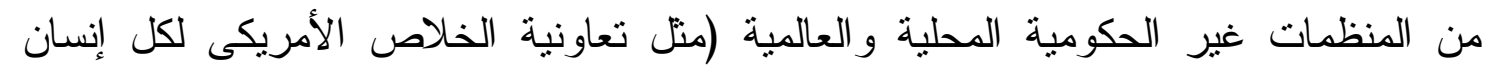
- CARE

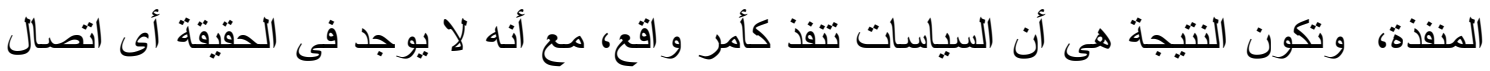
بين واضعى السياسات (المسئولون الحكوميون) وبين منفذى السياسات كأمر واقع (المانحون

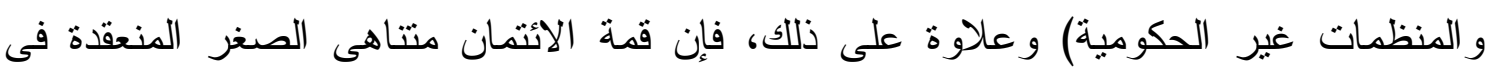

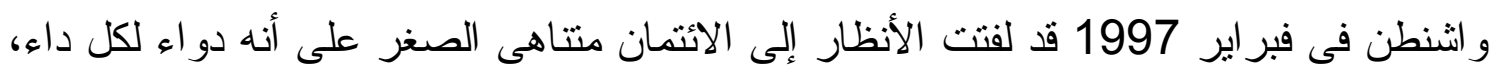

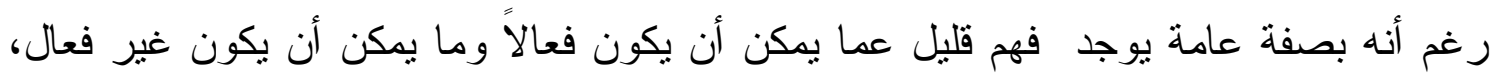
وخاصة عند التطبيق على الثباب من البالغين.

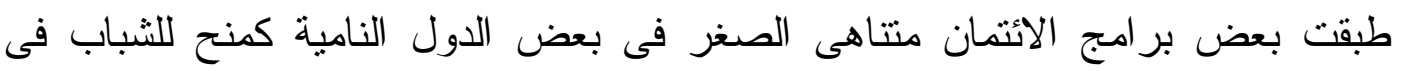

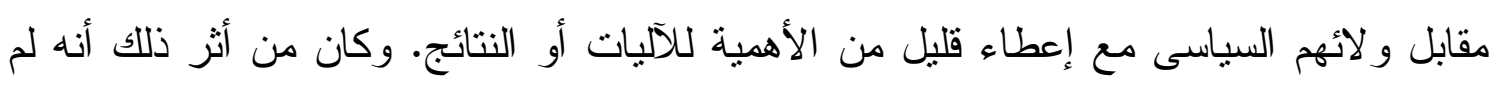

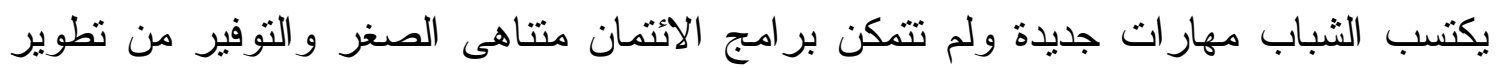

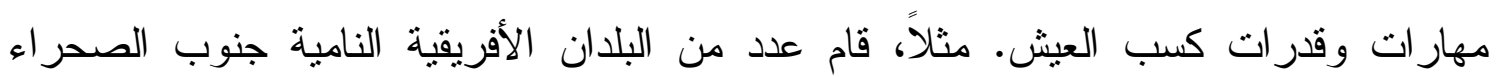




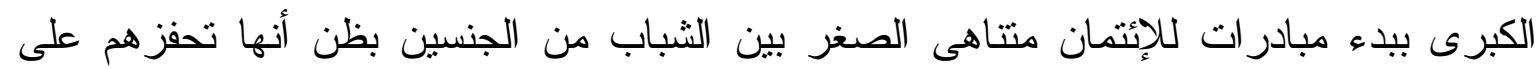

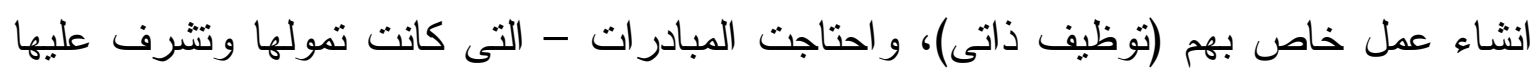

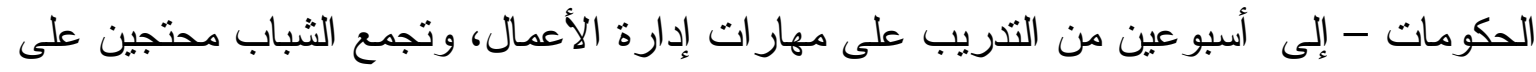
أنهم سيضيعون أسبوعين فى التدريب بينما غير هم من المشاركين فى مشروعات مهات أخرى للإنئمان متتاهى الصغير كانوا ينسلمون القروض مباشرة بدون أى تدريب على الإطلاق. ونتيجة لتلكي

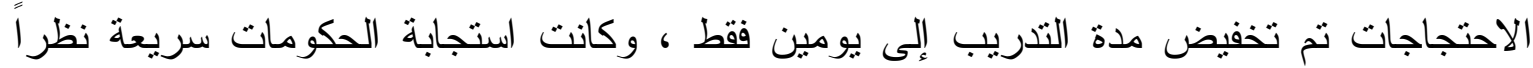
للطبيعة السياسية للعلاقات بين الحكومات و الثباب. وفى النهاية فنثلت برامج الايتمان وكانت سبباً

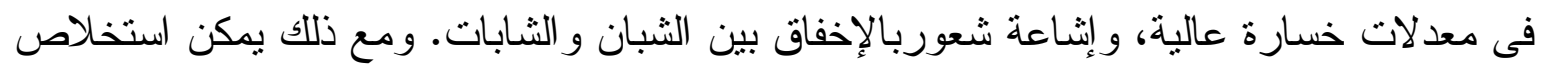

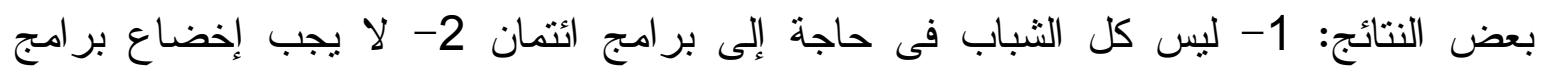
الائتمان لسيطرة الحكومة ولكن لإثر اف مشترك من وكالات التدريب ووكالات الائتمان 3-

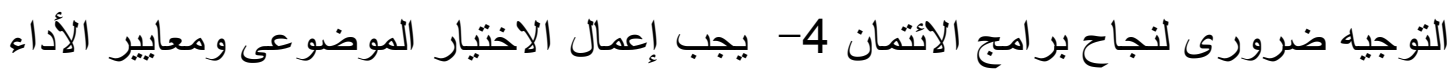

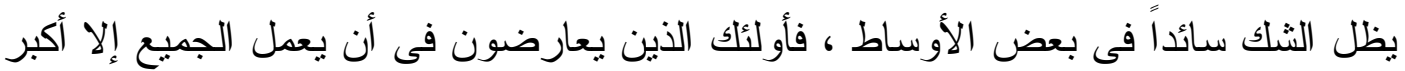

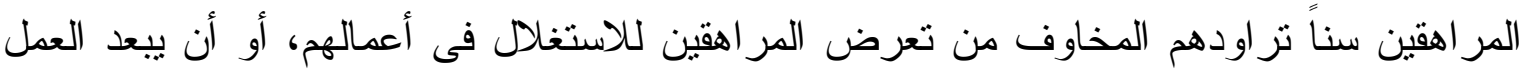

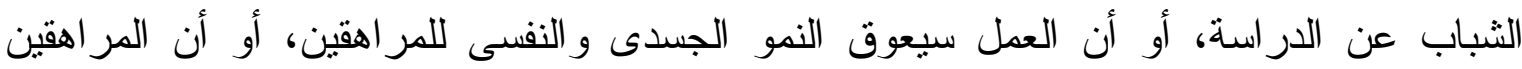

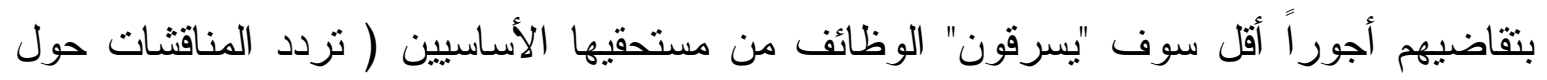

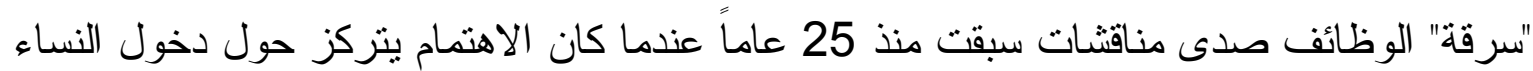

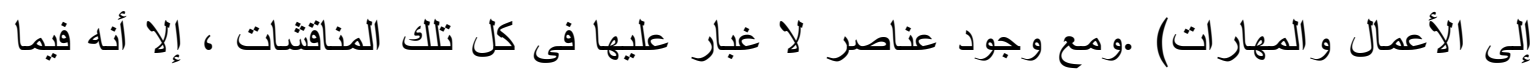

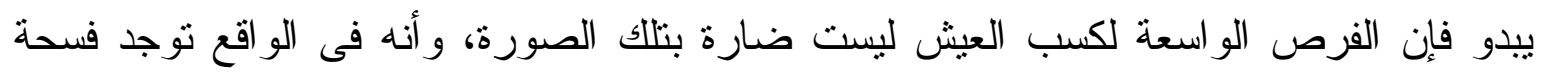

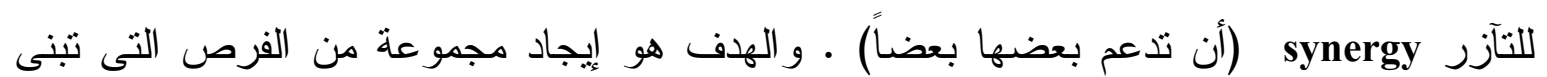

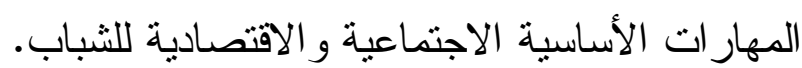

\section{ماهى الخبرات المتجمعة حتى الآن فى توليا و/أو دعم وسائل كسب العيش؟

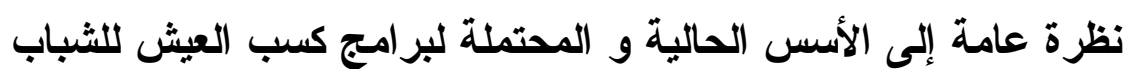

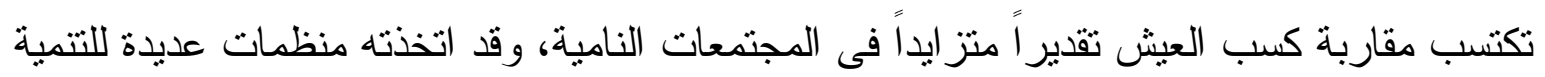

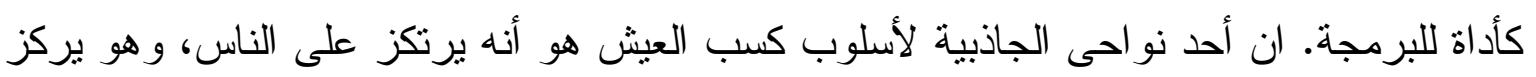
على الأهداف الاقتصادية للفرد وللأسرة، ولديه القدرة على استبعاب التفاعلات المركبة و الديناميكية

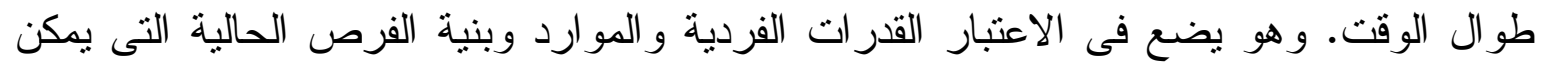
للناس من خلالها أن تمضى نحو أهدافهم الاقتصادية. 


\section{مجالات العمل}

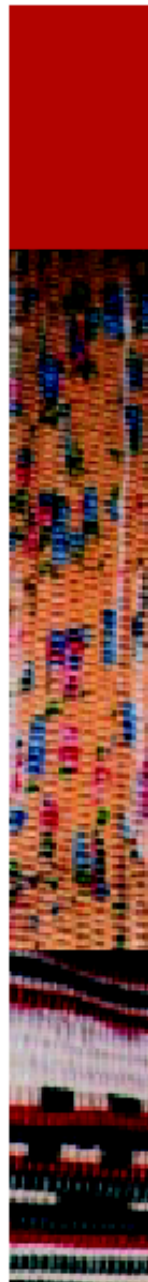

يمكن تعريف وسائل كسب العيش بأنها القدرات، و الموارد، و الفرص التى تمكن الناس من تحقيق أهدافهم الاقتصادية، وبناء على ذلك يمكن أن نأخذ فى الاعتبار ثناثة مجالات للعمل: القدرات : يمكن للبر امج التى تركز على تتمية قدرات كسب العيش آن نركز على المهارات الأساسية للقر اعة و الكتابة و الحساب و المهار ات المهنية، ومهار ات إدارة الأعمال و الأمو ال ، و المهار ات التقنية، وتتمية القدرة على الاستثمار ، و التدريب على مهار ات الحياة. ومن الممكن

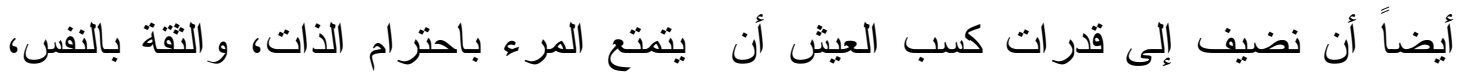
و التحرر من العنف خلال مسيرته لتحقيق أهدافه الاقتصادية. الموارد : ويتضمن المجال الثانى للعمل من أجل كسب العيش برامج تحسن القدرة على الحصول على الموارد و التحكم فيها. وربما تكون برامج التمويل متتاهى الصغر هى الأكثر شيوعاً فى هذا المجال، حيث توسع من فرصة الحصول على التمويل من خلال تقديم خدمات

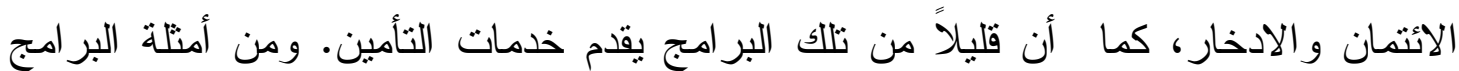
الأخرى التى تهنم بتوفير الموارد تلك التى تقدم تقنيات technologies جديدة، أو تؤكد على وسائل محسنة للوصول إلى المو ارد و التحكم فيها مثل الأر اضى أو الممتلكات المنتجة. الفرص: بتضمن المجال الثالث للعمل بر امج تهيىء الفرص ويمكن تقسيمها إلى خمس

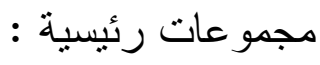

1-الوظائف، بما فيها خطط توليد الدخل، وبر امج الأعمال العامة، وتطوير استثمار ات تعاونية، وتطوير استثار ات صغيرة أو متوسطة تتولا عنها فرص للعمل للمر اهقين. 2- نتجيع الاخول إلى الأسواق، و البنية الأساسية، و الخدمات وفرص التوظيف 3- حماية وتثجيع الحقوق متضمنة حقوق الملكية، وحقوق العمال ، و الحق فى أجور متساوية، و الحق فى التمثيل 4- إنشاء مؤسسات منل منظمات الوساطة، ومنظمات المر أة، و التحالفات الاستر اتيجية التى تدافع عن الحقوق و البيئة الآمنة، أو تتشى شبكات للاعم الاجتماعى و المهنى 5- بر امج تعمل على ادخال التغيرات الهيكلية اللازمة المطلوبة لخلق فرص كسب الدخل من أجل المجموعات الفقيرة متضمنة تغييرات فى السياسات و القو انين و النظم و الأعراف الاجتماعية. 
إن العلاقات التازرية synergy بين تلاك المجالات الثلاثة للعمل مهمة للغاية، فالقدرات و الموارد مطلوبة ليمكن إيجاد الفرص و العكس بالعكس. ولاتحتاج البرامج المنفردة إلى المجالات الثناثة

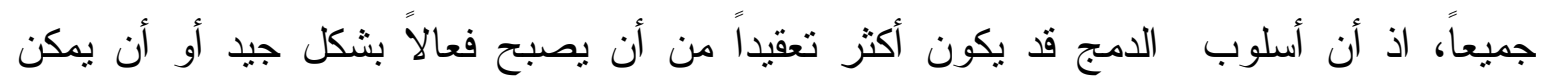

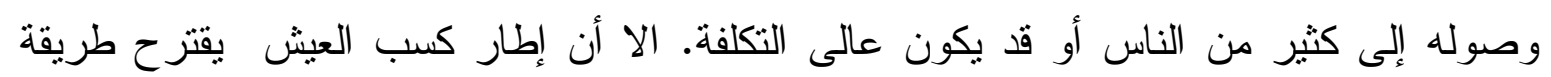
للنظر إلى سياق معين أو جمهور مستهدف، وهى طريقة تساعد على تقدير الخيارات المختلفة

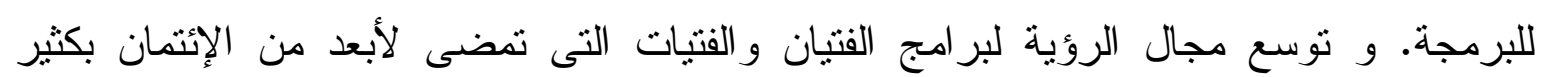

يعطى إطار كسب العيش قدراً من التبصر فى مساحات مجموعات البرامج الموجودة ويتحرى ما فيا

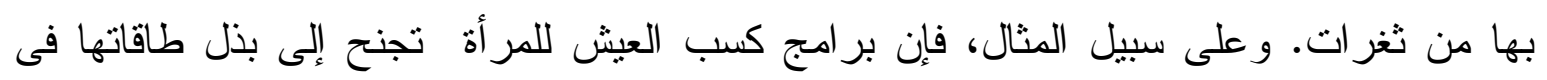

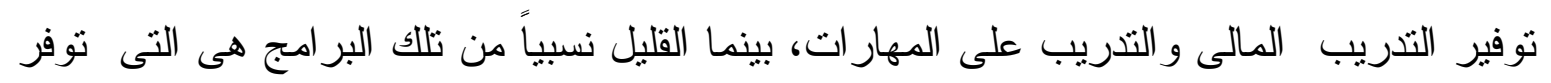

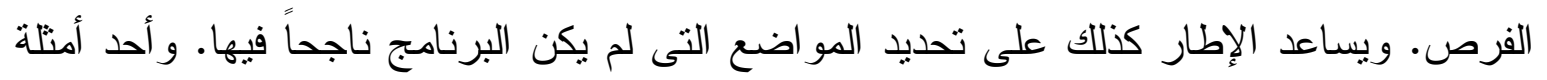

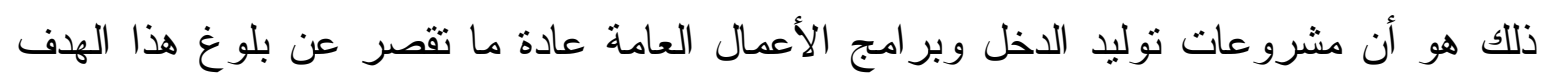

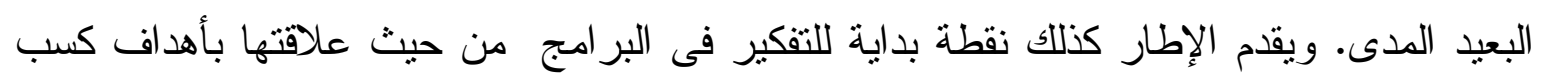

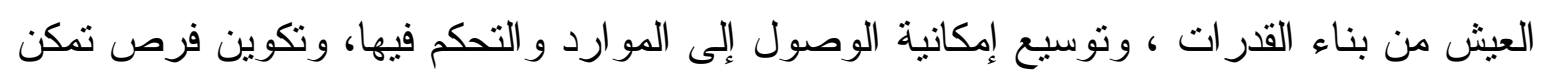
الناس من بلوغ أهدافهم الاقتصنادية.

ماهى إمكانية إثراك المراهقين فى مشروعات التمويل متناهى الصغر ؟

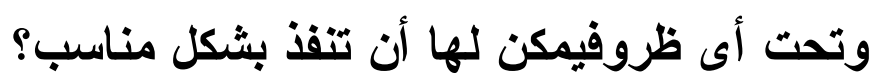

يوجد مابين 7000 إلى 10000 مشروع للتمويل متتاهى الصغر فى طريقها للتنفيذ على امنداد

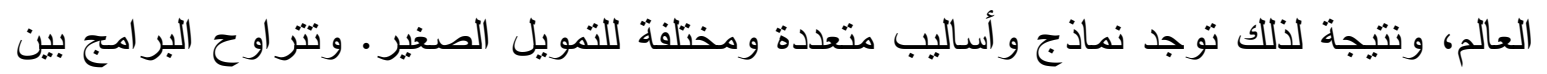
نماذج الحد الأدنى التى تركز على التمويل والأهداف المؤسسية متل استهداف أعداد كبيرة من

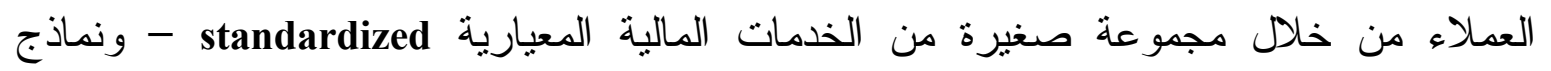

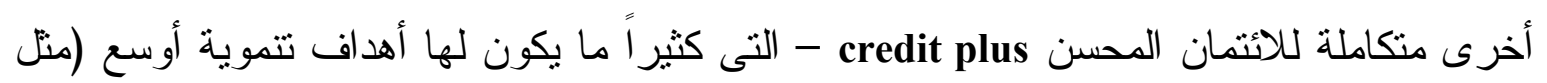

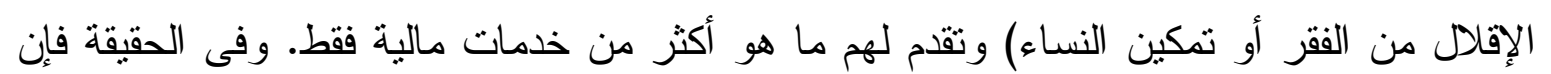
معظم البر امج مهجنة hybrids. ولكن الخبرة من بر امج المر اهقين محدودة، من حيث أنها عموماً 
لا تعنى باختلاف السياق الذى يضم المر اهقين باختلاف الأماكن والظروف، أو من حيث أنها لا تهتم بتجربة أساليب مبتكرة لتقديم المنتجات و الخدمات المالية المناسبة للمر اهقين.

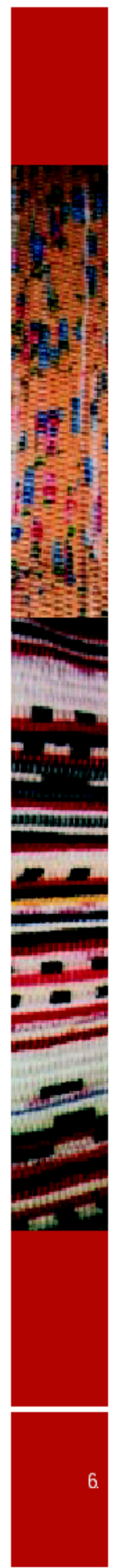

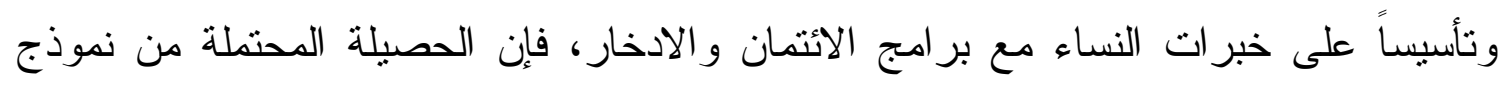

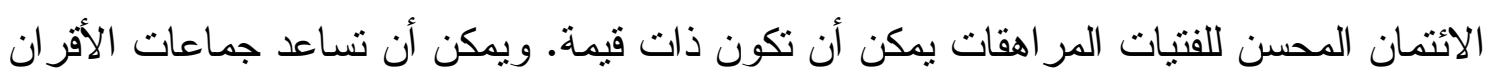

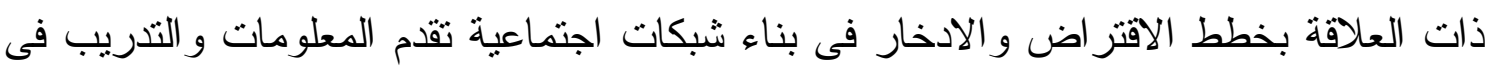

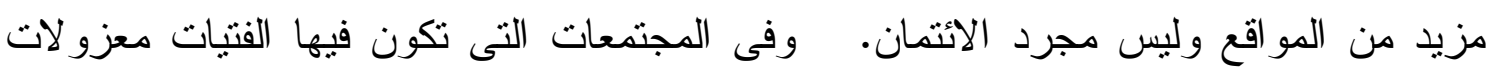

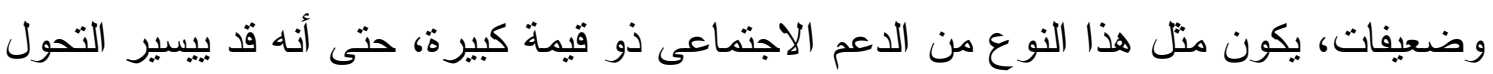

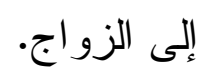


بنجلاديش BRAC

$$
\begin{aligned}
& \text { بنك الاستثمار الريفى فى } \\
& \text { كينيا } \\
& \text { Grameen بنك جر امين } \\
& \text { بنك الاتحاد النسائى للتوظيف } \\
& \text { SEWA الأتى للمر أة } \\
& \text { مركز التثقيف الجماعى } \\
& \text { والعلوم CMES } \\
& \text { تيتان (شركة للساعات) } \\
& \text { جمعية حماية البيئة } \\
& \text { (المقطم - القاهرة) }
\end{aligned}
$$

البرامج القطاعية للجنة تقدم

$$
\text { الريف فى بنجلاديش BRAC }
$$

$$
\text { جدول -1 }
$$

$$
\text { أنواع التخخلات }
$$

$$
\text { أهداف البرنامج }
$$

$$
\text { البرامج التى تنمى القدرات }
$$

$$
\text { خدمات التدريب (تدريب على }
$$

تتمية القدرات

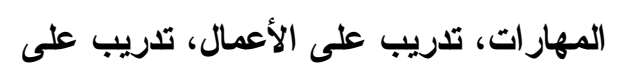

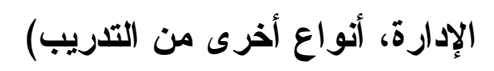

$$
\text { تنمية القدرة على الاستثمار }
$$

$$
\text { استر اتيجيات تنظيم المجموعات }
$$

وغيرها من الاستر اتيجيات الاجتماعية للوساطة

$$
\text { تمكين النساء }
$$

$$
\text { تنمية القدرات القيادية }
$$$$
\text { التدريب على التوعية السياسية }
$$$$
\text { البرامج التى تبنى الموارد }
$$

$$
\text { الاتنمان }
$$

$$
\text { تقديم الخدمات المالية }
$$

$$
\text { المدخر ات الاتمان }
$$

الخدمات المالية الأخرى (مثل تحويلات

$$
\text { (السداد الآلى، التأمين) }
$$

$$
\text { الإصلاح الزراعى وحقوق الملكية }
$$

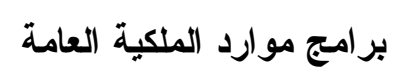$$
\text { التنمية التكنولوجية }
$$$$
\text { بر امج لبناء الفرص }
$$$$
\text { بر برامج توليد الدخل }
$$$$
\text { تقديم وظائف }
$$

الاستفادة من تحسين الموارد غير المالية

$$
\text { التعاونيات }
$$$$
\text { برامج تشجيع التوظيف }
$$
تطوير الاستثمارات الصغيرة التى تتولد

$$
\text { عنها وظائف للشباب }
$$

برامج ربط الأسواق

تثجيع النفاذ إلى الأسواق،

و الأراضى، و الخدمات، و البنية

الأساسية 


\begin{tabular}{|c|c|c|}
\hline (بلجيكا) & التظظيم من خلال الاتحادات المهنية & حماية ونشجيع حقوق الملكية \\
\hline برنامج الاتحاد النسائى & ومنظمات العمال واتحادات الثباب & وحقوق العمال وحقوق \\
\hline للتوظيف الذاتى للمر أة فى القطاع غير & رفع الوعى بالقو انين والحقوق & المساواة فى الأجور وحقوق \\
\hline الرسمى SEWA & خطط الحماية الاجتماعية للعمال & 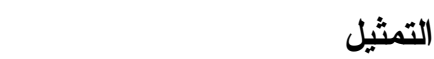 \\
\hline \multicolumn{3}{|l|}{ برنامج التدريب على التوعية } \\
\hline \multirow[t]{2}{*}{ بالقو انين والحقوق ADITH } & الاعم المالى والدعم الإدارى وتدريب & \\
\hline & العاملين فى منظمات توسع الفرص أمام الثباب & إنثاء مؤسسات \\
\hline \multicolumn{3}{|l|}{ التدريب على التمكين } \\
\hline \multirow[t]{2}{*}{ CMES } & الإصلاح القانونى & \\
\hline & إصلاح السياسات & \\
\hline برنامج الاتحاد النسائى & جهود لتغيير الأعراف الاجتماعية & تشجيع التغيرات الهيكلية \\
\hline للتوظيف الذاتى للمر أة SEWA & & (القوانين، السياسات والأعراف \\
\hline بنك جرامين & & الاجتماعية) \\
\hline GRAMEEN & & \\
\hline برنامـج التدريب على التوء & & \\
\hline
\end{tabular}

بالقو انين والحقوق ADITH 


\section{هل يمكن للفتيات المراهقات الحصول على الإتتمان؟ نظرة على الوضع فى بنجلاديش}

أصبحت الإتثمانات متتاهية الصغر هى أكبر مصدر للقروض الرسمية فى ريف بنجلاديش وتبلغ قيمتها حو الى تلثى مجموع الإتثمانات المؤسسية المتاحة فى المناطق الريفية ــونتشارك أكثر من

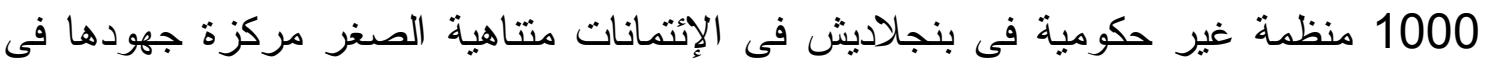

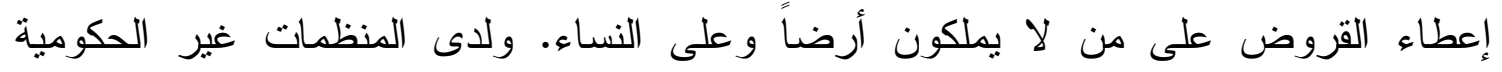

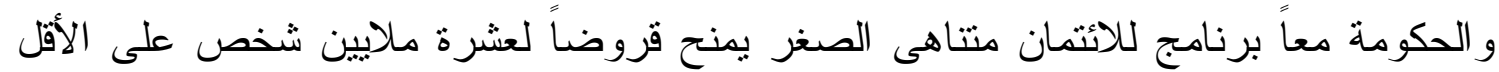

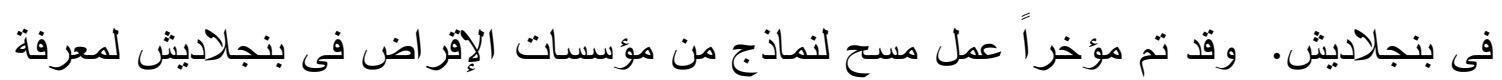

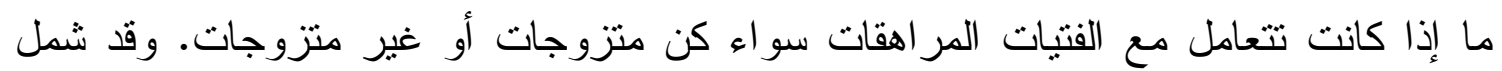
هذا المسح مركز تقدم الريف فى بنجلاديش BRAC واتحاد التقدم الاجتماعى ASA وبنك

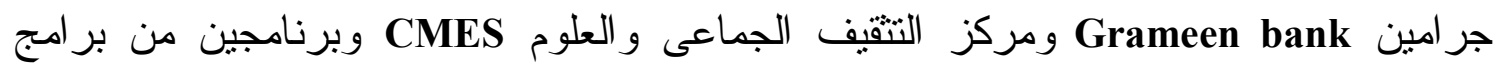
مجلس تتمية ريف بنجلاديش BRDB هما مشروع تتمية الريف RD و المشروع المتكامل لتتمية المر أة بالريف IRWDP. كان لكل مؤسسة دنها معايير لابد أن تتو افر فى المستقبد حتى يكون

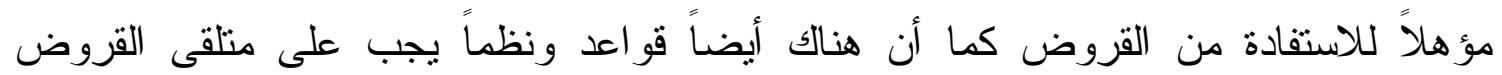

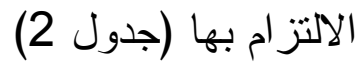

ويشجع مركز تقدم الريف فى بنجلاديش BRAC الفتيات المر اهقات على المشاركة فى كثير من أنشطته بما فى ذلك برامج التعليم الرسمى وغير الرسمى ، و التثقيف حول القانون و الحقوق،

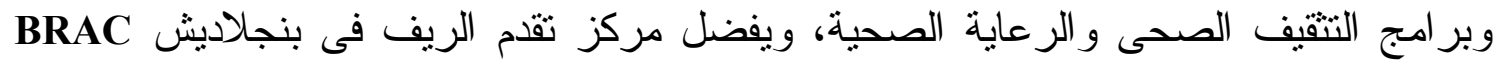
فى مجال التمويل بالغ الصغر التعامل مع المتزوجات حيث أن غير المنزوجات عادة ما ينتقلن

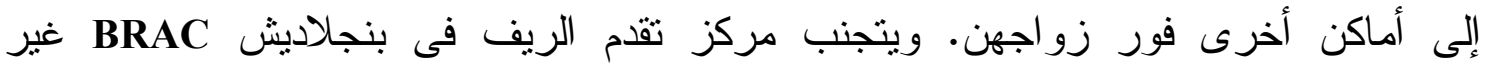
المتزوجات عن عدد فى مجال الإتنمان ليحافظ على معدلات سداد عالية على قدر الإمكان. بالاضافة الى ذلك، فان أكثر سئولى الائمان من الذكور مما يخلق مشكلة ثقافية من مسألة التعامل مع الإناث غير المتزوجات. لمان.

كذلك، يفضل اتحاد التقام الاجتماعى ASA ألا يقرض غير المتزوجات من المراهقات، ولنفس الأسباب ، فبمجرد أن تتزوج الفتاة يصبح من العسير سداد أي ديون متأخرة. 


\section{جدول 2 - معايير يجب تو افرها فى المستفيد ليكون مؤهلاً للحصول على قرض}

التحاد التقدم الاجتماعى ASA

مركز تقدم الريف فى بنجلاديش BRAC

$$
\begin{aligned}
& \text { من فقر اء الريف ( النساء أساساً) } \\
& \text { مقيم بصفة دائمة فى الجوار }
\end{aligned}
$$

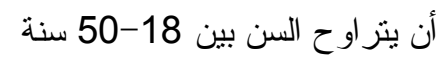

$$
\begin{aligned}
& \text { ألايزيد دخل الأسرة الثهرى عما يوازى } 24 \text { دولاركة }
\end{aligned}
$$$$
\text { يحصل على أجر من عمل يدوى ستة أثهر فى السنة }
$$$$
\text { يملك 2/1 فدان على الأكثر }
$$

قادر من الناحيتين الجسدية والعقلية على مزاولة أنشطة تدر دخلاً

$$
\text { ليس طالباً وليس منسو لاً }
$$

\section{أمريكياً}

متزوج (ولكن يمكن التعامل مع النسوة المطلقات
الحصول على أجر من عمل يدوى لمدة 100 يوم فى لئ

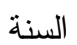

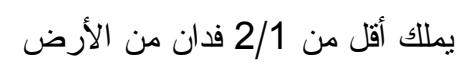

أن ينز اوح السن بين 18-55 سنة

للمستقيدات من النساء فقط

نشط بدنياً

مقيم بصفة دائمة فى الجو ار بليار

ليس له مورد دخل منتظم

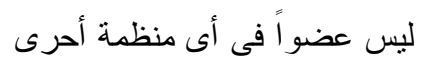

مجلس تنمية ريف بنجلاديش BRDB/ مشروع تنمية مجلس تنمية ريف بنجلاديش BRDB/ المشروع المتكامل

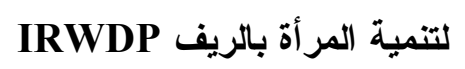

RD الريف

$$
\begin{aligned}
& \text { أنثى من 18- } 35 \text { سنة } \\
& \text { يملك أقل من 2/1 فدان } \\
& \text { تهتم بالمشاركة فى أنشطة بر امج المر أة } \\
& \text { أن يتز اوح السن بين 18-50 سنة } \\
& \text { مقيم بصفة دائمة فى الجوار } \\
& \text { ليس له مصدر دخل منتظم }
\end{aligned}
$$

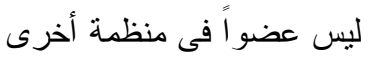

$$
\begin{aligned}
& \text { له عنو ان ثابت }
\end{aligned}
$$

تعتبر الفتبات غير المتزوجات غير ناضجات مما بسبب القلق لمانحى القروض خثية عدم التز امهن بالسداد، ولكن المتزوجات من الفتيات المراهقات متضمنات داخل مجموعة اتحاد التقدم الاجتماعى ASA التى تضع حداً أدنى لسن الحصول على قرض وهو 18 سنة ، وهو شرط يمكن التجاوز عنه بالنسبة للمنزوجات صغير ات السن 
بنك جر امين Grameen Bank وهو مؤسسة رائدة فى مجال التمويل متتاهى الصغر يتيح

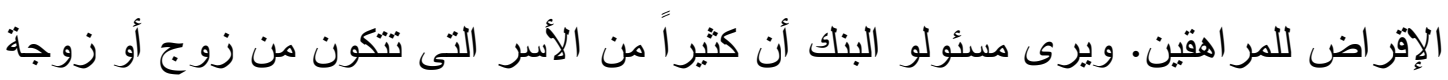

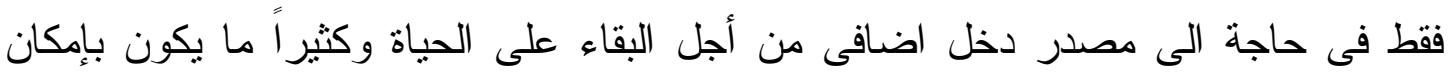

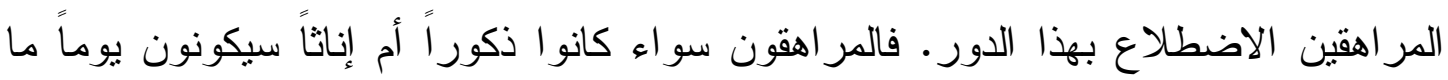

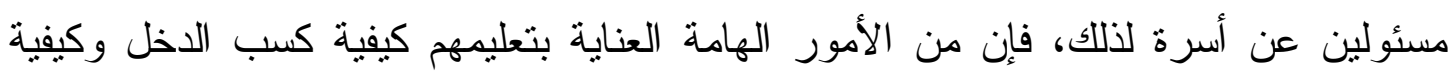

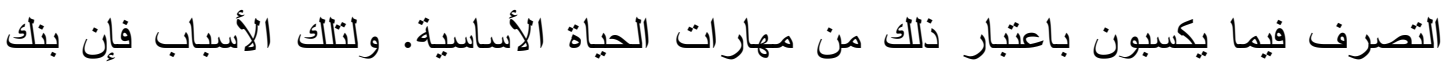

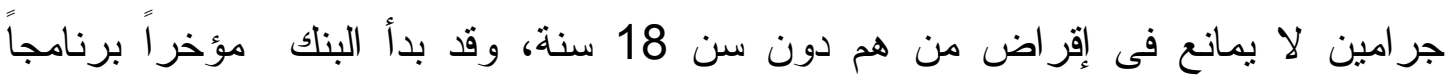

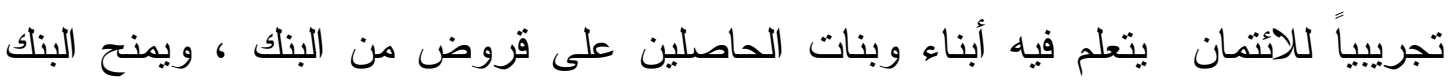

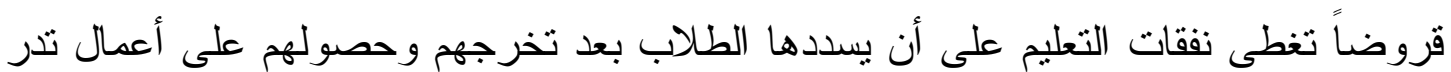
دخلاً.

تأسس مركز التثقيف الجماعى و العلوم CMES سنة 1991 ويقدم تعليماً غير تقليدى وتدريباً

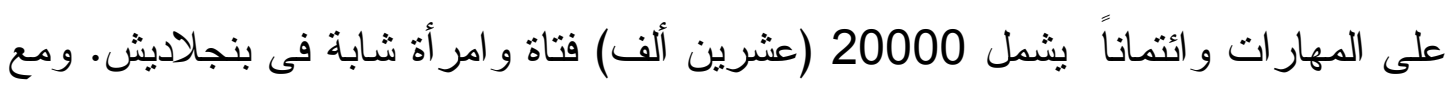

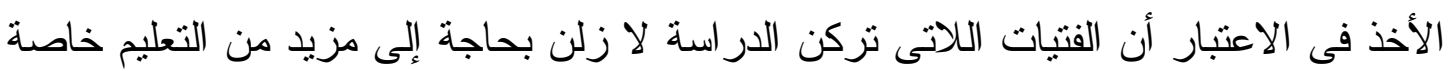

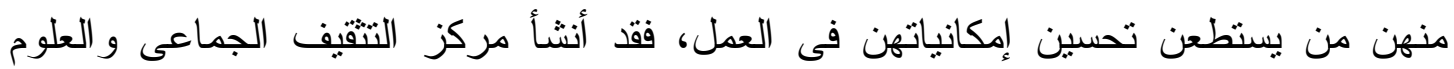
برنامجاً يقترن فيه التعليم مع كسب العيش كجزء من مجهود أكبر يعطى للفتيات فرصة للنمو و التطور الثخصى. 
و الفتيات مؤهلات للالتحاق بالبر امج المختلفة لمركز التثقيف الجماعى و العلوم CMES إذا ما كن خارج المدرسة وغير متزوجات. ورغم أن مركز التتقف الجماعى و العلوم CMES لم يبدأ

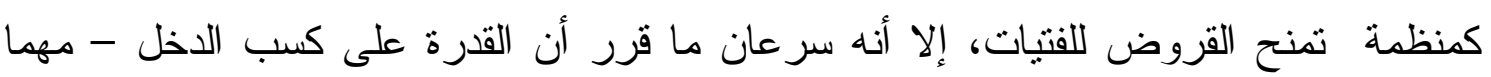

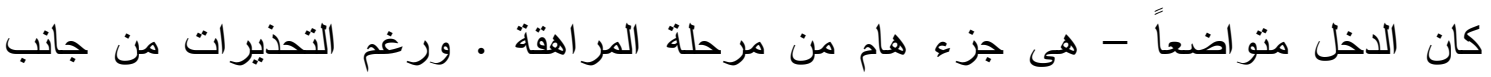

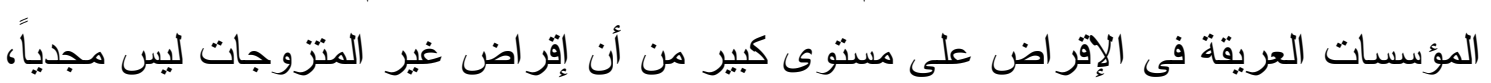

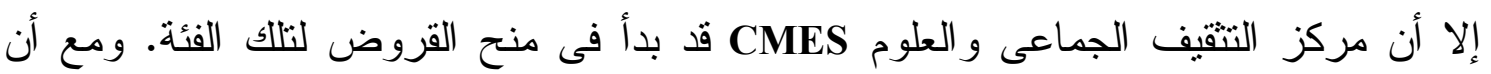

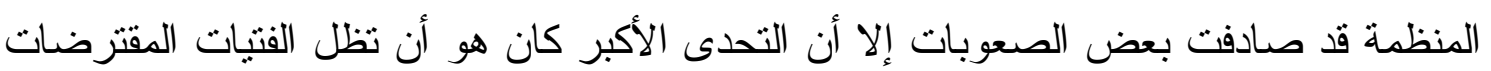

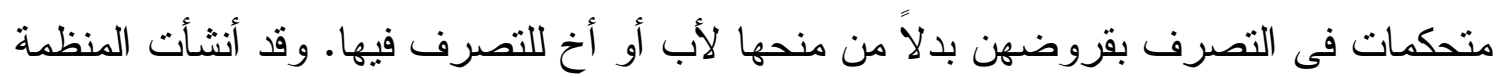

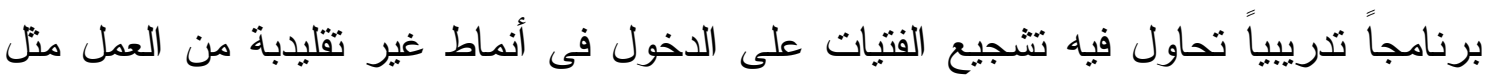

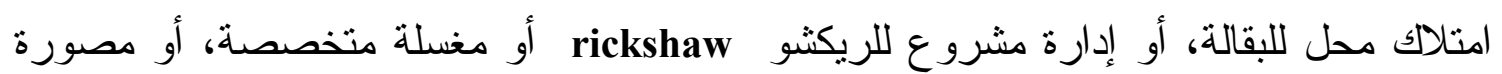

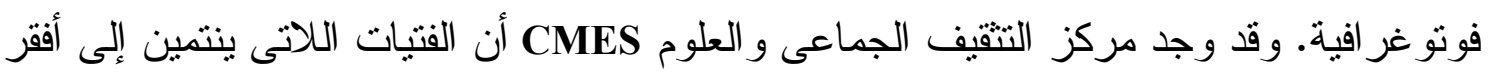

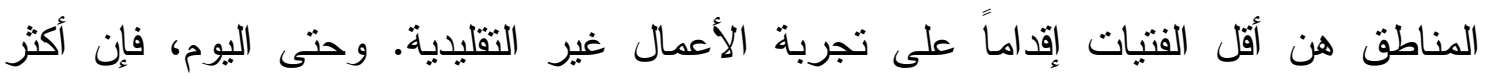

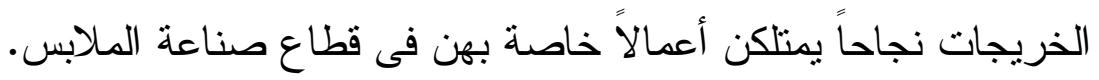

النظر إلى الفتيات كمقترضات محتملات

كما أثرنا سالفاً، فإنه ينظر إلى الفتيات المراهقات غير المتزوجات على أنهن فئة عالية الخطورة بالنسبة للاقتر اض بسبب نمط الانتقال الذى تتبعه الفتيات بعد زواجهن. كما أن هناك الك الكان

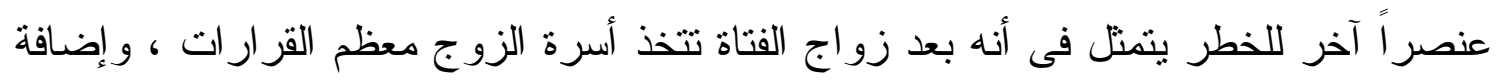

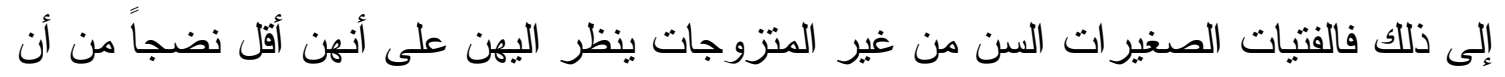

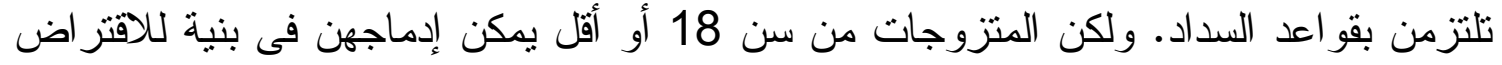

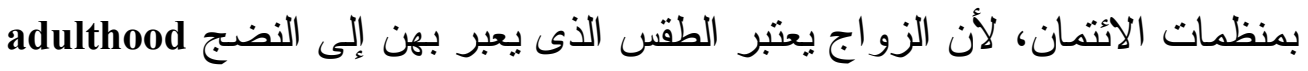

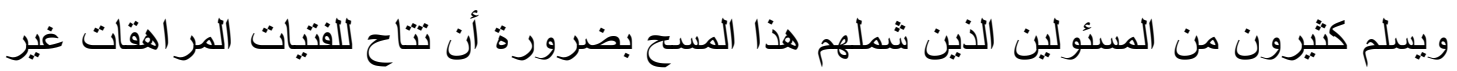

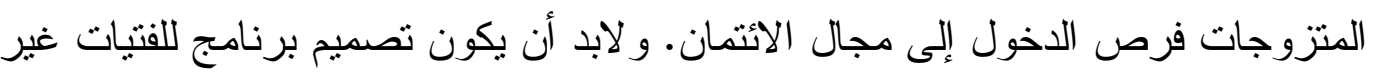

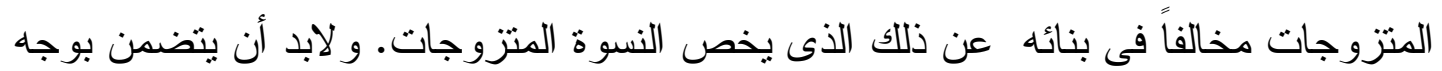
خاص آليات" الائتمان المحسن" وأن يدعم بمر اقبة و إنثر اف محكم، وتدريب على إنثاء و وإنتاج

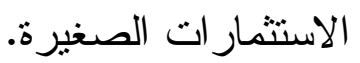

ماهى أنواع برامج كسب العيش المتاحة للفتيات فى الهند؟ 


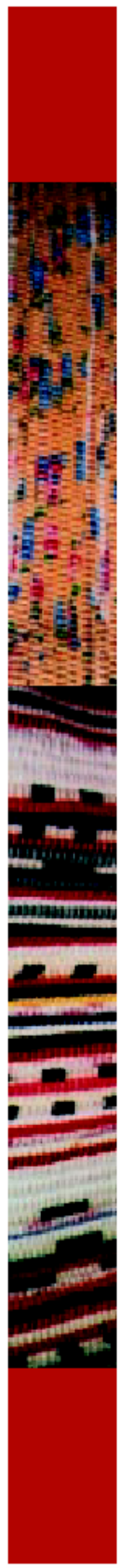

تركز طائفة كبيرة من بر امج كسب العيش للمر اهقات فى الهند على التنريب المهنى وتتمية المهار ات

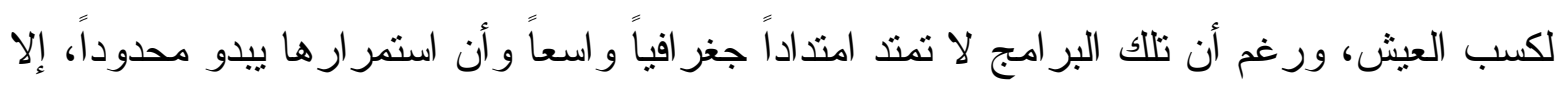

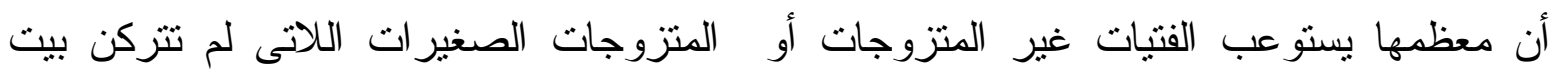

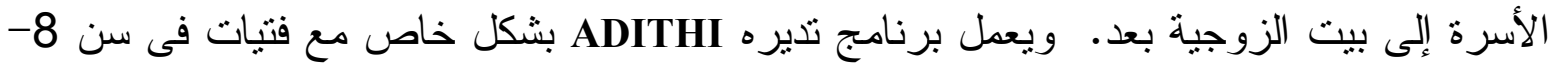

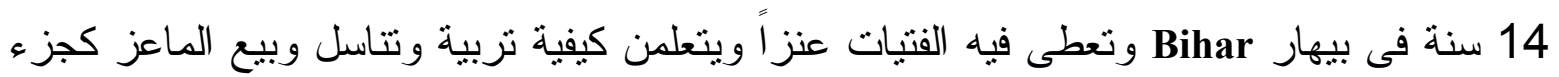

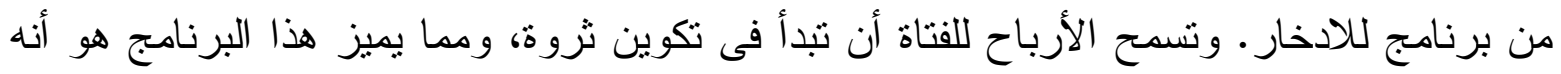

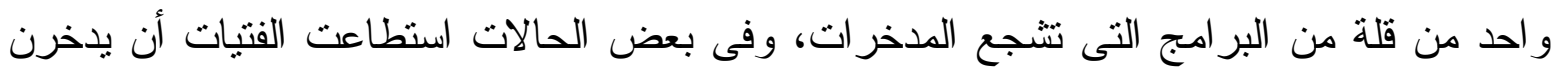

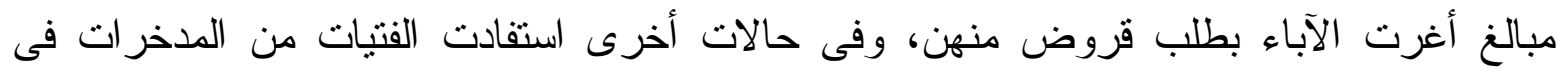

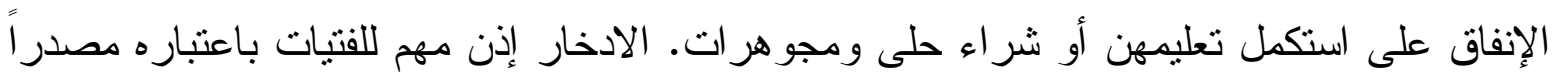

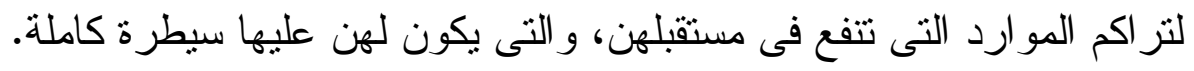

ويرتبط برنامج آخر تديره MYRADA بو احد من أكبر صناع الساعات فى الهند ، وتكمل الفنيات

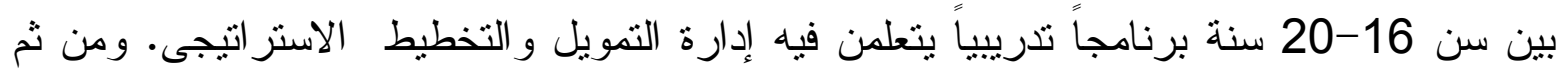

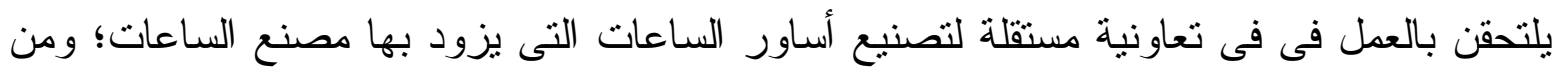
خلال ذلك يكتسبن الخبرة و الدخل و الدذخر ات.

هل تستطيع الفتيات فى الهند الحصول على الائتمان؟

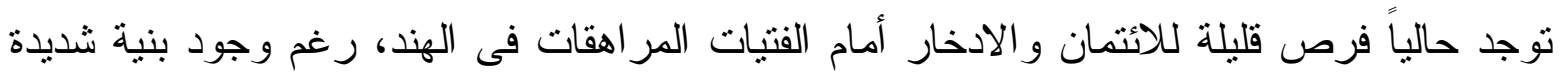
الحيوية لكسب العيش للفتيات الأكبر سناً (غالباً المتزوجات منهن) و هذا يتضمن إضافة اللفات إلى الائتمان

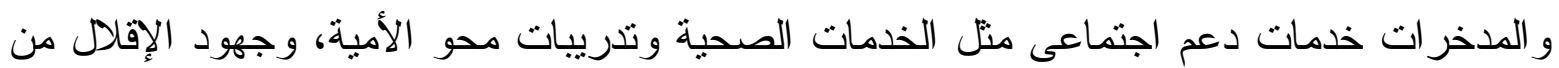

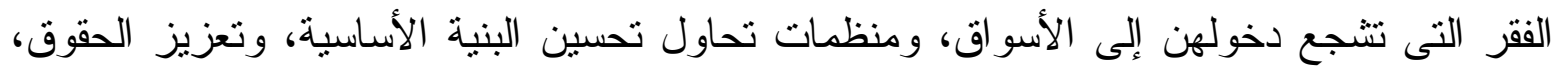
وتحسين فرص الحصول على ممتلكات. و لا يبدو أن هنالك برامج ائتمان تستهدف الفنتات المر اهقات، أو برامج للمر اهقين تقام الايتمان.

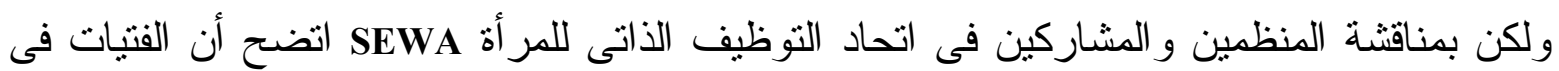

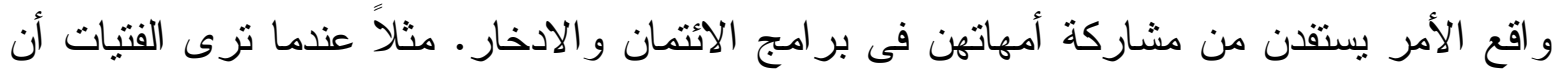

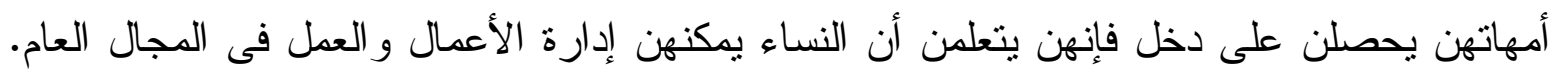
كذللك فإن أنشطة النساء التى تدر دخلاً نوفر فرصاً أكثر لبناتهن للحصول على إنى التعليم و الرعاية 
برنامج قبلى لمنح الاتتمان للفتيات المر اهقات فى نيروبى

قام مجلس السكان بالتعاون مع مشروع الريف فى كينيا ( هو مشروع قائد للتمويل متتاهى الصغرفى كينيا (K-Rep

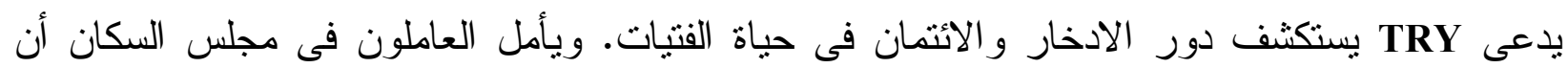

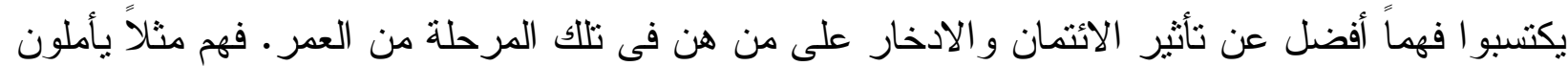

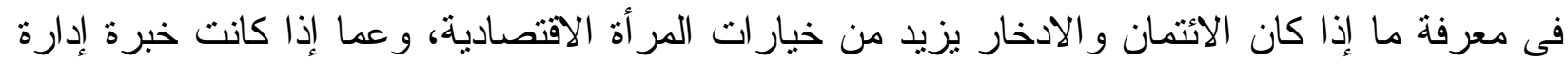

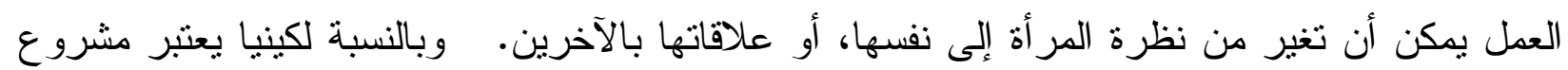

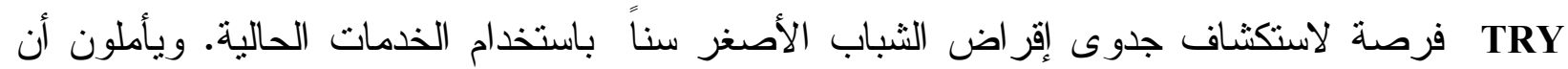

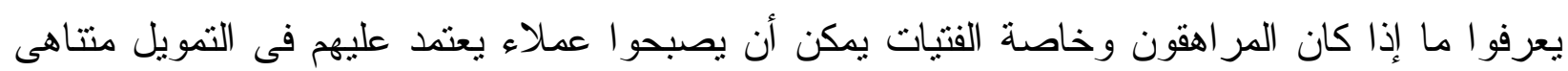

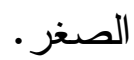

إنهم المشاركون فى مشروع TRY من سن 16-24 سنة وهم إما متخرجون من المدارس أو متسربون

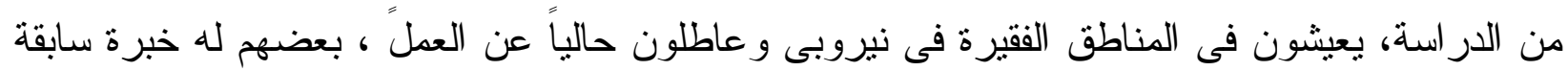

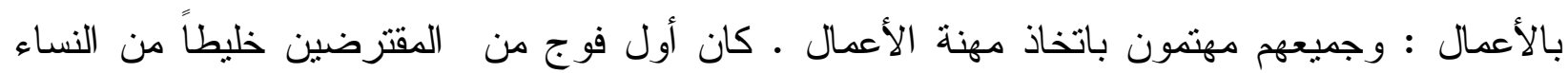
المتزوجات وغير المتزوجات، وبعضهن قد أصبحن أمهات بالفعل.

لم تزد القروض الأولى عن 200 دولار أمريكى : ويسدد المشاركون القروض بفائدة مقدارها 15\%

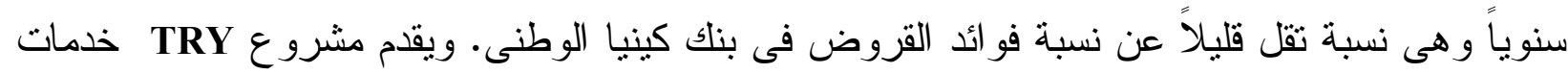

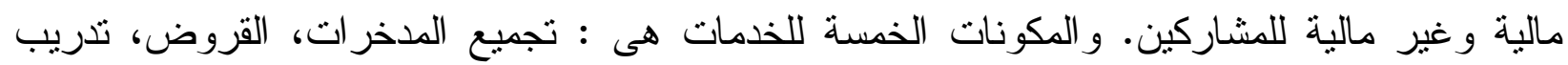

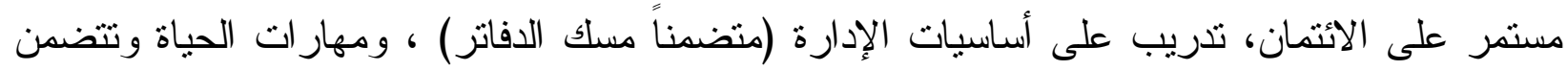

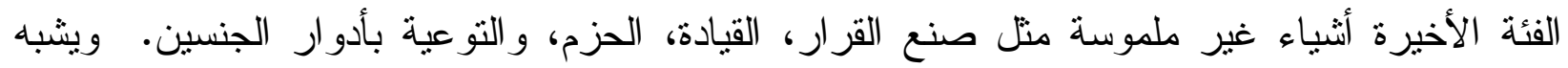
نموذج تقديم الائتمان فى مشروع TRY النموذج القياسى فى مشروع كينيا K-Rep و الذى بذوره يستند

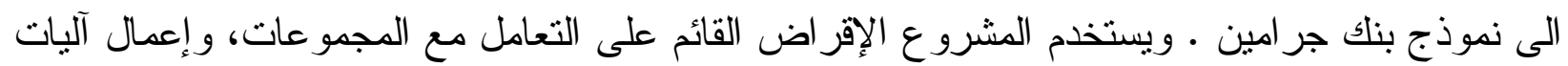

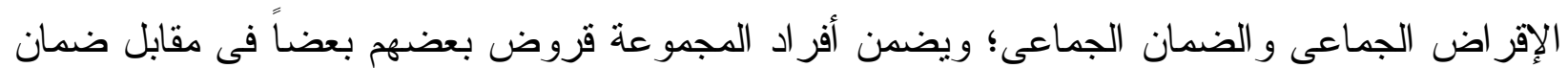

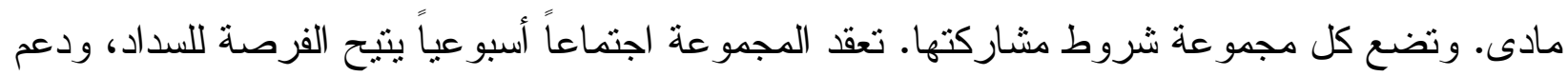
المجموعة، وخدمات مختلفة غير تمويلية. ومطلوب من كل مشارك أن يدخر مبلغاً ماً كل أسبو ع بانتظام.

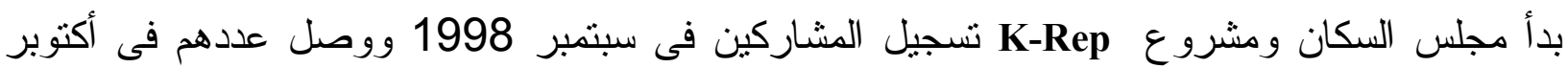

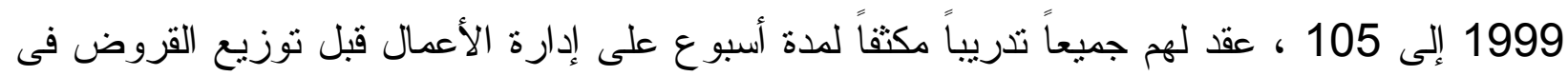


يونيو 1999 ، وحتى الآن فإن 90 فتاة قد تلقين قروضاً وحو الى 9 منهن نركن المشروع بعضهن بإر ادتهن

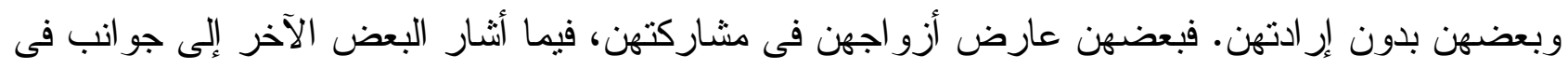

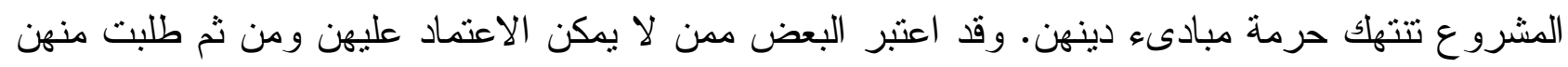

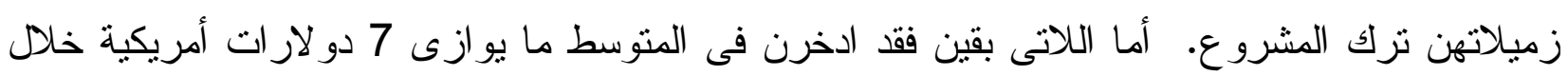
مشروعات عمل مختلفة منل تصفيف الثعر، بناء المنازل، التفصيل، البقالة، وبيع الملابس المستعملة.

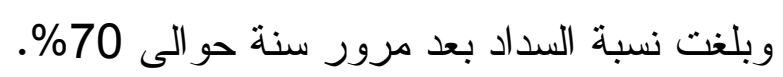

توثيق جدوى مشروع TRY القبلى

يقدم مشروع TRY فرصة فريدة للبحث. ويقوم مجلس السكان بنوثيق كل أوجه المشروع بعناية بما فى

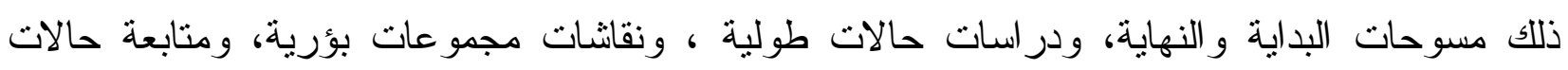

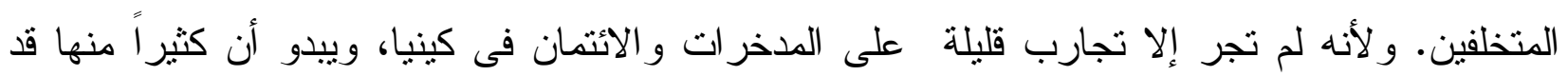

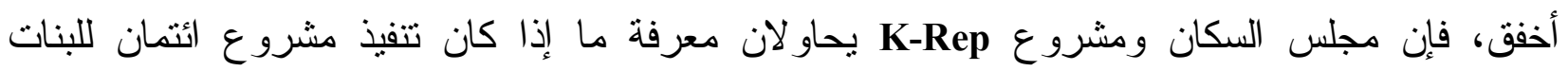

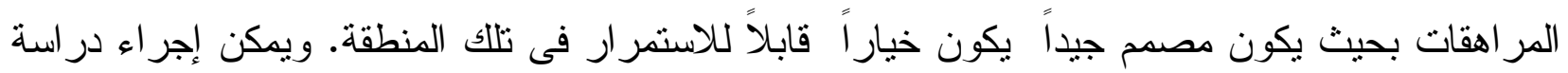

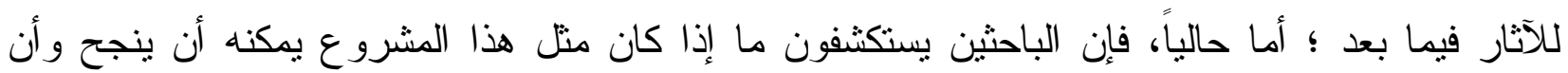
بستخلصو ا الدروس من التجربة.

ويتتبع باحثو المجلس متغير ات متعددة طولياً، وهم يسعون إلى معرفة المزيد عن كيفية قضاء المشاركين

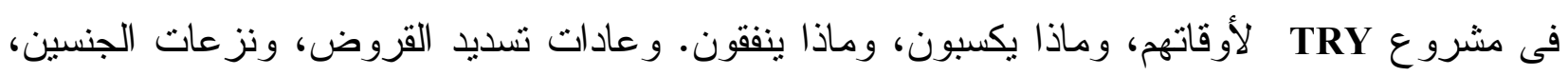

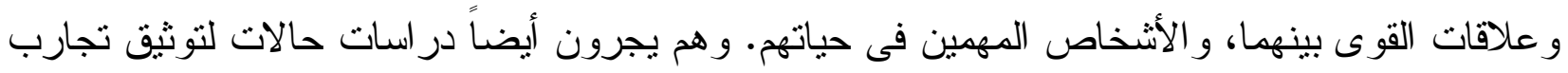

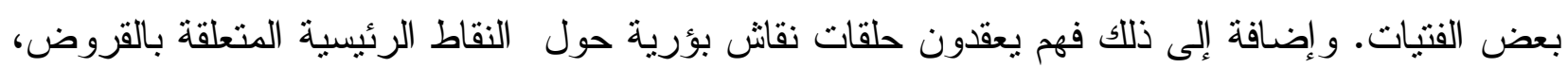

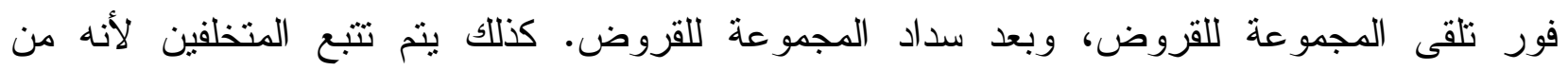

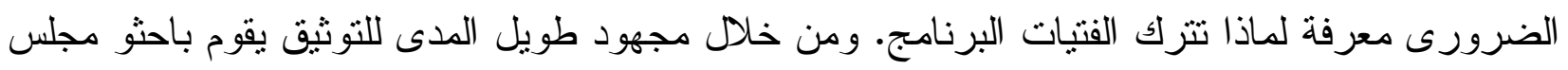

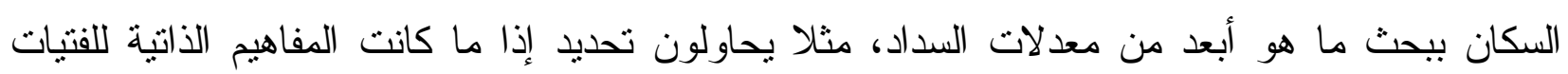

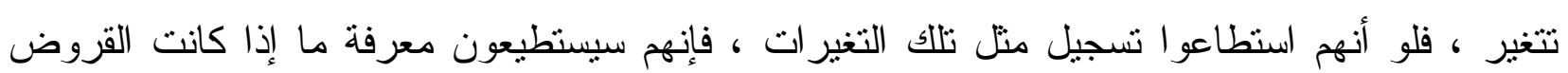
فرصة للفتبات أو أنها عبء عليهن.

الاروس المستفادة حتى الآن لاز ال مشروع TRY فى مر احله الأولى ولكن باحثو مجلس السكان قد تعلمو ا بعض الأشياء حتى الآن .

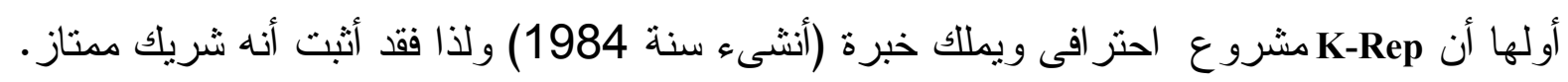

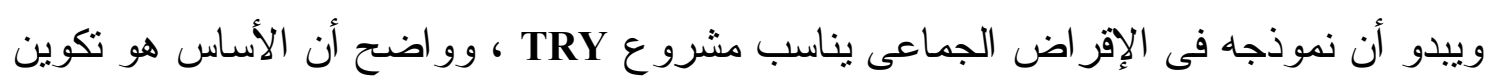


المجمو عات دن نوع (جنس sex) و احد. وقد اتخذت المجموعات لنفسها حياتها الخاصة، وهيأت للفتيات شبكات اجتماعية إلى جو ار فرص الائتمان والادخار، وقد أسست كل مجموعة قو اعدها الخاصة، التى يلتزم بها الأعضاء و التى تذهب كذلك إلى أبعد مما هو مطلوب. مثنلاً حينما تلا عضو فى المجموعة طفلاً فإن بقية الأعضاء يقدمون المساعدة و العون للأم. وتقوم المجمو عة بتلبية الاحتياجات الأخرى فى حباة المشاركات، مما أسهم فى تقوية البرنامج. وبالإضافة إلى هذا فإنه يبدو أن مكون التدريب مفيد جداً للفتيات المشاركات، فمعرفة كيفية التوفير ومن ثم تجميع مدخر ات منو اضعة، يساعد المشاركات فى TRY على تصور المستقبل و التخطيط له.

يفيد مسئولو K-Rep أن الثهور الخمسة الأولى من إقر اض المر اهقين كانت سلسة للغاية، وهم يشعرون أن تصميم المشروع شامل بشكل كاف من حيث مخاطبته لجماعة خاصة، وكذلك حزمة الخدمات المقدمة. و إضافة إلى ذلك فإنهم قد أدركوا أن عليهم اعتبار تأهل الفتاة المراهقة للقرض من خلال سياق أسرتها وكيانات المساعدة بدلاً من من الطريقة التى يعامل بها المقترضون الأكبر سناً.

ماهى مكونات التدريب الجيد اللازم لتطوير مشروع؟

بر امج التدريب المهنى و التذريب على الوظيفة هما سبيلان يمكن من خلالهما للمر اهقين الذكور و الإناث أن يحصلو العلى المهار ات التى تمكنهم من كسب العيش. إذا أخذنا فى الحسبان متطلبات تشغيل البرامج و الالتحاق بالتدريب فلابد أن تتوفر لتلك البرامج إمكانية أن تمنح مهارات عملية يمكن تسويقها. و لابد لبرنامج تدريب جيد دن أن يتعرف على البيئة التى ستمارس فيها المتدربة مهار اتها. وأن يتجنب بقدر الإمكان وضع البنات على طريق الوظائف قليلة الأجر التى تعمل بها الإناث تقليدياً.

\section{أسس إرشادية للتدريب على الاستثمار}

اعمل على تدريب الناس على العمل فى مناطق النمو الجديدة التى تتشأ بسبب الحاجة إليها؛ و احذر من التذريب الذى يؤهل الناس للعمل فى قطاعات قد ازدحمت بالفعل. تأكد من أن المهار ات تتو افق مع احتياجات المجتمعات المحلية ـ هل يستطيع المستهلك تحمل تكلفة السلع المنتجة؟ .إن المهارات التى تتاسب المجتمعات الحضرية قد لا تتتاسب بالضرورة مع المجتمعات الريفية.

عند العمل مع البنات و النساء يكون تشجيعهن على الدخول فى القطاعات المخصصة تقليدياً للرجال أقل جدوى من تدريبهن على قطاعات جديدة نامية ولم يتحدد بعد نوع العاملين فيها (ذكوراً أو إناثا) 
حافظ على بساطة وتماسك البرامج، وقد يكون فى هدف واحدا أو اثثين الكفاية، ويعود التذريب الجيد دائماً بالفائدة. مثناً ، برنامج يحاول تعليم مهار ات وتحسين المعارف و الممارسات الصحية للمتدربين

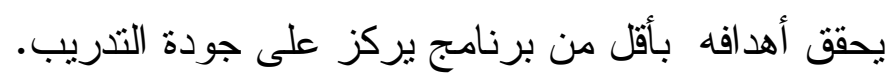

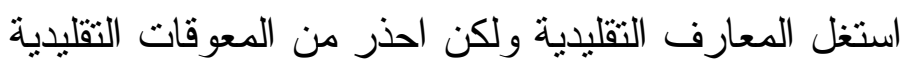

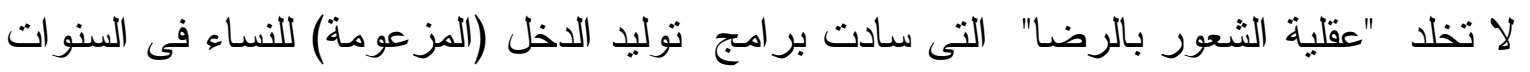

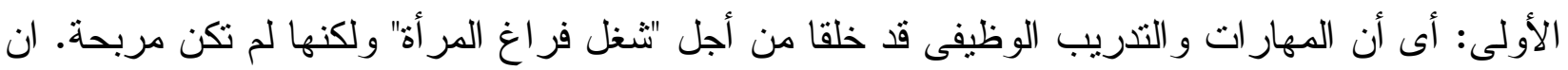
المقاربة التى تتميز بعقلية العمل هى الأسلوب الأكثر و اقعية وهى تحمل فى ثناياها إمكانيات أكبر للنجاح على المدى البعيد.

لو لم تكن لدى البنات مهارات مرنة و يمكن تطويعها فإن هنالك خطر وقوعهن فى دائرة قد تساعدهن على المدى القريب ولكنها لا تساعدهن على المدى البعيد، حينما تصبح مهار اتهن غير مناسبة.

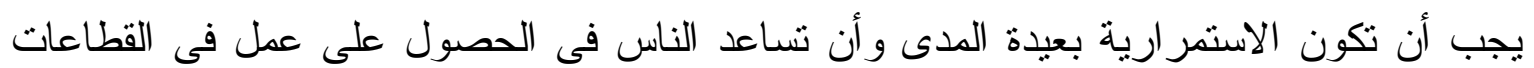

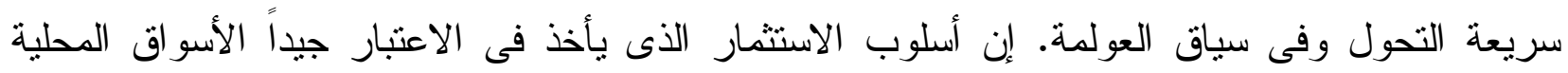

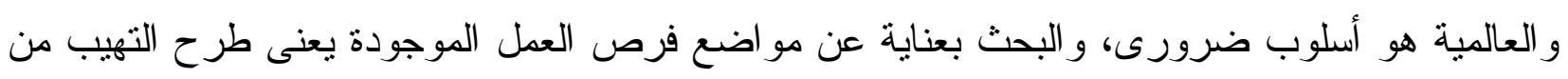
الدخول إلى القطاع المشترك جانباً

إن أحد الجوانب التى تبعث على الأمل فى أسلوب "كسب العيش" هو أنه يحترم ثقافة الثباب

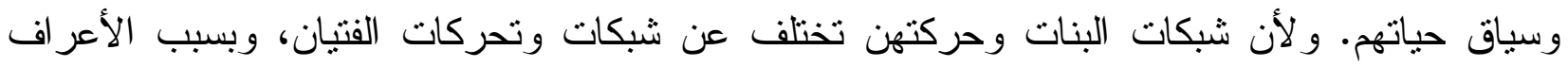

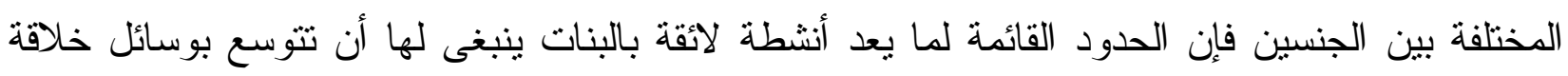
يتم التفكير فيها جيداً . يجب معرفة المزيد عن الأنشطة التى يرغب المر اهقون فى مزاولتها، ويجب نزويدهم بالأدوات

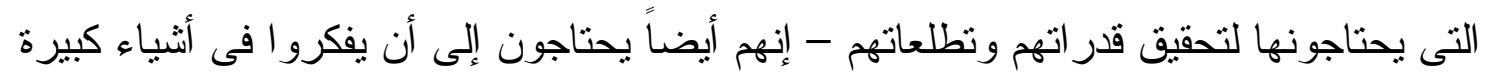
يعمل المراهقون لأنهم فقراء، وفى ظل مستويات الفقر المرتفعة يجب بذل الاهتمام لحساسية

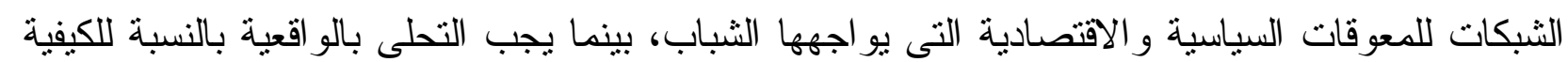
التى يمكن بها تفعيل البرامج على مستوى المنظمات غير الحكومية

\section{نظرة إلى المستقبل}

لقد أولي المزيد من العناية فى السنوات القليلة الماضية للمر اهقين وذلك من جانب الحكومات، و المنظمات

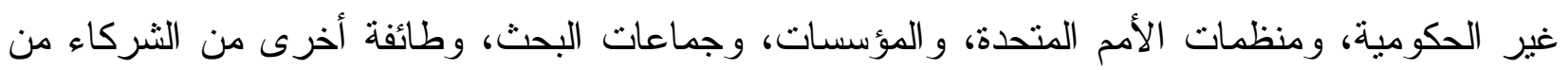

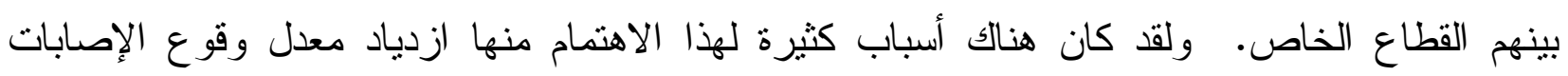

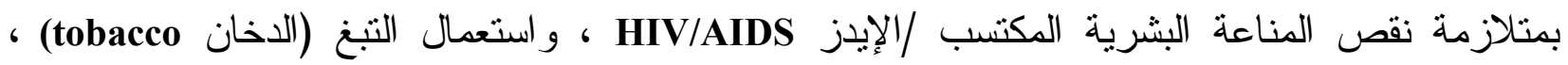

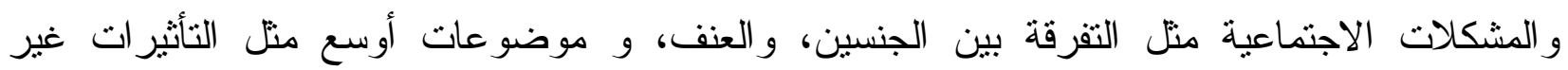


المتكافئة للعولمة. ولقد أصبح من المفهوم جيداً الآن ضرورة التركيز على المراهقين من أجل الحاضر و المستقبل - المر اهقة مرحلة من الحياة تعطى الفرصة لكسر بعض الحلقات الخبيثة التى تدمر التطور

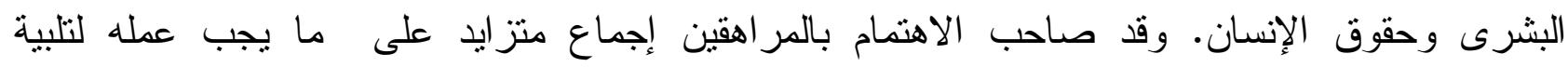
الاحتياجات اللازمة لإقرار وحماية حقوق المر اهقين فى النطور، و إدر الك أنه يوجد لطائفة من المشكلات

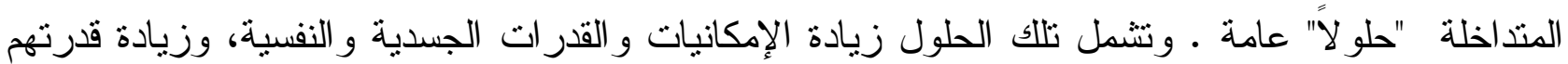
على الوصول إلى نطاق من الخدمات و الفرص، وخلق بيئة آمنة و داعمة بمكنهم فيها العيش و الدراسة،

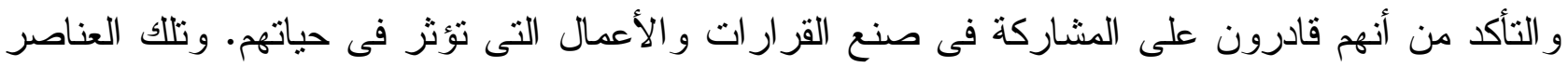

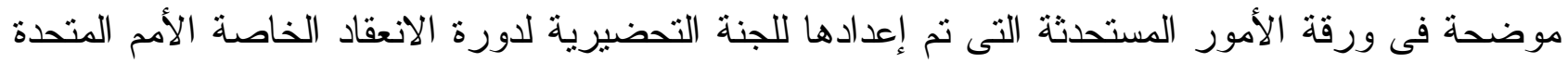

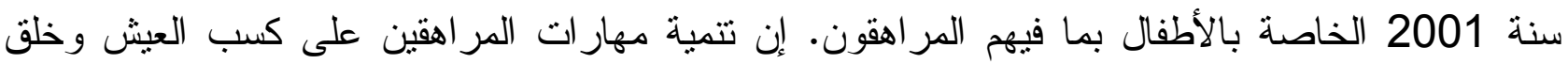

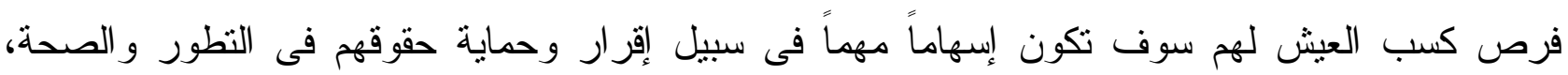

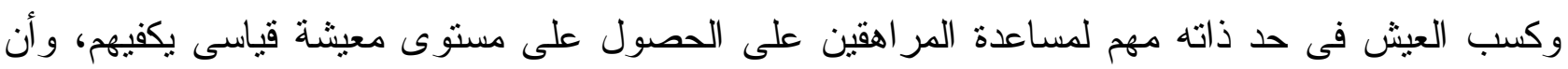

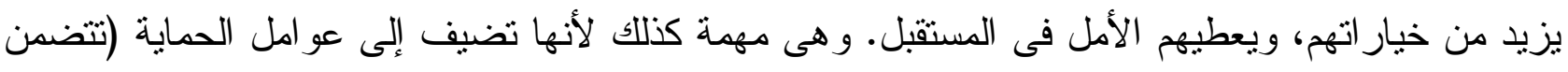

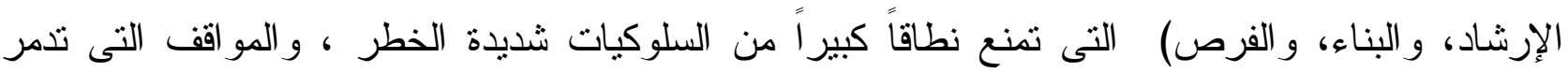
صحة ونمو المر اهقين, وتعرضهم للاستخلال و المهانة.

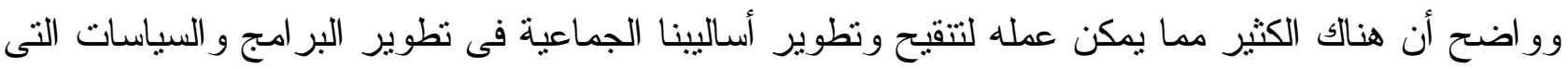

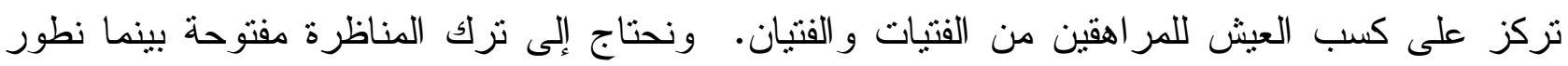

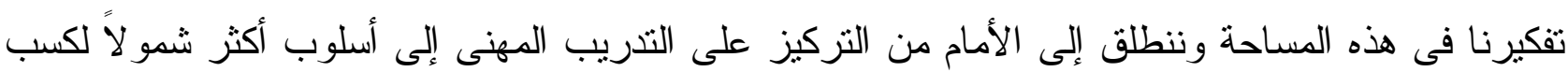

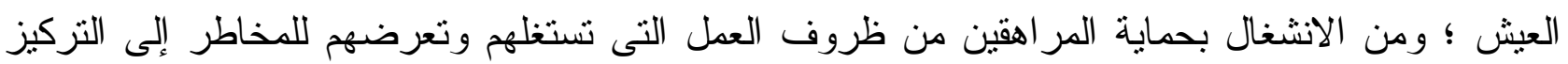

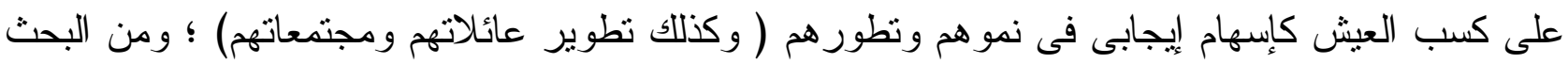

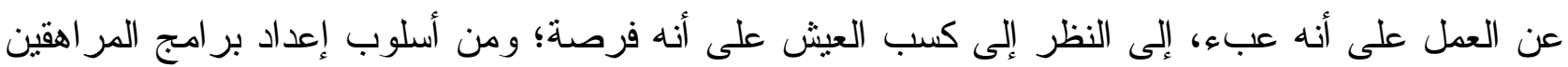

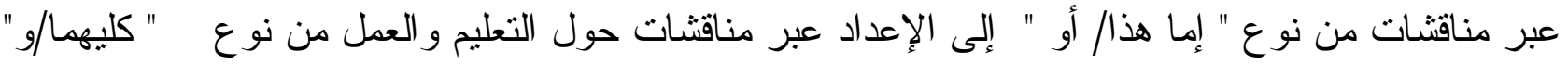
• و لا زالت الحاجة مستمرة للافاع عن تللك المساحة من البرمجة من خلال نطاق من المناقتشات التى نتثنمل على الاقتصاديات و الصحة العامة، وحقوق الإنسان، ولكننا لسنا فقط محتاجون إلى القدرة على عنى صنع حالة

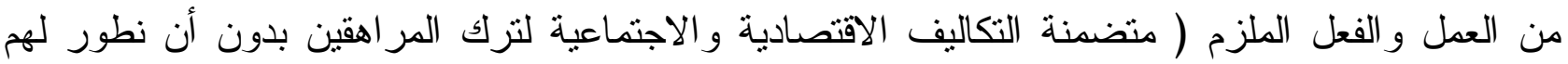

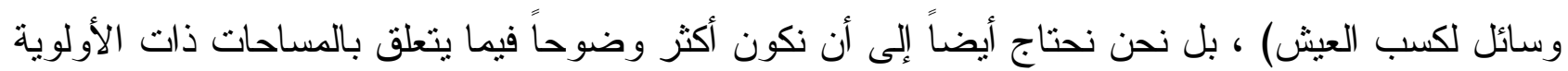

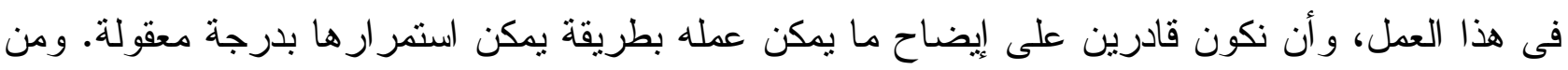

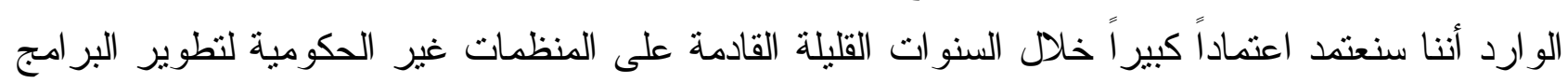

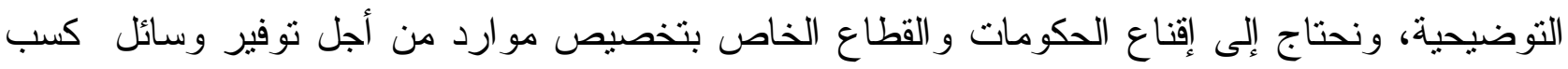
عيش للمر اهقين. 
إن أسلوب "كسب العيش" يبعث القوة فى الكثير من الموضوعات التى يناقشها حالياً قطاع التعليم، منل الإقلال من التفاوت و الطرد، و الزيادة فى جودة وملائمة التعليم. لقد أسهم المنتدى عن التعليم الذى عقد فى داكار ، السنغال فى إبريل 2000 - و المؤتمر العالمى الذى سبقه عن التعليم للجميع سنة 1999 - إسهاماً هاماً فى ذلك النطاق من البرمجة من خلال عروض لأساليب رسمية وبديلة عن تهيئة بيئات تعليمية آمنة وداعمة للمر اهقين. يحتاج المراهقون إلى هئ

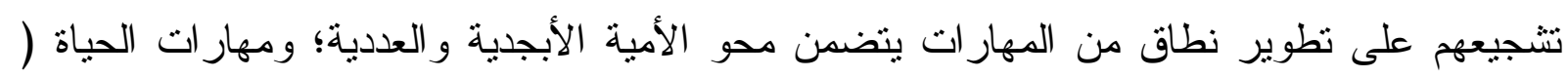
النفسية الاجتماعية والكفاءات) و المهارات التقنية (مثل كيفية الحصول على الائتمان) و المهارات الاجتماعية (مثل كيفية العمل مع الآخرين) و المهارات الإدارية والاسنر اتيجية ( مثل كيفية التعرف ولهنه على عو اقب الخيار ات الحالية) وكلما تقدمنا إلى الأمام فى هذه المساحة من البرمجة سيكون من المهم تحديد الموضوعات المحورية، مثلاً متلازمة نقص المناعة البشرية المكتسب /لإيدز HIV/AIDS تطرح نطاقاً من الفرص لأسلوب كسب العيش من حيث المساهمة فى الوقاية من تلك الجائحة العالمية Pandemic و التخفيف من وطأنها، من خلال الوقاية بعيدة المدى (الإيدز مرض يتز ايد مع الفقر) والاستجابة للمر اهقين المصابين بالعدوى بما فيهم من فقدوا آباءهم و أصبحوا هم على رأس أسرهم. وربما ينطبق هذا أيضاً على هردي العنف من حيث الوقاية و الاستجابة.

إن التزكيز على كسب العيش سيضيف مادة إلى التركيز المتز ايد على المراهقين بصفتهم موارد

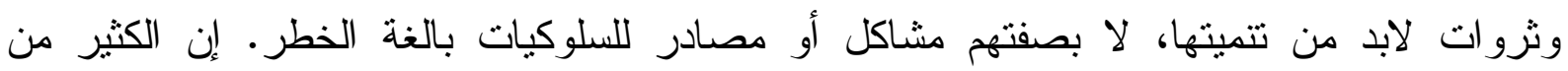
المر اهقين يضيفون حالياً إسهامات هامة إلى عائلاتهم ومجتمعاتهم، بما فى ذلك تلبية الاحتياجات

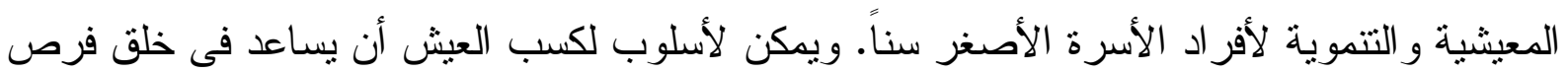
للمر اهقين؛ ويضمن أنهم يستقيدون من إسهاماتهم ؛ وأن يمنع مشاركتهم فى أعمال استغلالية مهينة تذمر حقوقهم.

توجد حاجة مستمرة لتفكيك فترة المر اهقة مع تزكيز معين على الجنس (النوع) و السن ، ولكننا نحتاج كذلك إلى إدر اج موضو عات مثل الإنجاز ات التعليمية، و الحالة الزواجية، حتى نتأكد من أننا نبنى على الإمكانيات المستحثة لاى المراهقين. وأبعد من ذلك فمن المهم توضيح اختلاف الاحتياجات بين المر اهقين (10-19 سنة) و الثباب (14-24 سنة) . وبينما نحتاج إلى التعلم من الخبرات الو اسعة من برنامج "كسب العيش" فإننا أيضاً لابد أن نتزود بنظرة نقدية عند تطبيق ممارسة جيدة على الهى المر اهقين، مثنلًا قد تكون الدروس المستفادة من الثباب الأكبر سناً محل نساؤل عند تطبيقها على من هم فى سن 15-18 سنة. 
من الواضح أن أسلوب "كسب العش" ينحنا فرصة للتركيز على الكثير من الموضوعات المجتمعية

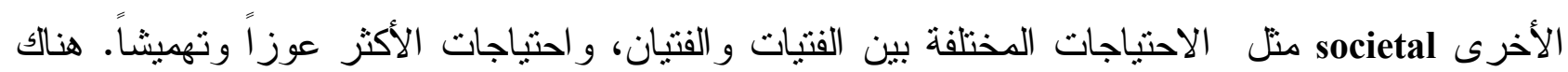

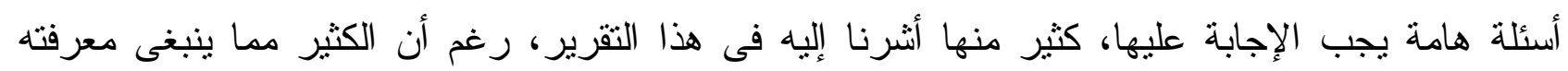

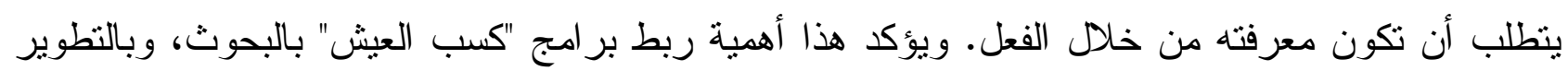

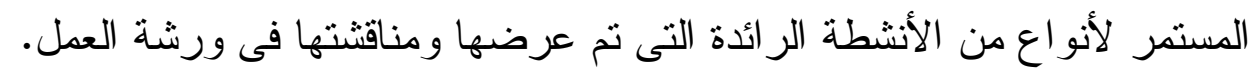

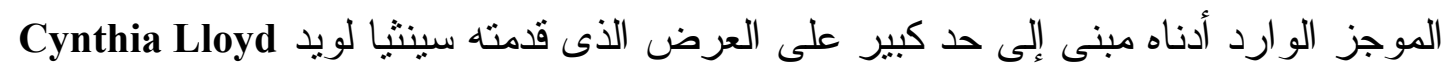

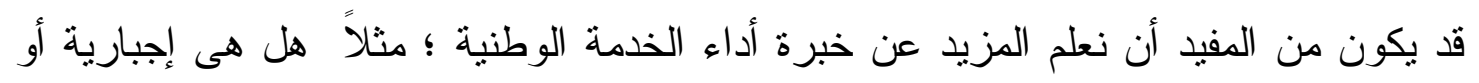

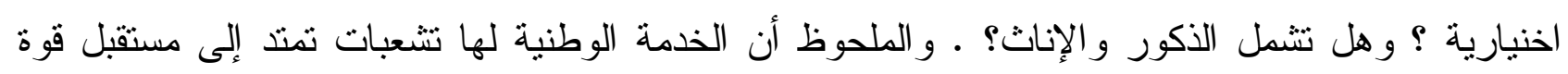

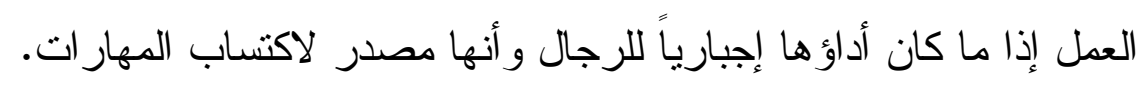

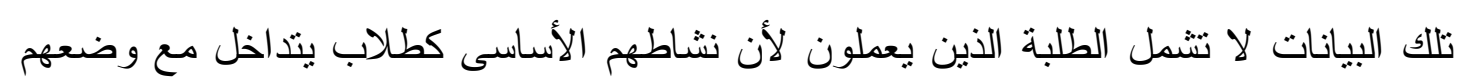

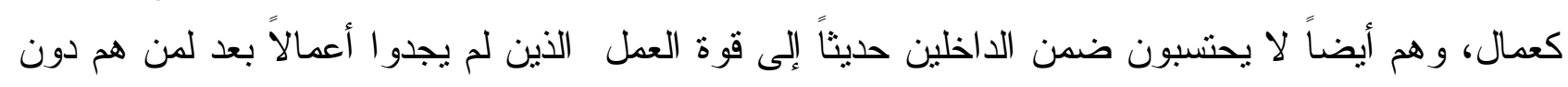

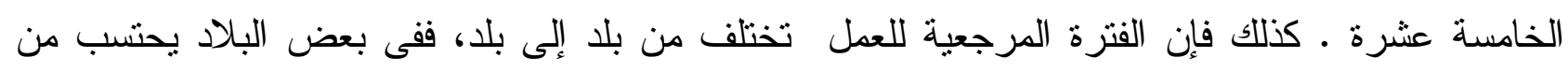

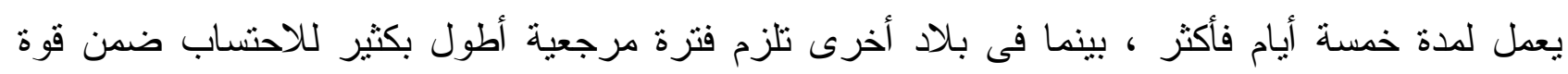
طرحت فاليرى ديور انت Valerie Durrant مفهوم "الفتاة التى لا تعمل شيئًا" فى ورشة العمل العمل، كما أنها قامت بعرض الحالة فى باكستان.

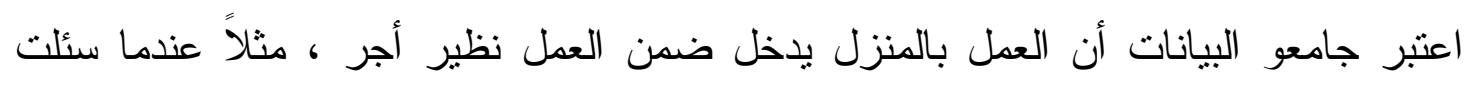

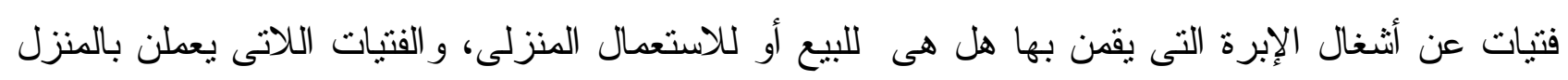
اعتبرن ممن "لا يعملن شيئاً"

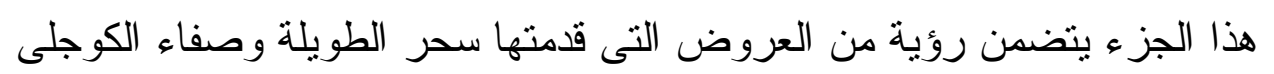

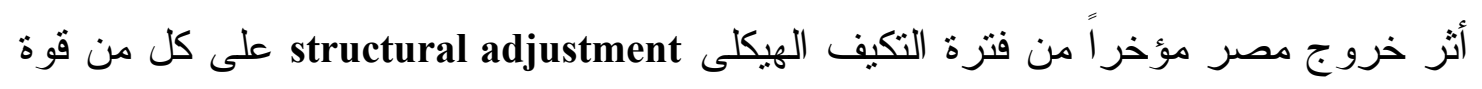
العمل وسوق الزواج. وأحد هذه الآثار هو أنه فى بعض القطاعات ومنها قطاع الملابس يعمل المتعلمون

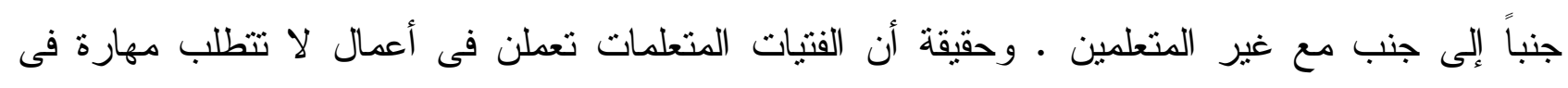

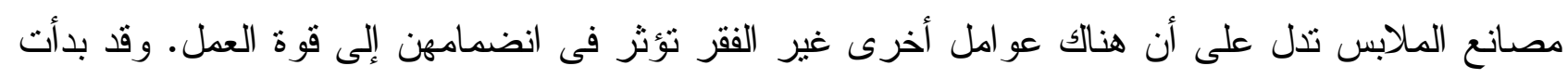

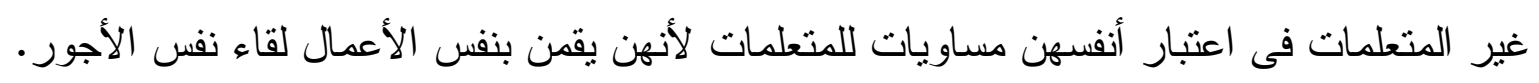

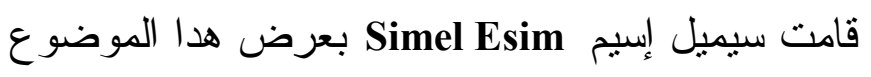




$$
\text { قدم ألك فايف Alec Fyfe عرضناً لهذا الموضوع }
$$

يستمد هذا القسم من عرض نجاح حسن عن بحثها الأصلى لهذا الموضوع.

يستمد هذا القسم من عرض مارى كوار Mary Kawar عن بحثها الأصلى للموضوع

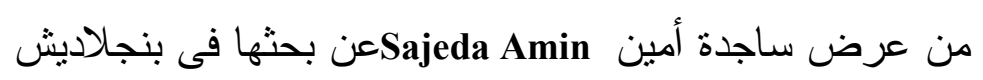

Simel Esim and ملخص مستمد من عرض سيمل إسيم وجايمى شنورر

Jennefer Sebstad. ملخص مبنى على أعمال جنيفر سبستاد

هذا القسم مستمد من معلومات فى عرض جواخيم فيكتور جومز Joachim Victor

\section{Gomes}

عرض محمد إبر اهيم مدير مركز التتقيف الجماعى و العلوم CMES نظرة عامة على

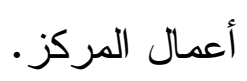

عرض ساجارى سينج Sagri Singh معلومات عن فرص كسب العيش للمر اهقات فى

Banu Khan, هذا القسم مستمد من عرض بانو خان وأنابل ارلوكار وستيفن ميريرو

عرض جون جريرسون وهارون بهية ونجمة شريف John Grierson, Harun Bhaiya, and Najma Sharif

$$
\text { الذى عرضوه }
$$

\section{REFERENCES}


Chambers, Robert and Gordon R. Conway. International Labour Office. 1993, 1994. Year 1992. "Sustainable rural livelihoods: Practical Book of Labour Statistics. Geneva, Switzerland: concepts for the 21st century," discussion paper no. 296. Sussex: United Kingdom: Institute of Development Studies.

El-Tawila, Sahar, Barbara Ibrahim, Omayma El Gibaly, Fikrat El Sahn, Sunny Sallam, Susan M. Lee, Barbara Mensch, Hind Wassef, Sarah Bukhari, and Osman Galal. 1999. Transitions to Adulthood: A National Survey of Egyptian Adolescents. Cairo, Egypt: Population Council.

Espínola, Basílica et al. 1988. In the Streets: Working Street Children in Asunción: A Book for Action.Colombia: Gente Nueva.

International Labour Organization. 1996. "Child labor: What is to be done?" document for discussion at the Informal Tripartite Meeting at the Ministerial Level. Geneva, Switzerland: International Labour Organization.

Mensch, Barbara, Judith Bruce, and Margaret E. Greene. 1998. The Uncharted Passage: Girls' Adolescence in the Developing World.New York: Population Council.

Szanton Blanc, Cristina. 1994. Urban Children in Distress: Global Predicaments and Innovative Strategies.Langhorne, Pennsylvania: Gordon \& Breach Science Publishers, UNICEF. 


\section{APPENDIX A}

\section{WORKSHOP AGENDA}

Wednesday, October 13

Welcome

Geeta Rao Gupta, Barbara Ibrahim, Ellen

Marshall, Bruce Dick, and Judith Bruce

What Is the Livelihoods Approach?

Chair: Judith Bruce

- Overview (30 minutes)—Simel Esim

- An example from Africa: Rationale and current operations of the International

Development Research Centre's Livelihoods

Network (10 minutes)—Jamie Schnurr

- Discussion (20 minutes)

Where Are Adolescents Working?

Chair: Aboubacry Tall

- Data on the working experiences of adolescents in developing countries (20 minutes) -

Cynthia Lloyd

- The Egyptian module to capture male and female adolescent work experience in more depth (20 minutes) - Safa'a El-

Kogali

- Methods for learning and the results of an investigation into the mystery of the high proportion of girls in Pakistan who are not married, not reported working, and not in school (20 minutes)_Valerie Durrant

- Discussion (1 hour)

Girls' Work and the Policy and

Normative Environment

Chair: Barbara Ibrahim

- Overview of child protection measures and adolescent livelihoods: International

Labour Organization's international standards and overview of the program strategy of the International Programme on the Elimination of Child Labour (Theresa Smout) and country applications (Alec Fyfe) (30 minutes)

- Reviewing the work/education link: 
Available literature and alternative interpretations of the trade-ons/trade-offs between work and school (Simel Esim) and

the Egyptian perspective (Sahar El-Tawila)

(20 minutes)

- Discussion (40 minutes)

How Do Adolescent Girls Experience

Their Working Conditions? What

Contribution Does Working Make to

Their "Adolescence"?

Chair: Sajeda Amin

- Perspectives from three countries on assessments of how girls experience work

and how they feel about their work opportunities ( 2 hours)

- Research on garment workers in

Bangladesh-Sajeda Amin

- The reasons young women in Jordan

work; their families' perceptions of

their work; how these perceptions

affect young women's employment

opportunities; and young women's perceptions of their own work experience-Mary Kawar

- Case studies of young working women

in Egypt-Nagah Hassan

47 
Thursday, October 14

What Is the Program Experience to

Date in Supporting and/or Generating

Livelihoods for Adolescent Girls?

Chair: Sharon R. Lapp

- Introduction to reiterate the livelihoods

definition and framework and to outline

possible domains for action (15 minutes) - Jennefer Sebstad

- Microfinance strategies

- Overview of microfinance strategies, ranging from programs that may offer a

window to adolescents but whose primary focus is on sustainability, scale, and deepening financial markets to programs where financial services are part of an explicit social development agenda (15 minutes) - Jennefer Sebstad

- Summary of findings from a review of outreach to adolescents by Bangladeshi microfinance institutions (15 minutes + 5-10 minutes of discussion)_Joachim Victor Gomes

- Experience of the Kenya Rural

Enterprise Program as an example of a mainstream microfinance institution that is working with adolescent girls as a matter of explicit policy and program experimentation ( 20 minutes +10 minutes of discussion) - Banu Khan, Annabel Erulkar, and Stephen Mirero

- Results of interviews with Indian micro-

finance institutions $(20$ minutes +10

minutes of discussion) - Sagri Singh

- Other financial innovations

- Experience of the Centre for Mass

Education in Science in offering credit

to 3,000 adolescent girls in the context

of a social development scheme (15

minutes)—Mohammad Ibrahim

- An inquiry into the best means of offering savings opportunities for garment workers (15 minutes) — Joachim Victor

Gomes

- Discussion (30 minutes)

- Training for enterprise development

Chair: Simel Esim

- How training for enterprise development can address adolescent girls'

livelihoods needs (John Grierson) and

comments (Harun Bhaiya and Najma

Sharif) (45 minutes)

- Discussion (30 minutes) 
- Reflecting on UNICEF's experience

Chair: Bruce Dick

- Discussion of knowledge acquired in seeking to place the issue of livelihoods

within the context of adolescent development and rights; the divide between preventing child labor and encouraging

adolescent livelihoods; and country

experiences ( 1 hour)

Wrap-up

Judith Bruce, Geeta Rao Gupta, Barbara

Ibrahim, and Jennefer Sebstad

48 


\section{APPENDIX B}

\section{WORKSHOP PARTICIPANTS CONTACT LIST}

Institute of Sociology

27 Tran Xuan Soan Street

Hanoi, Vietnam

telephone: 84-4-733-0577

fax: 84-4-733-0588

e-mail: pc_anh@netnam.org.vn

Marie Assaad

1095 Corniche El-Nil

3rd floor, Garden City

Cairo, Egypt

telephone: 20-2-794-3305

Paul Bennell, Consultant

60 Rugby Road

Brighton, East Sussex

BN1 6ED, United Kingdom

telephone: 44-1-273-503259

e-mail: swainson@bennell.u-net.com

Harun Bhaiya, Chief Executive

Strengthening Informal Sector Training

and

Enterprise

MultiChoice Towers, 5th floor, Lower Hill

Road

P.O. Box 34336

Nairobi, Kenya

telephone: 254-2-718-155/716-099

fax: 254-2-716-059

e-mail: hbhaiya@africaonline.co.ke

Leila Bisharat, Representative

United Nations Children's Fund

87 Misr Helwan Agriculture Road

Maadi, Cairo, Egypt

telephone: 20-2-526-5083

fax: 20-2-526-4218

e-mail: lbisharat@unicef.org

Martha Brady, Program Associate

Population Council

One Dag Hammarskjold Plaza
Romany Abadir

Centre for Development and Population Activities

53, Manial Street, Suite 500

Manial EI Rodah

P.O. Box 110

Cairo 11451, Egypt

telephone: 20-2-365-4567

fax: 20-2-365-4568

e-mail (group): cedpa@intouch.com

Rahnuma Afrin, Programme Officer

ActionAid Bangladesh

House \#41, Road \#8

Dhanmondi R/A, Dhaka 1205, Bangladesh

telephone: 880-2-811-802/763, 810-933

fax: 880-2-813-150

e-mail: aabcr@dhaka.agni.com

Sajeda Amin, Associate

Population Council

One Dag Hammarskjold Plaza

New York, NY 10017

telephone: 212-339-0680

fax: 212-755-6052

e-mail: samin@popcouncil.org

Dang Nguyen Anh 
New York, NY 10017

telephone: 212-339-0618

fax: 212-755-6052

e-mail:mbrady@popcouncil.org

Carlos Brambila-Paz, Program Associate,

Frontiers

Population Council

Mailing address:

P.O. Box 593478

Miami, FL 33159-3478

Office location:

8a Calle 14-44, Zona 13

Guatemala City 01013, Guatemala

telephone: 502-3-32-3848/2365

fax: 502-3-62-7227

e-mail: cbrambila@guate.net

Judith Bruce, Program Director, Gender, Family,

and Development

Population Council

One Dag Hammarskjold Plaza

New York, NY 10017

telephone: 212-339-0641

fax: 212-755-6052

e-mail: jbruce@popcouncil.org

49 
Bonnie Brusky, Programme Officer

South Asian Network of Microfinance Initiatives

House 206, Road 10

New DOHS, Mohakhali

Dhaka 1206, Bangladesh

telephone: 880-2-887-200

e-mail: bjbrusky@club-internet.fr;

bjbrusky@mailexcite.com

Bruce Dick, Senior Adviser, Youth Health,

Programme Division

United Nations Children's Fund

633 Third Avenue, 24th floor

New York, NY 10017

telephone: $212-824-6324$

fax: 212-824-6465

e-mail: bdick@unicef.org

Valerie Durrant

National Research Council

Committee on Population

2101 Constitution Avenue NW

Washington, DC 20418

telephone: 202-334-3167

fax: 202-334-3768

e-mail: vdurrant@nas.edu

Willem van Eekelen, Associate Expert,

Labour Market Policies

International Labour Organization, Cairo

9 Taha Hussein Street

Zamalek, Cairo, Egypt

telephone: 20-2-341-9290/340-0123

fax: 20-2-341-0889

e-mail: eekelen@ilo.org

Safa'a El-Kogali, Economist

The World Bank

1818 H Street NW

Washington, DC 20433

telephone: 202-458-9869

e-mail: selkogali@worldbank.org

Sahar El-Tawila, Research Associate

Social Research Center 
American University in Cairo

Cairo, Egypt

telephone: 20-2-357-6947

fax: 20-2-355-7298

e-mail: sahart@auc.aucegypt.edu

Annabel Erulkar, Staff Program Associate

Population Council

General Accident House

Ralph Bunche Road

Nairobi, Kenya

telephone: $254-2-713-480 / 1 / 2 / 3$

fax: 254-2-713-479

e-mail: aerulkar@popcouncil.or.ke

Simel Esim, Economist

International Center for Research on Women

1717 Massachusetts Avenue NW, \#302

Washington, DC 20036

telephone: 202-797-0007

fax: 202-797-0020

e-mail: Simel_Esim@dai.com

Tamara Fetters

Ipas USA

Chapel Hill, NC 27516

Alec Fyfe, Senior Adviser, Child Labour

United Nations Children's Fund

3 United Nations Plaza, T26A

New York, NY 10017

telephone: 212-824-6639

fax: 212-824-6485

e-mail: afyfe@unicef.org

Joachim Victor Gomes, Independent Consultant

147-E Green Road, Flat E-3

Dhaka 1205, Bangladesh

e-mail: snmjvg@bdonline.com; vicg32@yahoo.com

John Grierson, Senior Specialist,

Enterprise Development

FTP International Ltd.

P.O. Box 484 
FIN-00101 Helsinki, Finland

telephone: 358-9-7701-3323

fax: 358-9-7701-3498/3499

e-mail: john.grierson@ftpinter.fi

Geeta Rao Gupta, President

International Center for Research on Women

1717 Massachusetts Avenue NW, \#302

Washington, DC 20036

telephone: 202-797-0007

fax: 202-797-0020

e-mail: geeta@icrw.org

Nicole Haberland, Program Associate

Population Council

One Dag Hammarskjold Plaza

New York, NY 10017

telephone: $212-339-0676$

fax: 212-755-6052

e-mail: nhaberland@popcouncil.org

Minhaj ul Haque, Program Officer Population

Council

House No. 7, Street No. 62

Sector F 6/3

Islamabad, Pakistan

telephone: 92-51-277-439

fax: 92-51-821-401

e-mail: minhaj@pcpak.org

Nagah Hassan, Research Assistant Population

Council P.O. Box 115

Dokki 12211

Cairo, Egypt

telephone: 20-2-573-8277

fax: 20-2-570-1804

e-mail: nhassan@pccairo.org

Karen Heissler, Assistant Programme Officer, Protection Section

United Nations Children's Fund

P.O. Box 38

Dhaka-1000, Bangladesh

telephone: 880-2-933-6701/2/3/. . / 20

fax: 880-2-933-5641/2

e-mail: kheissler@mail.unicef.bangla.net

Aziza Helmy, Women in Development Officer

United States Agency for International

Development 
Mansour Building

Zahraa El Maadi

Cairo, Egypt

telephone: 20-2-516-5505

fax: 20-2-521-8501

e-mail: ahelmy@usaid.gov

Ishrat Husain

USAID/Africa Bureau (AFR/SD)

1325 G Street NW, Suite 400

Washington, DC 20005

telephone: 202-219-0477

fax: 202-216-3373

e-mail: ihusain@afr-sd.org

Barbara Ibrahim, Regional Director,

West Asia and North Africa

Population Council

P.O. Box 115

Dokki 12211

Cairo, Egypt

telephone: 20-2-573-8277

fax: 20-2-570-1804

e-mail: bibrahim@pccairo.org

Mohammad Ibrahim, Executive Director Centre for Mass Education and Science

828 Dhanmondi Road \#19

Dhaka 1209, Bangladesh

telephone: 880-2-811-898

fax: 880-2-803-559

e-mail: ibrahim@citechco.net; cmes@citechco.net

Saad el Din Ibrahim, Director

Ibn Khaldoun Center for Development Studies

17, Street 12 Maqattam

P.O. Box 13

Maqattam, Cairo, Egypt

telephone: 20-2-508-1617

fax: 20-2-508-1030

e-mail: semibrahim@hotmail.com

Lubna Izziddin, Programme Assistant,

Adolescent Project

United Nations Children's Fund,

Jordan

P.O. Box 1551

Amman 111821, Jordan

telephone: 962-6-553-9977 
fax: 962-6-553-1112

e-mail: Lubna_Izziddin_at_PO320A01@

smtplink.unicef.org

Laila Kamel

11 Gabalaya Street

Apt. \#9, 3rd floor

Zamalek, Cairo, Egypt

telephone: 20-2-332-0752/0832

fax: 20-2-340-2660

e-mail: cid@intouch.com

Mary Kawar

Aresco Centre

P.O. Box 11-4088

Beirut, Lebanon

telephone: 961-1-752-400, ext. 229

fax: 961-1-752-406

e-mail: kawar@ilo.org.lb

Amira Kazem, Economist

Human Development Sector

The World Bank

World Trade Center

1191 Corniche El-Nil, 15th floor

Cairo, Egypt

telephone: $20-2-574-1670 / 1$

fax: 20-2-574-1676

e-mail: akazem@worldbank.org

\section{Banu Khan}

Population Council

General Accident House

Ralph Bunche Road

Nairobi, Kenya

telephone: $254-2-713-480 / 1 / 2 / 3$

fax: 254-2-713-479

e-mail: bkhan@popcouncil.or.ke

Tamer Kirolas

The Egyptian Small \& Micro-enterprise Association

No. 2 Maroof Street, 4th floor

Cairo, Egypt

telephone: 20-2-577-7273/5

e-mail: esma@intouch.com 
Jayasankar Krishnamurty, Senior

Economist

Employment and Labor Market Policies

Employment and Training Department

International Labour Office

4, route des Morillons

CH-1211 Geneva 22, Switzerland

telephone: 41-22-799-8946

fax: 41-22-799-7678

e-mail: krishnamurty@ilo.org;

Attallah Kuttab, Director

Save the Children

P.O. Box 580

Ataba, Cairo, Egypt

telephone: $20-2-353-4505$

fax: 20-2-355-6343

e-mail: careegp@starnet.com.eg

Sharon R. Lapp, Program Officer

The Ford Foundation

P.O. Box 2344

Cairo, Egypt

telephone: $20-2-355-2121$

fax: 20-2-355-4018

e-mail: s.lapp@fordfound.org

Susan M. Lee, Independent Consultant 1724 V Street NW

Washington, DC 20009

telephone: 202-518-5986

e-mail: susanmlee@juno.com

Cynthia Lloyd

Population Council

One Dag Hammarskjold Plaza

New York, NY 10017

telephone: 212-339-0664

fax: 212-755-6052

e-mail: clloyd@popcouncil.org

Ellen Marshall

United Nations Foundation

1301 Connecticut Avenue NW, Suite 700

Washington, DC 20036

telephone: 202-887-9040

fax: 202-887-9021

e-mail: emarshall@unfoundation.org 
Krista Masonis, Development Consultant c/o DPA/Karim el Gawhary

P.O. Box 366

Mohammed Farid, Maspero

Cairo, Egypt

telephone/fax: 20-2-508-7728

e-mail: kritsam@eis.egnet.net

Pamela McCloud

Centre for Development and Population Activities

53, Manial Street, Suite 500

Manial El Rodah

P.O. Box 110

Cairo 11451, Egypt

telephone: $20-2-365-4567$

fax: 20-2-365-4568

e-mail (group): cedpa@intouch.com

Carey Meyers, Program Coordinator Population

Council

One Dag Hammarskjold Plaza

New York, NY 10017

telephone: 212-339-0637

fax: 212-755-6052

e-mail: cmeyers@popcouncil.org

Stephen Mirero

Kenya Rural Enterprise Program

Executive Head, Special Projects

K-Rep Group Coordination Office

P.O. Box 39312

Nairobi, Kenya

telephone: $254-2-572-422$

fax: 254-2-711-645

e-mail (group): krep@arcc.or.ke

Richard Mkandawire, Director

Center for Youth Studies

University of Venda

Private Bag X5050

Thohoyandou 0950, South Africa

telephone: 27-159-824-757

fax: 27-159-824-756

e-mail: mkanda@mweb.co.za;

mkandr@caddy.univen.ac.za 
Nadir A. L. Mohammed, Country

Economist, MNSED \& MNCEG, Middle

East \&

North Africa Region

The World Bank

World Trade Center

1191 Corniche El-Nil, 15th floor

Cairo, Egypt

telephone: $20-2-574-1670 / 1$

fax: 20-2-574-1676

e-mail: nmohammed@worldbank.org

Valerie Moulay-Omar, Regional Coordinator

for Operations

Population Council

128 Sotrac Mermoz

P.O. Box 21027

Dakar, Senegal

telephone: 221-824-1993/4

fax: 221-824-1998

e-mail: vmo@telecomplus.sn

Eglal Rached, Regional Director

Middle East and North Africa

International Development Research Centre

3 Amman Square, 5th floor

Dokki, Cairo, Egypt

telephone: $20-2-336-7051 / 2 / 3$

fax: 20-2-336-7056

e-mail: erached@idrc.org.eg

Eva Rathgeber, Regional Director

Eastern and Southern Africa

International Development Research Centre

P.O. Box 62084

Nairobi, Kenya

telephone: $254-2-713-160 / 1$

fax: 254-2-711-063

e-mail: erathgeber@idrc.or.ke;

EvaRathgeber@netscape.net 
Jane Rosser, Senior Program Advisor, World

\section{Education}

27 Myrtle Street

Brattleboro, VT 05301

telephone: 802-254-3893

e-mail: rossvita@sover.net

Lydia Zoungrana-Saloucou, Research Expert

Population Council

01 BP 6250, Cité An III

Ouagadougou 01, Burkina Faso

telephone: $226-31-1242 / 3$

fax: 226-31-1246

e-mail: Isaloucou@popcouncil.bf

Zeba Sathar, Program Associate

Population Council

House No. 7, Street No. 62

Sector F 6/3

Islamabad, Pakistan

telephone: 92-51-277-439

fax: 92-51-821-401

e-mail: zsathar@pcpak.org

Jamie Schnurr, Research Specialist, Youth Livelihoods

International Development Research Centre P.O. Box 8500

Ottawa, ON

Canada K1G 3H9

telephone: 613-236-6163, ext. 2320

fax: 613-567-7748

e-mail: jschnurr@idrc.ca

Jennefer Sebstad, Independent Consultant

P.O. Box 18973

Addis Ababa, Ethiopia

US mailing address:

c/o HIID

14 Story Street

Cambridge, MA 02138

telephone: 251-1-712-626

e-mail: jsebstad@telecom.net.et;

jsebstad@aol.com 
Najma Sharif, Economics Professor

St. Mary's University

6 Village Crescent

Bedford, Nova Scotia

Canada B4A 1J2

telephone: 902-420-5616

e-mail: najma.sharif@stmarys.ca

Andrew Simmons, Chief Program Officer

Commonwealth Youth Program Gender

and Youth Affairs Division

Commonwealth Secretariat

Marlborough House, Pall Mall

London SW1Y 5HX, United Kingdom

telephone: $44-20-7839-3411$

fax: 44-20-7930-1647

e-mail: simmonsa@commonwealth.int

Marja Simojoki, Programme Officer

Embassy of Finland, Department of

Development Cooperation

P.O. Box 30379

Nairobi, Kenya

telephone: 254-2-336-717/740, 334-408

fax: 254-2-335-986

e-mail: finland@form-net.com

Sagri Singh

2850 North Charles Street, \#14C

Baltimore, MD 21218

telephone: 410-662-7025

e-mail: emailsagri@yahoo.com

Allison Smith, Consultant,

Adolescent Reproductive Health

P.O. Box 1573

Red Lodge, MT 59068

e-mail: smitha@hsph.harvard.edu Theresa

Smout

Gender Focal Point

International Program on the Elimination of Child Labour

International Labour Organization

4 , route des Morillons

CH-1211 Geneva 22, Switzerland telephone:

41-22-799-6929 
Aboubacry Tall, Senior Programme Officer

United Nations Children's Fund, Egypt

87 Misr Helwan

Agricultural Road

Maadi, Cairo, Egypt

telephone: 20-2-526-5083/4/5/6/7

fax: 20-2-526-4218

e-mail: atall@unicef.org

Eve Thompson, Country Director

Joint Center for Political and Economic Studies

20 Melle Street, 4th floor, Van der Stel Place

Braamfontein, 2017

P.O. Box 23881

Joubert Park 2044, South Africa

telephone: $27-11-403-8641$

fax: 27-11-339-8386

e-mail: jcsa@wn.apc.org

Hind Wassef

10 EI-Saleh Ayoub Street

Apt. 24, 2nd floor

Zamalek, Cairo, Egypt

telephone: 20-2-217-7454

e-mail: hwassefh@yahoo.co.uk

Salma Youssef

Economic Research Forum

7 Bolous Hanna

Dokki, Egypt

telephone: 20-2-337-0810

fax: 20-2-348-5553

e-mail: erf@idsc.gov.eg

Nadia Zibani, Researcher

16 Rue Vladimir Komorov

93200 Saint Denis, France

e-mail: nadiazibani@hotmail.com 